\title{
Patterned Poly(chlorotrifluoroethylene) Guides Primary Nerve Cell Adhesion and Neurite Outgrowth
}

By

Samar Saneinejad

\begin{abstract}
A thesis submitted in conformity with the requirements for the degree of Masters of Applied Science,

Graduate Department of Chemical Engineering and Applied Chemistry Institute of Biomaterials and Biomedical Engineering in the University of Toronto
\end{abstract}

CCopyright by Samar Saneinejad (1999) 
National Library

of Canada

Acquisitions and Bibliographic Services

395 Wellington Street Ottawa ON KIA ONA Canada

\section{Bibliothèque nationale} du Canada

Acquisitions et services bibilographiques

395. ne Wellington Othawa ON KIA ONA Canada
The author has granted a nonexclusive licence allowing the National Library of Canada to reproduce, loan, distribute or sell copies of this thesis in microform, paper or electronic formats.

The author retains ownership of the copyright in this thesis. Neither the thesis nor substantial extracts from it may be printed or otherwise reproduced without the author's permission.
L'auteur a accordé une licence non exclusive permettant à la Bibliothèque nationale du Canada de reproduire, prêter, distribuer ou vendre des copies de cette thèse sous la forme de microfiche/film, de reproduction sur papier ou sur format électronique.

L'auteur conserve la propriété du droit d'auteur qui protège cette thèse. Ni la thèse ni des extraits substantiels de celle-ci ne doivent être imprimés ou autrement reproduits sans son autorisation.

\section{Canadă}


Pattemed Poly(chlorotrifluoroethylene) Guides Primary Nerve Cell Adhesion and Neurite Outgrowth M.A.Sc., 1999

By Samar Saneinejad

Department of Chemical Engineering and Applied Chemistry

Institute of Biomaterials and Biomedical Engineering

University of Toronto

\section{ABSTRACT}

Central nervous system (CNS) neurons do not regenerate following injury. Recently, it has been shown that in the developing CNS a combination of cell-adhesive and cell-repulsive cues guide growing axons to their targets. By mimicking the effects of these cues, it may be possible to guide nerve cell adhesion and neurite outgrowth in vitro. The objectives of this research project were to modify poly(chlorotrifluoroethylene) (PCTFE) surfaces, incorporating patterns of cell-adhesive (peptide) and non-adhesive [polyethylene glycol (PEG)] regions and to study primary nerve cell interaction with these surfaces. PCTFE was modified with PEG-alkoxide, patterned with gold by sputtercoating, and PCTFE-Au regions were modified with laminin-derived peptides, CGYIGSR or CSIKVAV. On homogeneously modified surfaces, cell adhesion increased in the order: PEG $<$ PCTFE $\sim$ Au $<$ CSIKVAV $<$ Poly(L-lysine)/laminin $<$ CGYIGSR. Neurite outgrowth studies showed that CSIKVAV surfaces were comparable to positive controls [(Poly(L-lysine)/laminin] with respect to neurite length. On patterned surfaces, cell adhesion and neurite outgrowth were successfully directed on $180 \mu \mathrm{m}$ PEG/90 $\mu \mathrm{m}$ peptide patterns. 


\section{Acknowledgements}

I would like to begin by thanking Professor Molly Shoichet for her supervision and guidance throughout the last two years. Working under Molly's supervision proved to be a challenging yet wonderful learning experience and I feel fortunate to have been a member of her research group. I would also like to thank the other members of the "Shoichet Research Group": Xudong Cao, Yen Tong, Dan Lousenberg, Chantal Holy, Paul Dalton, and Yumin Yuan, for their help and advice and for sharing their expertise! I would especially like to thank Xudong for passing on his cell culture techniques, Dan for his help in the lab, and Yen for his help with cell culture and with any computer problems that were encountered!

I would also like to acknowledge the assistance of Suzanne Mamiche with the sputtering machine, Prof. Rana Sodhi with XPS analysis, and Prof. Chris Yip for his help with AFM analysis and for his numerous helpful suggestions. In addition, I would like to thank Prof. Sefton for his unique teaching style and for taking time out of his busy schedule to be on my defense committee.

I was very fortunate to go have gone through this stage of my academic life alongside two exceptional young ladies, Nikki Porter and Dolores Baksh (a.k.a. the Biomaterials Girls). Our morning coffee break conversations where we tackled research obstacles and discussed future plans (4 years!) were memorable moments. I would like to thank Nikki and Dolores for their invaluable friendship. I would also like to thank a special friend, Anandhi Narayanan, for listening to me complain and for making me smile. :-

Finally, I am grateful to my parents for their love, support, and encouragement throughout the last 25 years. I would like to thank them for allowing me to make my own decisions and for teaching me so many things about life that are not taught in school. I would also like to thank my brother Ali for his support and for the beautiful house he is going to design for me one day! 


\section{TABle of Contents}

List of Tables vii

List of Figures viii

List of Abbreviations $\quad$ xi

1. Introduction 1

1.1 Axonal Regeneration 1

1.2 Axonal Guidance 3

1.3 Primary Nerve Cells 4

1.4 Hippocampal Cells $\quad 5$

1.5 Surface Modification 6

1.6 Patterning Techniques 9

$\begin{array}{lll}1.7 & \text { Fluoropolymers } & 13\end{array}$

1.8 Poly(chlorotrifluoroethylene) 14

1.9 Protein/Cell-Resistant Surfaces - 16

$\begin{array}{ll}1.10 \text { Poly(ethylene glycol) } & 17\end{array}$

$\begin{array}{ll}1.11 \text { Cell-Adhesive Surfaces } & 21\end{array}$

1.12 Cell-Adhesive Peptides $\quad 23$

$\begin{array}{ll}1.13 \text { Hypothesis } & 25\end{array}$

1.14 Objectives $\quad 25$

2. Experimental 26

2.1 Materials 26

2.2 Surface Modifications $\quad 27$

2.2.1 PEG Modification $\quad 28$

2.2.2 Gold Sputtering $\quad 29$

2.2.3 Patterning $\quad 30$

2.2.4 Peptide Modification 31

2.2.5 Peptide Labeling and Quantification 32

2.3 Surface Characterization 33

2.3.1 Contact Angle Analysis 33

2.3.2 X-ray Photoelectron Spectroscopy 33

2.3.3 Angle-Resolved XPS 34

$\begin{array}{lll}2.3 .4 & \text { Ellipsometry } & 36\end{array}$

$\begin{array}{lll}2.3 .5 & \text { AFM } & 36\end{array}$

2.4 Cell Culture Experiments 37

2.4.1 Sterilization of Substrates 37

2.4.2 Preparation of Positive Control 37 
2.4.3 Cell Dissociation and Plating 38

2.4.4 Competitive Cell Adhesion Assay 39

2.4.5 Cell Viability Assay 39

2.4.6 Quantitative and Qualitative Analysis $\quad 40$

2.4.7 Statistical Analysis $\quad 40$

3. Results 41

3.1 PEG Modification $\quad 41$

$\begin{array}{lll}3.1 .1 & \text { XPS } & 41\end{array}$

3.1.1.1 The Effect of Reaction Time 41

3.1.1.2 The Effect of PEG MW 44

3.1.1.3 The Effect of Solvent System 47

3.1.2 Contact Angle $\quad 47$

3.1.3 Thickness and Surface Coverage $\quad 50$

3.1.4 AFM 51

3.2 Peptide Modification $\quad 54$

3.2 .1 XPS $\quad 54$

3.2.2 Contact Angle $\quad 55$

3.2.3 Thickness and Surface Coverage 56

3.3 Cell Culture $\quad 58$

$\begin{array}{ll}\text { 3.3.1 Qualitative Analysis } & 58\end{array}$

3.3.2 Cell Adhesion Analysis 66

3.3.3 Competitive Cell Adhesion Assay 67

3.3.4 Neurite Outgrowth Analysis 68

3.3.5 Neurite Length Analysis $\quad 69$

3.3.6 Patterned Surfaces 71

4. Discussion $\quad 78$

$\begin{array}{lll}4.1 & \text { PEG Modification } & 78\end{array}$

4.1.1 The Proposed Mechanisms $\quad 79$

4.1.2 The Effects of PEG MW 81

4.1.3 The Effects of the Co-solvent System 82

4.2 Peptide Modification 83

4.3 Cell-Surface Interactions on Homogeneous Surfaces 84

4.4 Cell-Surface Interactions on Patterned Surfaces 87

4.5 The Effects of Pattern Dimension on Guiding Cell Adhesion 89 and Neurite Outgrowth 
5. Conclusions and Recommendations for Future Work

5.1 Conclusions

91

5.2 Recommendations for Future Work

92

6. References

93 


\section{LIST OF TABLES}

Table 2.1: The sputtering system parameters used in the deposition of Au onto modified PCTFE films.

Table 2.2: Grid dimensions used to create micron scale patterns on modified PCTFE.

Table 3.1: XPS results for PEG MW5000 modification of PCTFE ( $90^{\circ}$ take-off angle).

Table 3.2: XPS results for PEG MW5000 modification of PCTFE ( $15^{\circ}$ take-off angle).

Table 3.3: XPS results comparing different MW PEGs in toluene vs. toluene/THF solvents ( $90^{\circ}$ take-off angle).

Table 3.4: XPS results comparing different MW PEGs in toluene vs. toluene/THF solvents ( $15^{\circ}$ take-off angle).

Table 3.5: XPS results for peptide modification reactions $\left(90^{\circ}\right.$ take-off angle).

Table 3.6: XPS results for peptide modification reactions $\left(15^{\circ}\right.$ take-off angle). 


\section{LIST OF FIGURES}

Figure 1.1: In vivo, growing axons are guided by a combination

of adhesive and repulsive cues.

Figure 1.2: An image of a typical hippocampal cell in culture.

Figure 1.3: The molecular formulas of PTFE and PCTFE.

Figure 1.4: The molecular formula of PEG.

Figure 1.5: Surface bound PEG molecules are highly hydrated and their excluded volume is believed to play a key role in resisting protein adsorption and cell adhesion.

Figure 1.6: The structure of laminin, showing the locations of YTGSR, IKVAV, and RGD peptide sequences.

Figure 2.1: The experimental scheme showing the three surface modification steps: 1) PEG modification, 2) Au sputtering, and 3) Peptide modification.

Figure 2.2: The preparation of PEG-alkoxide and its reaction with PCTFE films.

Figure 2.3: A mask in combination with EM grids is used to create micron scale patterns on the surface of the films.

Figure 2.4: Peptide modification of PCTFE-Au films.

Figure 3.1: High resolution XPS spectra showing the $\mathrm{Cls}$ regions of a) PCTFE, b) PCTFE-PEG at a take-off angle of $90^{\circ}$, and c) PCTFE-PEG at a take-off angle of $15^{\circ}$.

Figure 3.2: For the same depth of modification (h) and the same depth of analysis (d), an increase in surface percentages of carbon and oxygen with decreasing MW PEG suggests that the surface coverage is greater on the PEG MW2000-modified surface.

Figure 3.3: Advancing and receding contact angle data for the PEG modification reactions. 
Figure 3.4: AFM height images of A) PCTFE and B) PCTFEPEG surfaces showing surface topography (scan size of $5 \mu \mathrm{m} \times 5 \mu \mathrm{m}$ ).

Figure 3.5: Advancing and receding contact angle data for the peptide modification reactions.

Figure 3.6: Representative images of hippocampal cells on PCTFE on a) day 1, b) day 4 , and c) day 7 after cell plating.

Figure 3.7: Representative images of hippocampal cells on a) PCTFE-PEG - day 1 after cell plating ( $100 \mathrm{X}$ magnification), b) PCTFE-PEG - day 1 after cell plating (200X magnification), and c) PCTFE-PEG$\mathrm{Au}$ - day 1 after cell plating (200X magnification).

Figure 3.8: Representative images of hippocampal cells on CGYIGSR-modified surfaces on a) day 1 after cell plating, b) day 4 after cell plating, c) day 7 after cell plating.

Figure 3.9: Representative images of hippocampal cells on CSIKVAV-modified surfaces on a) day 1 after cell plating, b) day 4 after cell plating, and c) day 7 after cell plating.

Figure 3.10: Representative images of hippocampal cells on PLL/laminin (positive control) surfaces on a) day 1 after cell plating, b) day 4 after cell plating, c) day 7 after cell plating.

Figure 3.11: Average number of cells per field ( 1 field $=25 \mathrm{~mm}^{2}$ ) as determined for 10 random fields per surface.

Figure 3.12: Results of the competitive assay showing a significant reduction in the number of cells per field if the cells were pre-incubated with peptides.

Figure 3.13: Average number of neurites per cell as determined for 50 random cells per surface.

Figure 3.14: Average neurite length on each surface as determined for 50 random cells per surface. 
Figure 3.15: An image of hippocampal cells on a PCTFE/Au patterned surface $(180 \mu \mathrm{m}$ regions of PCTFE $/ 90 \mu \mathrm{m}$ regions of $\mathrm{Au}$ ).

Figure 3.16: An image of hippocampal cells on a

PCTFE/CGYIGSR patterned surface $(180 \mu \mathrm{m}$ regions of PCTFE/90 $\mathrm{\mu m}$ regions of CGYIGSR).

Figure 3.17: An image of hippocampal cells on a PEG/CGYIGSR patterned surface on day 2 after cell plating (180 $\mu \mathrm{m}$ regions of PEG/90 $\mu \mathrm{m}$ regions of CGYIGSR).

Figure 3.18: An image of hippocampal cells on a PEG/CGYIGSR patterned surface on day 4 after cell plating ( $180 \mu \mathrm{m}$ regions of PEG/90 $\mu \mathrm{m}$ regions of CGYIGSR).

Figure 3.19: An image of hippocampal cells on a PEG/CGYIGSR patterned surface (day 4). Upon encountering the PEG regions, neurites often change direction and continue to grow on the peptide surface.

Figure 3.20: An image of hippocampal cells on a PEG/CGYIGSR patterned surface on day 7 after cell plating (180 $\mu \mathrm{m}$ regions of PEG/90 $\mu \mathrm{m}$ regions of CGYIGSR).

Figure 3.21: An image of hippocampal cells on a PEG/CGYIGSR patterned surface on day 4 after cell plating (40/22 EM grids were used to pattern the surface; however, the resulting patterns generally consisted of $30 \mu \mathrm{m}$ regions each of $P E G$ and peptide).

Figure 3.22: An image of hippocampal cells on a PEG/CGYIGSR

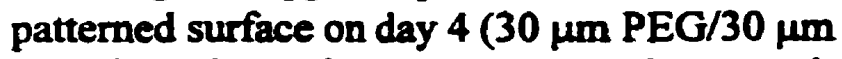
peptide regions) showing some neurites crossing over the PEG regions.

Figure 4.1: Mechanism 1 - The nucleophilic substitution of chlorine on PCTFE by the lithium salt of PEGalkoxide.

Figure 4.2: Mechanism 2 - Metal-halogen exchange/elimination of PCTFE by the lithium salt of PEG-alkoxide. 


\section{LIST OF ABBREVIATIONS}

\begin{tabular}{ll} 
AFM & Atomic Force Microscopy \\
CNS & Central Nervous System \\
E18 & Embryonic day 18 \\
ECM & Extracellular Matrix \\
EDA & N-(2-aminoethyl-3-aminopropyl)trimethoxysilane \\
EM & Electron Microscopy \\
FEP & Fluorinated Ethylene Propylene \\
IKVAV & Isoleucine-Lysine-Valine-Alanine-Valine \\
KE & Kinetic Energy \\
M-PEG-OH & Methoxy-Poly(ethylene glycol) \\
MW & Molecular Weight \\
NGC & Nerve Guidance Conduit \\
OTS & N-octadecyltrichlorosilane \\
PBS & Phosphate Buffered Saline \\
PCTFE & Poly(chlorotrifluoroethylene) \\
PEG & Poly(ethylene glycol) \\
PET & Poly(ethylene terephthalate) \\
PLL & Poly(L-lysine) \\
PNS & Peripheral Nervous System \\
PTFE & Polytetrafluoroethylene \\
PVDF & Polyvinylidene Fluoride \\
RGD & \\
& Arginine-Glycine-Aspartic Acid \\
\hline
\end{tabular}


RT

SAM

$\mathrm{SC}$

SFM

THF

XPS

YIGSR
Room Temperature

Self-assembled Monolayer

Spinal Cord

Serum Free Medium

Tetrahydrofuran

$\mathrm{X}$-ray Photoelectron Spectroscopy

Tyrosine-Isoleucine-Glycine-Serine-Arginine 


\section{INTRODUCTION}

\subsection{Axonal Regeneration}

Injury to the central nervous system (CNS) often leads to permanent disability with loss of sensory, motor, and reflex functions. These severe consequences result from the fact that CNS neurons unlike most other cells in the body lack the ability to spontaneously regenerate following injury. Following axonal injury, most adult neurons are able to survive for prolonged periods of time provided that the lesion site is not too close to the cell body (Schwab and Bartholdi, 1996). The damaged nerve cell is capable of making a series of regenerative attempts such as initial sprouting; however, the sprouts fail to elongate and soon undergo regression. This failure to regenerate is partially attributed to the inhibitory factors of the immediate lesion-induced environment. Recently, it has been shown that the adult CNS environment that lies beyond the inhibitory lesion area is capable of supporting regeneration (Davies et al., 1997). It is therefore thought that CNS regeneration is possible if the axons are presented with a growth-permissive environment at the lesion site.

With this idea in mind, several experimental approaches have been undertaken to promote axonal regeneration in the adult mammalian CNS. Of these approaches, the implantation of fetal CNS grafts and peripheral nervous system (PNS) grafts into the injured CNS area have shown some successful results to date. The work of Aguayo et al. in the 1980s showed that injured CNS axons were able to regenerate into PNS grafts implanted at the site of injury; however, they were seen to stop within 1-2 mm from the exit of the grafts (David and Aguayo, 1981). Similar results were obtained from studies involving embryonic transplants placed into the injured adult CNS. Jakeman and Reier 
placed pieces of embryonic spinal cord (SC) into the injured SC of adult rats (Jakeman and Reier, 1991). Their results showed that many axons grew within the embryonic grafts but very few were seen past the exit of the grafts, in the host CNS environment. These experiments indicated that the PNS and the embryonic CNS represent favorable and growth-promoting microenvironments for CNS regeneration. The next step involved the identification of the specific properties of these tissues that allowed regeneration following injury. It was thought that once these properties were identified, they could be incorporated into artificial matrices and implanted into the site of injury thereby avoiding the problems of graft origin and graft harvesting. These artificial grafts or nerve graft conduits (NGCs) would simplify end-to-end repair, protect the regenerating nerve from infiltrating scar tissue, and direct axonal growth towards the target region (Bellamkonda and Aebischer, 1994). Liu et al. explored the possibility of using tubular implants made of collagen to bridge the spinal cord to the periphery. They investigated axonal regeneration across a $3 \mathrm{~mm}$ gap in a rat brachial plexus injury and found axonal regrowth through the tubes to be as effective as in nerve grafting experiments (Liu et al., 1997). Although the results of this study were very encouraging, the site of injury was not in the CNS and the size of injury was not critical. To date, minimal success has been achieved in studies involving regeneration in the CNS using artificial NGCs.

One of the obvious requirements for a successful NGC is to guide axons in a desired direction. In order to successfully incorporate this function into an artificial conduit, it is important to look at axonal guidance. 


\subsection{Axonal Guidance}

In the developing CNS, differentiating neurons send out axons that travel through the embryonic environment and form appropriate connections with specific target cells. Studies of axonal migration in vivo have shown that this process occurs with astounding precision. Several types of mechanisms are believed to contribute to the guidance of axons toward their appropriate targets. Two of these mechanisms are known as contactattraction and contact-repulsion (Tessier-Lavigne and Goodman 1996). Several extracellular matrix molecules possessing adhesive or repulsive characteristics have been identified in the developing CNS as well as the adult PNS. For example, laminin (an extracellular matrix (ECM) glycoprotein) has been shown to have cell-adhesive characteristics while some sulfated proteoglycans such as keratan sulfate proteoglycan (KSPG) have been shown to possess cell-repulsive characteristics (Tessier-Lavigne and Goodman, 1996). The appropriate combination of adhesive (+) and repulsive (-) cues in vivo allow axonal growth to be channeled thereby allowing the formation of specific neuronal connections (Figure 1.1).

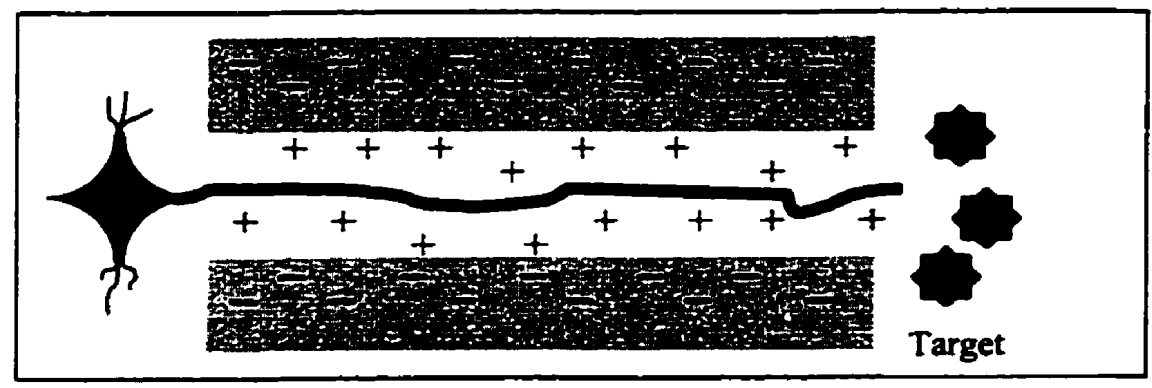

Figure 1.1: In vivo, a combination of adhesive $(+)$ and repulsive $(-)$ cues guide the growing axon to its appropriate target. 
Since the success of axonal guidance in the developing CNS and the adult PNS is partially attributed to the presence of these adhesive and repulsive cues, it may be possible to guide axonal outgrowth in vitro by mimicking the effects of these cues on artificial substrates. Once axonal outgrowth can be successfully directed on a twodimensional surface, the techniques can be applied to create three-dimensional artificial conduits for directing axonal regeneration in vivo.

The goal of this research project is to modify 2-D polymeric surfaces to mimic the effects of both cell-adhesive and cell-repulsive cues and to study nerve cell interaction with these surfaces.

\subsection{Primary Nerve Cells}

The majority of cells, when dissociated from the tissue and plated onto culture substrates divide, reach confluency, and then begin to differentiate (Goslin et al., 1998). Primary neurons, however, do not proliferate making their study in culture very different from the study of other cell types. For the sake of convenience, several cell lines have been developed which can be stored, cultured when needed and passaged; however, the suitability of available cell lines as models for CNS neurons is limited (Goslin et al., 1998). As a result, many researchers have chosen to work with embryonic CNS neurons that have reached the end of their division stage but have not yet begun to differentiate. Several examples of CNS neurons used in culture include spinal cord cells, striatal cells, and hippocampal cells (Kleinfeld et al., 1988; Ventimiglia et al., 1995; Schaffiner et al., 1995). Cerebellar cells have also been used in both the embryonic and postnatal stage (Kleinfeld et al., 1988). When looking at morphological and physiological aspects of 
primary cultures, heterogeneity is a serious complication. It is therefore important to develop techniques for identifying and purifying a desired cell type in a mixed population of cells. It is also important to note that several regions of the nervous system are more complicated than others. The choice of cell type and its developmental stage can greatly reduce the preparation time as well as the analysis following cell plating in in vitro studies. Out of the four cell types mentioned above, we chose to work with embryonic hippocampal neurons.

\subsection{Hippocampal Cells}

The hippocampus is located in the limbic system of the brain and is a critical component of the memory system (Fox, 1996). It is a source of a relatively homogeneous cell population of pyramidal neurons that have well characterized properties typical of CNS neurons (Goslin et al., 1998). Hippocampal cells, like most neurons, have a single axon and several highly branched dendrites (Figure 1.2). They make direct synaptic connections with one another as well as with other neurons. Typically, embryonic day 18 (E18) to 19 rat hippocampal cells are used for in vitro cell culture studies since the generation of pyramidal cells is essentially complete by this time but the generation of dendate granule cells has scarcely begun (Goslin et al., 1998). At this stage of embryonic development, it is relatively easy to dissociate the cells from the hippocampal tissue and the number of background cells (i.e. glial cells) are modest. In the current project, E18 rat hippocampal cells were used to study primary nerve cell interaction with surface-modified polymer substrates. 


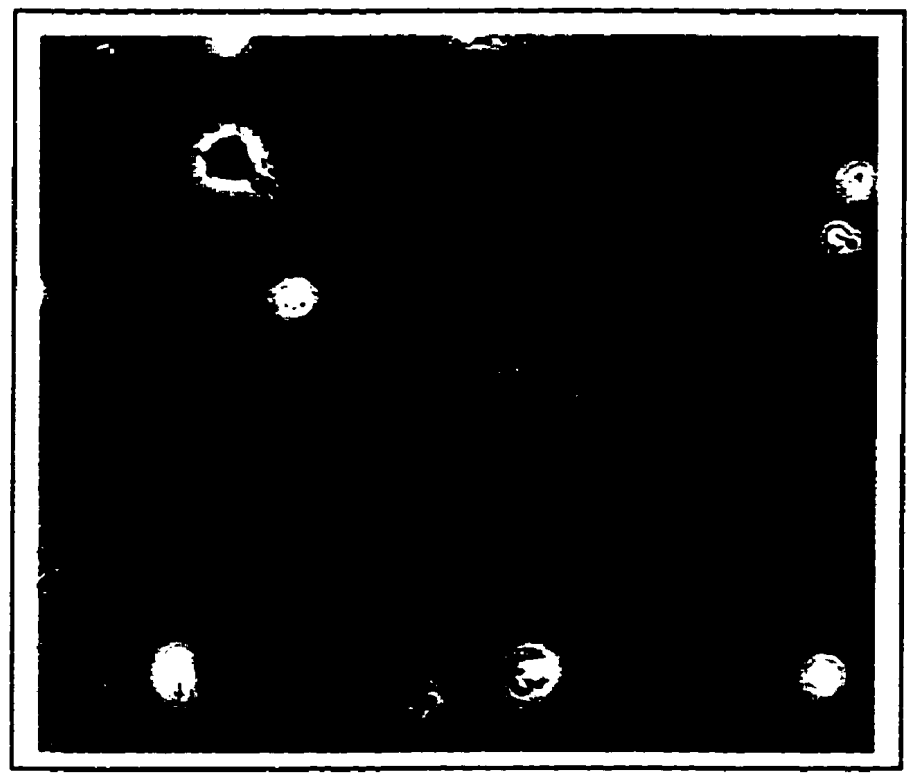

Figure 1.2: Hippocampal cells have a pyramidal shaped cell body with several branching dendrites and one long axon.

\subsection{SuRface Modification}

Surface modification techniques are used when the surface properties of a material need to be changed to meet a specific application (e.g. biomedical application), without affecting the bulk. Using these techniques, the functionality and the mechanical properties of the material are unaffected while the outer surface is modified thereby improving the material interaction with a biological environment (Ratner and Hoffman, 1996). Most surface modification techniques which are applied to biomaterials are used to either render the material bioactive or bioinert (Neff and Caldwell, 1999). For example, a bioactive surface may improve cell adhesion and growth while a bioinert surface may minimize protein adsorption. There exist a variety of modification techniques including chemical, physical, mechanical, and biological treatments. Chemical modification alters the chemistry of a particular surface. For example, it is 
possible to introduce desired functional groups by chemically grafting a molecule onto a surface. We have previously used this technique to covalently attach molecules containing amine functional groups onto glass surfaces (Saneinejad and Shoichet, 1998). Once the desired amine groups were available on the surface, it was possible to further modify these groups with polyethylene glycol (PEG) molecules to create a cell nonadhesive substrate. The main advantage of specific chemical surface modifications are that only one particular functional group is targeted and there are generally few side reactions involved.

Other chemical modification methods involve treating the surface with vapors or radiation. Gas plasma technology is widely used to alter the surface chemistry of polymeric materials. Gombotz et al. exposed poly(ethylene terephthalate) (PET) surfaces to an allylamine plasma glow discharge to obtain amine groups on the surface (Gombotz et al., 1991). The advantages of plasma modification are that it can be applied to a variety of materials ranging from metals to polymers and different types of plasma can be used to introduce a large variety of functional groups onto surfaces. One major disadvantage, however, is that the technique often involves non-specific reactions and is therefore difficult to control. A variety of factors such as energy and angle of collision affect the type of bond formed at the surface. As a result, it is often possible to introduce a variety of different functional groups on the same surface (Neff and Caldwell, 1999).

Modification with self-assembled monolayers (SAMs) is another technique that has been used to achieve highly ordered structures on specific substrates. Examples of SAM films include alkyl silanes on hydroxylated surfaces (Stevens, 1999) and alkane thiols on metal surfaces such as gold (Dimilla et al. 1994). A process called 
chemisorption involving the strong adsorption of an anchoring group to the surface drives the formation of SAMs. One advantage of surface modification using SAMs, is their ease of formation (Ratner and Hoffman. 1996); however, one disadvantage is that the structure of some SAMs, specifically alkylsiloxanes, are not well established and the resulting monolayer is less ordered than SAMs of alkylthiolates.

Physical modification includes coating or lamination techniques. For example, it is possible to physically deposit a thin metal layer on a surface using metal sputtering or evaporation techniques (Saneinejad and Shoichet, 1998). A major concern with the physical deposition of metals is the stability of the resulting surface. An adhesion promoter is often added prior to metal deposition to improve the stability of the coating. Micromanipulation using atomic force microscopy (AFM) probes is an example of mechanical modification (Hoffman, 1996). Lasers can also be used to mechanically etch the surface and alter its topography (Ratner and Hoffman, 1996). Biological modifications include covalent grafting or physical adsorption of biomolecules such as proteins onto surfaces to increase or decrease cell-surface interactions (Kim et al., 1974;, Kottke-Marchant et al., 1989). Albumin adsorption is an example of biological modification that is used to reduce thrombogenicity and platelet adhesion to a particular surface (Kottke-Marchant et al., 1989). The maintenance of albumin coverage on implants, however, is a problem that is encountered when the material is implanted in vivo. Another example of biological modification is the immobilization of cell adhesion peptides on biomaterials in order to achieve specific cell-surface interactions. The use of these peptides will be discussed later in detail. 
Chemical, physical, and biological modification techniques were all used in this research project to create cell-adhesive and non-adhesive regions on polymeric substrates. Chemical modification was achieved using specific reactions to create welldefined surfaces. SAM techniques were also used in the biological modification of surfaces with cell adhesive peptides. By creating alternating patterns of varying chemistry, it is possible to study the dual effects of adhesive and non-adhesive regions on nerve cell adhesion and neurite outgrowth.

\subsection{Patterning Techniques}

One of the key issues in tissue engineering is the ability to control cell-surface interactions. The ability to control cell adhesion, spreading, migration, and proliferation are potential requirements for the development of advanced tissue-engineered devices such as artificial organs and biosensors. In recent years, patterning techniques have been widely used for spatial control of cells in culture (Nicolau et al., 1999; Zhang et al., 1999; Bhatia et al., 1997; Matsuzawa et al., 1996a). Many patterning strategies have employed variations in charge (Lee et al., 1993), surface topography (Clark et al., 1991), and surface chemistry (Matsuzawa et al., 1996a; Ranieri et al., 1993) to manipulate cellsurface interactions. Current techniques used to create patterns of varying surface chemistry include photolithography (Bhatia et al., 1997) and microcontact printing (Zhang et al., 1999). Photolithography involves the use of photoresist technology in combination with UV irradiation treatment through lithographic masks (Blawas and Reichert, 1998). This technique was used by Kleinfeld et al. to create alternating patterns of amine functional groups and alkyl chains on glass surfaces to study spinal cord and 
cerebellar cell-surface interactions (Kleinfeld et al., 1988). Healy et al. also used photolithography to create patterns of different silane reagents to study the spatial organization of bone-derived cells (Healy et al., 1996). They found that the bone cells required the presence of serum in the medium or the pre-adsorption of serum in order to organize according to the lithographically defined surface chemistry. One important issue that needs to be considered when using UV irradiation in photolithography is the amount of control over the resulting surface chemistry.

Microcontact printing involves the use of an elastomeric stamp containing defined features on the mircro-meter scale. The stamp is nked" with a solution and placed directly on top of the substrate thereby creating patterns of modified regions. This technique was used by Singhvi et al. to create patterns of self-assembled monolayers of alkanethiols on gold surfaces (Singhvi et al., 1994). This technique works well with a variety of surfaces including polymers.

When considering the use of biological molecules such as proteins for surface modification, it is important to consider the possibility of losing protein activity following some of the modification steps (Blawas and Reichert, 1998). An ideal patterning technique would minimize the number of modification steps in creating wellcontrolled surface chemistries. If the patterns contain biomolecules such as proteins, steps would be taken to ensure that the protein-modified surfaces are not exposed to harsh reaction conditions (such as UV irradiation) that may lead to loss of bioactivity.

The ability of nerve cell processes to extend to their targets is partially dependent on their adhesion to underlying substrates. Patterning techniques can be used to control nerve cell-surface interactions and to guide neuronal processes in a desired direction. 
Research in this area dates back to 1975 when Letoumeau studied axonal outgrowth on a variety of patterned surfaces (Letourneau, 1975). He showed that on a petri dish sputtered with alternating regions of palladium (Pd), dorsal root ganglia adhered preferentially to the Pd regions whereas on tissue culture plastic sputtered with regions of Pd, the cells adhered preferentially to the tissue culture substrate. This study was one of the first in a series of studies performed by various researchers which showed preferential adhesion on patterned surfaces. In another study, Kleinfeld et al. used silane chemistry and lithographic techniques to create patterns of amine groups and alkane groups on silicon (Kleinfeld et al., 1988). They studied spinal cord and cerebellar cell-surface interactions and found that in the presence of serum, the cells were confined to the amine modified regions; however, in serum free medium, cells were found to adhere onto both aminated and alkylated regions. This observation suggests that surface chemistry alone was unable to control the spatial organization of the cells. It appears that the interaction of serum proteins with the differing surface chemistry was a pre-requisite for achieving cell organization on the patterns. Corey et al. used a photolithographic technique to create patterns of polylysine on glass surfaces and showed that it was possible to significantly restrict hippocampal neurons to the polylysine regions of the surface (Corey et al., 1991). They concluded that cells randomly encountered the patterned substrate during plating and migrated onto the more adhesive polylysine regions over time. After 72 hours in culture, however, some processes started to migrate off the polylysine patterns.

These referential adhesion' studies had one th ing in common: they all studied alternating regions of different degrees of adhesivity. Given a choice between polylysine 
and glass, a cell will preferentially adhere to polylysine but that does not necessarily mean that glass is a non-adhesive substrate. To gain more control over nerve cell adhesion and neurite outgrowth, researchers began to experiment with patterns of both adhesive and non-adhesive regions. Matsuzawa et al. modified the surface of glass with $N$-octadecyltrichlorosilane (OTS), a non-adhesive silane reagent (Matsuwaza et al., 1993). They then used UV irradiation through a lithographic mask to photocleave the OTS from the surface and then modified these areas with $N$-(2-aminoethyl-3aminopropyl) trimethoxysilane (EDA), an adhesive silane reagent. They cultured neuroblastoma cells on the surfaces and found the patterns to be effective as long as the alternating non-adhesive regions were at least 150 um wide. The cells remained true to the patterns for up to 15 days in culture. Two years later, Matsuwaza et al. went one step further and investigated the specific interaction between nerve cells and immobilized biomolecules on patterned surfaces (Matsuzawa et al., 1997). They created alternating patterns of OTS and a synthetic peptide to show that hippocampal cells adhered to and extended neurites onto the peptide regions only.

A great deal of progress has been made in the use of patterning to control nerve cell-surface interactions over the last 20 years. Researchers have also started to apply these developed techniques to more relevant biomaterial surfaces such as polymers (Ranieri et al., 1993; Makohliso et al., 1998). The focus of this research project was to extend the techniques that we developed on glass surfaces to polymeric substrates. 


\subsection{FLUOROPOLYMERS}

The major commercial fluoropolymers include polytetrafluoroethylene (PTFE), fluorinated ethylene propylene (FEP), poly(chlorotrifluoroethylene) (PCTFE), and polyvinylidene fluoride (PVDF). Fluoropolymers are known for their chemical and thermal stability and their excellent electrical properties (Feiring, 1994). In addition, their low surface energy makes them ideal for non-stick applications such as coatings for cookware surfaces. In the medical industry, their good mechanical properties and their inert and non-adhesive character makes them suitable materials for implants. Both PTFE and FEP have a history of use as vascular grafts. Fluoropolymers have also previously been used in nerve regeneration studies. Valentini et al. used electrically charged PTFE tubes for peripheral nerve regeneration in mice (Valentini et al., 1989). They submitted PTFE tubes to either a positive or a negative corona poling procedure in order to inject electrical carriers into them. In this way, they formed PTFE electrets displaying a surface charge due to the presence of trapped monopolar charge carriers. They reported that the tubes elicited a minimal tissue reaction and their results showed that charged PTFE tubes contained significantly more myelinated axons than uncharged tubes. In another study by Fine et al., piezoelectric NGCs were constructed from a copolymer of PVDF and trifluoroethylene and were used for peripheral nerve regeneration in rats (Fine et al., 1991). They observed myelinated axons and numerous small and large blood vessels in the tubes and reported minimal tissue reaction. In addition to the in vivo studies mentioned above, some in vitro studies using fluoropolymer substrates have also been performed. In a study by Tong and Shoichet, FEP surfaces were modified with peptide sequences to study hippocampal cell adhesion and neurite outgrowth. It was found that 
cell-surface interactions on FEP could be greatly enhanced by the surface modification techniques employed (Tong and Shoichet, 1998a). Teflon was used in a recent study involving the patteming of neuronal cell lines (Makohliso et al., 1998). The surfaces contained alternating patterns of spin coated $\mathrm{Teflon}$ and $\mathrm{SiO}_{2}$. The cell culture results were similar to those obtained by Kleinfeld et al. in 1988 . In the presence of serum, the cells remained true to the patterns; however, in serum-free medium, no bio-patteming was observed. Our goal was to achieve spatial organization in the absence of serum since the CNS, under normal physiological conditions, contains no serum proteins.

\subsection{POLY(CHLOROTRIFLUOROETHYLENE)}

PCTFE is structurally different from the more traditional perfluorinated fluoropolymers such as PTFE in that it has a chlorine group on each monomer unit (Figure 1.3). It is semi-crystalline and in comparison to PTFE, has improved mechanical properties (Feiring, 1994). The presence of the chlorine group in the backbone decreases the chemical resistance of the polymer slightly; however, it is still resistant to most strong acids and alkalis. It is attacked by alkali metal complexes such as organolithium and organomagnesium compounds and certain organic amines (Mark et al., 1985). PCTFE film is optically transparent and stable under vacuum. As a result, it is suitable for use in light microscopy as well as high vacuum surface analytical studies. 


\section{$-\left(\mathrm{CF}_{2}-\mathrm{CF}_{2}\right)_{\mathrm{n}}-$ PTFE \\ $-\left(\mathrm{CF}_{2}-\mathrm{CFCl}\right)_{n}-$ \\ PCTFE}

Figure 1.3: The molecular formulas of PTFE and PCTFE.

PCTFE is used in a variety of applications including packaging of medical devices as well as insulating electrical equipment. It is extremely effective in protecting moisture sensitive products such as pharmaceutical drugs (AlliedSignal Inc.). It is nontoxic and has been approved by the U.S. Food and Drug Administration for the handling and packaging of food (AlliedSignal Inc.).

In addition to the above industrial applications, PCTFE has also been used as a tissue culture substrate for culturing a variety of cell types (Kingsley and Cole, 1988). Aclar ${ }^{\text {TM }}$ (AlliedSignal tradename for PCTFE) was used by Kingsley $e t$ al. as a substitute for tissue culture plastic to grow macrophages, fibroblasts, neurons and glia from a variety of species. With Aclar', it is possible to prepare the cells for electron microscopy studies without having to remove them from the substrate. Also, unlike glass coverslips or tissue culture plastic, Aclar ${ }^{\text {Tw }}$ film can be easily cut to any dimension following cell culture thereby creating multiple samples for analysis. Bunge and Wood used collagen coated Aclar ${ }^{\mathrm{T}}$ film to maintain hemisections of embryonic rat spinal cord for future transplantation (Bunge and Wood, 1973). They also cultured dorsal root ganglia on Aclar ${ }^{\mathrm{TM}}$ and successfully maintained cultures for up to 5 months. 
PCTFE was the chosen substrate for this research project mainly due to the presence of the chlorine functionality in its backbone. As mentioned earlier, the presence of the chlorine group decreases the chemical resistance of the polymer. As a result, better control and greater ease of modification can be achieved using chemical reaction techniques. PCTFE has been previously modified with a variety of lithium reagents, incorporating functional groups onto the surface (Dias and McCarthy, 1987). McCarthy et al. introduced carboxylic acid, hydroxyl, and aldehyde groups onto PCTFE by using different lithium reagents containing protected functional groups. By introducing functional groups onto the surface, it was then possible to further react the surface with other reagents. In one study, Lee and McCarthy reacted hydroxyl-modified PCTFE with a silane reagent in order to increase the adhesivity of the polymer to glass (Lee and McCarthy, 1988). In another study, the adhesivity of PCTFE to epoxy resins was increased by its reaction with the mild reducing agent, potassium t-butoxide/benzoin (Hung and Burch, 1995). Hung and Burch also reported that by reducing fluoropolymers, it is possible to improve fluoropolymer-metal adhesion. Our modification technique involved the reaction between a lithiated PEG-alkoxide solution and PCTFE films. The details of the reaction mechanism will be presented in section 4.1.1.

\subsection{Protenn/Cell Resistant Surfaces}

Protein adsorption is the initial event that occurs when a foreign material is implanted in the body. This initial response then leads to a host of other responses, which often lead to inflammatory and immune reactions. Over the years, a great of deal of research has been done to improve material biocompatibility by minimizing protein and 
cell adhesion following implantation. A variety of surface modification techniques have been employed to create ioinert" surfaces. One particular surface treatment which has been applied to hydrophobic surfaces is the pre-adsorption of the plasma protein, albumin. This technique has been used to reduce platelet adhesion for increased bloodmaterial compatibility (Kim, 1996). A problem that is encountered with the prealbumination of implants, however, is the finite life-time of the albumin coating (Neff and Caldwell, 1999). In the body, the adsorbed albumin can be displaced by other proteins like fibrinogen; although, this displacement process (the roman Effect") is less pronounced on hydrophobic surfaces (Neff and Caldwell, 1999). As mentioned earlier, surface modifications using adsorption techniques are often less stable than grafting techniques. Several groups have used organosilane reagents to chemically modify the surface of materials (Healy et al., 1994; Matsuzawa 1996a). Healy et al. modified glass coverslips with three different silane reagents and found that the alkyl silane modified surfaces showed decreased cell adhesion in comparison to the aminosilane modified surfaces. They attributed the decrease in adhesion to the lack of charge on the alkylsilane-modified surfaces. Matsuzawa et al. also used silane chemistry on modified glass surfaces to incorporate OTS groups on the surface. They were also able to show decreased cell adhesion following modification. One particular molecule that has received a great deal of attention due to its non-interactive nature with both proteins and cells is polyethylene glycol (PEG). PEG was the molecule of choice in this project for creating the non-adhesive regions on PCTFE. Its properties and history of use are discussed in detail in the following section. 


\subsection{Poly(EThYLENE GLYCOL)}

PEG is a non-ionic and hydrophilic polymer (Figure 1.4) that is soluble in both aqueous and many organic solvents (Harris, 1992). It has been widely used in biomaterials research for the surface modification of a variety of materials such as polyurethane (Han et al., 1996), poly(acrylonitrile-co-vinyl chloride) (Shoichet et al., 1994), poly(ethylene terephtalate) (Desai and Hubbell, 1992), and poly(acrylamide-covinyl amine (Yamamoto and Sefton, 1998).

\section{$-\left(\mathrm{CH}_{2} \mathrm{CH}_{2} \mathrm{O}\right)_{n^{-}}$}

Figure 1.4: Poly(ethylene glycol)

Studies have shown that PEG-modified surfaces exhibit low degrees of protein adsorption and cell adhesion (Drumheller and Hubbell, 1995; Lee et al., 1989). Several theories have been developed to explain this phenomenon. PEG minimal interfacial free energy is thought to contribute to its passivity (Lee et al., 1989). Proteins near a low interfacial energy interface will not feel any greater effects from the surface than they do from the bulk solution. Protein adsorption is often driven by hydrophobic interactions and since PEG is a hydrophilic polymer, PEG-modified surfaces provide little incentive for protein adsorption (Malmsten et al., 1998). In solution, PEG molecules form hydrogen bonds with water creating a highly connected network. This hydration effect is the basis of the xcluded volume" theory, which is represented in Figure 1.5. Surface bound PEG molecules surrounded by a hydration shell are highly flexible and their 
mobility is believed to hinder the adsorption of proteins or cells to the underlying surface (Lee et al., 1989). PEG passivity has also been attributed to the steric stabilization effect. It is believed that when a particle approaches the surface, there is a loss of configurational entropy of the surface bound PEG and this leads to the formation of a repulsive force. The excluded volume theory is also related to the steric stabilization effect since there is a loss of conformational freedom due to the hydration of molecules. The above theories have generally been accepted; however, no definite conclusions on PEG ability to resist protein adsorption and cell adhesion have yet been made. It is likely that the ioinert" characteristics achieved following PEG modification are not simply due to one but are a result of a combination of the above theories.

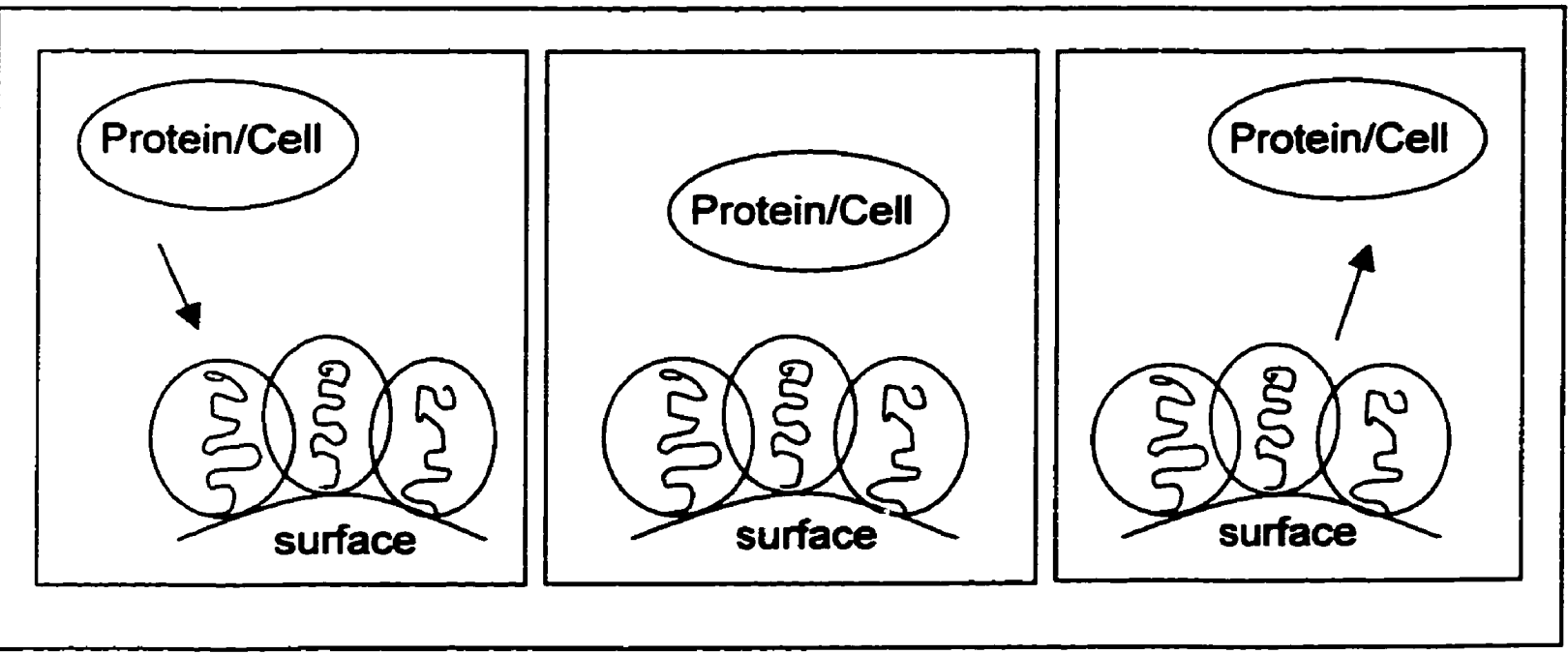

Figure 1.5: Surface bound PEG molecules are highly hydrated and their excluded volume is believed to play a key role in resisting protein adsorption and cell adhesion.

The studies on the effect of PEG molecular weight (MW) on protein adsorption have shown a general trend: as PEG molecular weight increases, protein adsorption decreases. Recently, however, the effect of PEG surface density has also been studied 
and the results indicate that there is a relationship between PEG grafting density and protein adsorption (Sofia et al., 1998). Grafting density and MW are also related. As the MW increases, grafting density decreases. The relationship between MW, grafting density, and protein adsorption have led to the identification of an optimum MW range for decreased protein adsorption. Gombotz et al. reported this MW range to be between 2000 and 3500 (Gombotz et al., 1992). Surfaces with PEG MW less than 2000 are not considered as effective in repelling proteins; since the hydration shell of the PEG molecules occupies a smaller volume, it is thought that particles will be able to penetrate the PEG overlayer. For high MW PEG surfaces, it is difficult to get a high surface density; therefore, it is again possible for particles to penetrate the overlayer. PEG molecules of MW 2000 to 3500 are small enough to achieve high surface densities but are large enough to present overlapping hydration shells to prevent protein adsorption. With reference to cell adhesion, studies have shown that as PEG MW is increased, cell adhesion is decreased; however, the effects of surface density have yet to be studied (Drumheller and Hubbell, 1995).

PEG surfaces can be prepared by a variety of techniques. The simplest technique involves the adsorption of PEG or PEG copolymers to the surface (Caldwell, 1992). The lack of chemical bonding to the surface, however, makes the overlayer less stable and so under certain environmental conditions the PEG could be desorbed (Gombotz et al., 1992). More stable systems can be prepared by covalently grafting PEG to the surface. Covalent grafting of PEG may involve initial surface modifications to introduce desired functional groups for PEG attachment. Derivatization of the PEG molecule itself can also be used to graft it to a surface (Litauszki et al., 1997). In previous work, we 
modified the surface of glass with amine groups and then covalently grafted PEGaldehyde molecules onto our surface by reductive amination. (Saneinejad and Shoichet, 1998). Recent work by Emoto et al. studied the effects of varying pH on the stability of amine-functionalized surfaces reacted with epoxy-terminated PEGs (Emoto et al., 1998). They found that PEG surfaces were stable in buffer solutions with $\mathrm{pH}$ ranging from 4 to 11 over a period of three weeks.

In this research project, PEG was covalently attached to PCTFE via a simple derivatization step. A methoxy-terminated PEG was reacted with an organolithium reagent to form a highly reactive PEG-alkoxide. The alkoxide derivative was then reacted with PCTFE to create a cell non-adhesive surface. The details of the reaction will be discussed later.

\subsection{Cell-Adhesive Surfaces}

Creating a bioactive surface is often a necessity for obtaining a desired cellmaterial response. When considering anchorage dependent cells, adhesion is a prerequisite step for other cellular functions such as migration, proliferation, or differentiation. It is not surprising then that a great deal of tissue engineering research has focused on creating surfaces that promote cell adhesion. Recent studies have shown that cell adhesion for some cell types, such as fibroblast cells, appears to be maximized on surfaces with intermediate hydrophilicity or surface energy (Lee et al., 1998). These results were obtained from cell culture studies in the presence of serum. There is therefore an indirect interaction between the cells and the surface that is mediated by the adsorption of serum proteins. The effects of polar groups on cell adhesion have also been 
studied for certain cell types. In a study involving fibroblast cells, Massia and Hubbell showed that amine-containing organic molecules that were covalently attached to surfaces promoted cell adhesion and spreading (Massia and Hubbell, 1992). From their study, they concluded that positively charged surface molecules interact with the negatively charged cell membrane, to promote cell attachment. In another study involving hippocampal cells, Tong and Shoichet modified the surface of FEP with amine groups and showed increased cell adhesion on the amine-modified polymer in comparison to the unmodified FEP (Tong and Shoichet, 1998b). The effects of surface energy on cell adhesion are considered to be a result of a non-specific interaction between the cell and the surface. The effects of polarity, are considered to be specific to a certain extent since certain polar groups are able to interact with cell receptors to mediate adhesion. The specificity of the interaction, however, is dependent on the molecular configuration of the attached polar group (Massia and Hubbell, 1992). Specificity of interaction is also dependent on the presence of serum proteins adsorbed on the modified surface. Cell membrane receptors are able to interact directly. with adsorbed proteins if the protein molecules are oriented in a way that exposes their active sites. Recent studies have focused on identifying and mimicking the interactions between cells and their ECMs. One of the ways in which these interactions can be mimicked is by modifying the surface of a desired biomaterial with cell-adhesive components of the ECM. This is the basis of our strategy for creating cell-adhesive regions on PCTFE. 


\subsection{Cell-Adhestve Peptides}

The ECM and its components play an important role in the development and the regeneration of tissues and organs. The developing CNS ECM is made up of a multitude of components including proteins, various proteoglycans, and immunoglobulins. Of the proteins, laminin in particular has been shown to play a major role in cell adhesion and neurite outgrowth (Leisi, 1990). Laminin is an $800 \mathrm{kDa}$ basement membrane glycoprotein that is highly expressed in the developing CNS and is also present at lower concentrations in the mature nervous system (Huber et al., 1998). Laminin is composed of three chains (A, B1, and B2) that are arranged in a cross-shaped structure (Figure 1.6) (Engel, 1992).

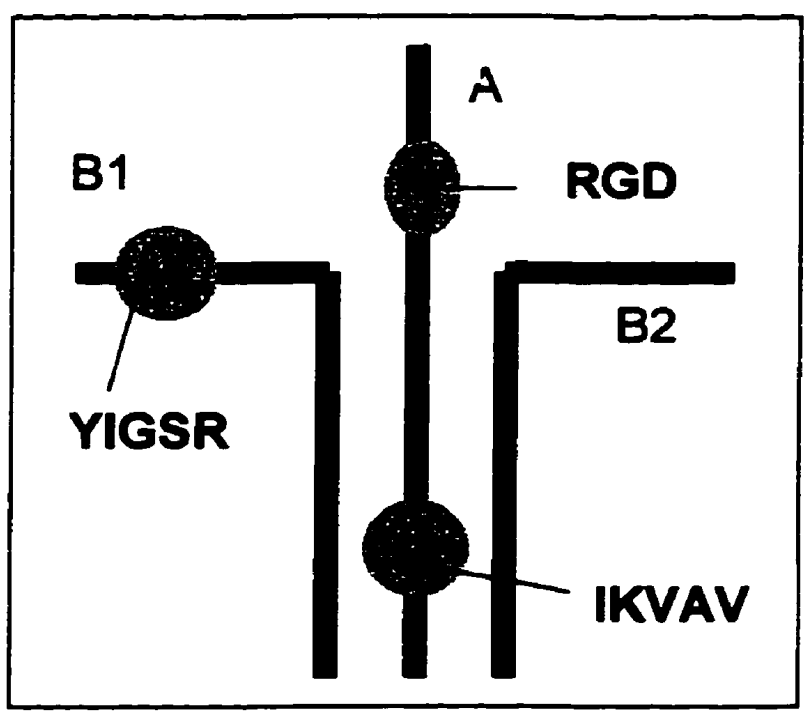

Figure 1.6: The structure of laminin showing the locations of the cell-adhesive peptide sequences YIGSR,IKVAV, and RGD (adapted from Engel, 1992).

In the developing CNS, laminin is thought to promote the outgrowth and migration of axons to their appropriate targets. It is also believed to play a role in 
neuronal attachment and survival (Powell and Kleinman, 1997). Numerous in vitro studies have looked at the effects of laminin modified surfaces on cell adhesion and neurite outgrowth (Manthorpe et al., 1983, Lein et al., 1992; Baron-Van Evercooren et al., 1982). The results of these studies have all confirmed that neuronal cells interact better with laminin modified surfaces in comparison to unmodified ones. In recent years, researchers have identified several cellular receptors that interact with laminin to mediate a neuronal response. These receptors interact with specific regions of the laminin molecule and several of these regions have also been identified. Two amino acid sequences found on laminin, YIGSR and IKVAV, are recognized by a $67 \mathrm{kDa}$ and a 110 kDa cell membrane receptor respectively (Powell and Kleinman, 1997). The YIGSR sequence is found on the Bl chain of laminin while the IKVAV sequence is on the A chain (Figure 1.6). The identification of these sequences has led to the use of synthetic peptides for the surface modification of a variety of materials to study cell-surface interactions (Huber et al., 1998; Vargo et al., 1995; Ranieri et al., 1995). The results of nerve cell studies have shown that the effects of laminin on cell adhesion and neurite outgrowth can be significantly mimicked by these peptide sequences. Specifically, the YIGSR sequence has been shown to promote cell adhesion while the IKVAV sequence has been mainily shown to promote neurite outgrowth (Powell and Kleinman, 1997).

It is important to note that another peptide sequence (RGD) on the A chain of laminin has also been found to interact with integrin receptors on the cell membrane. This sequence has also been synthesized and studied in culture with a variety of cell types and has been shown to promote cell adhesion (Vargo et al., 1995; Ruoslahti and Pierschbacher, 1987). Based on previous studies with RGD, YIGSR, and IKVAV, we 
concluded that the best cellular response was achieved with the YIGSR-and IKVAVmodified surfaces (Saneinejad and Shoichet, 1998). As a result, only these two sequences were chosen for surface modification in the current research project.

Surface modification with synthetic peptides has recently been coupled with patterning techniques in an attempt to guide nerve cell adhesion and neurite outgrowth (Matsuzawa et al., 1997, Ranieri et al., 1994). Ranieri et al. created patterns of cell adhesive peptides containing the YIGSR or the IKVAV sequence on FEP. They studied the attachment of two cell lines on the patterned surfaces and showed selective attachment on the peptide regions for a maximum of three days in culture. Matsuzawa et al. created similar patterns with peptides and a non-adhesive silane reagent. They were also able to direct nerve cell attachment onto the peptide regions. Our strategy was similar in that we used peptides to create the cell-adhesive regions on PCTFE. The nonadhesive regions, however, were created using PEG.

\subsection{HYPOTHESIS}

Nerve cell adhesion and neurite outgrowth can be directed on PCTFE.

\subsection{OBJECTIVES}

1. To modify PCTFE surfaces and incorporate alternating patterns of cell-adhesive (peptide) and non-adhesive (PEG) regions.

2. To study the interaction of primary CNS neurons with these patterned surfaces. 


\section{EXPERIMENTAL}

\subsection{Materials}

All chemicals were purchased from Sigma-Aldrich Co. (Oakville, Ontario) unless otherwise specified. Anhydrous toluene (99.8\%), 1,10-phenanthroline, and tertbutyllithium (1.7 $\mathrm{M}$ solution in pentane) were all stored under $\mathrm{N}_{2}$. Methoxy-PEGs (MPEG-OH) of MW 750, 2000, and 5000 were stored in a dessicator at room temperature (RT). Dichloromethane (99.9\%), methanol (99.9\%), and tetrahydrofuran (THF) (99.9\%) were purchased from Fisher (Nepean, Ontario). THF was distilled from sodium benzophenone dianion and was stored under $\mathbf{N}_{2}$. Anhydrous sodium acetate (BDH Inc., Toronto, Ontario), acetic acid (ACP Chemicals Inc., Montreal, Quebec), and anhydrous ethanol (99\%) (Commercial Alcohols Inc., Brampton, Ontario) were all used as received. Unless otherwise noted, water was distilled and deionized using Millipore Milli-RO 10 Plus and Milli-Q UF Plus (Bedford, MA) at $18 \mathrm{M} \Omega$ resistance. The peptides (CGYIGSR and CSIKVAV) were purchased from Procyon Biopharma (Ontario) and were stored at 4 ${ }^{\circ} \mathrm{C} . \mathrm{Na}^{125} \mathrm{I}$ was purchased from Amersham Life Science Inc. (Arlington Heights, II). Phosphate buffered saline (PBS) was purchased from The Materials Distribution Centre at the University of Toronto, (Toronto, Ontario). Neurobasal medium, L-glutamine, and B27 serum-free supplement were purchased from Gibco BRL (Grand Island, NY). The LIVE/DEADQ viability/cytotoxicity kit was purchased from Molecular Probes Inc. (Eugene, Oregon).

Electron microscopy (EM) grids were purchased from Electron Microscopy Sciences (Fort Washington, PA). Aclar 33C sheets (5.00 mil thickness) were received from Allied Signal Inc. (Morristown, N). The sheets were cut into squares (1.5 x 1.5 
$\mathrm{cm}$ ) and extracted in refluxing dichloromethane for $2 \mathrm{~h}$. They were dried under vacuum at RT for a minimum of $1 \mathrm{~h}$ before use. E18 rat hippocampal tissue was purchased from Southern Illinois University, School of Medicine (Springfield, IL) and was dissociated according to a published protocol (Brewer et al., 1993).

\subsection{SURFACE Modifications}

The surface modification of PCTFE consisted of 3 steps that are outlined in Figure 2.1. After each modification step, several analytical techniques were used to characterize the surface. Once the desired surfaces were prepared, cell culture experiments were conducted to study nerve cell-surface interactions. The details of the experimental methodology and surface characterization are discussed in the following sections.

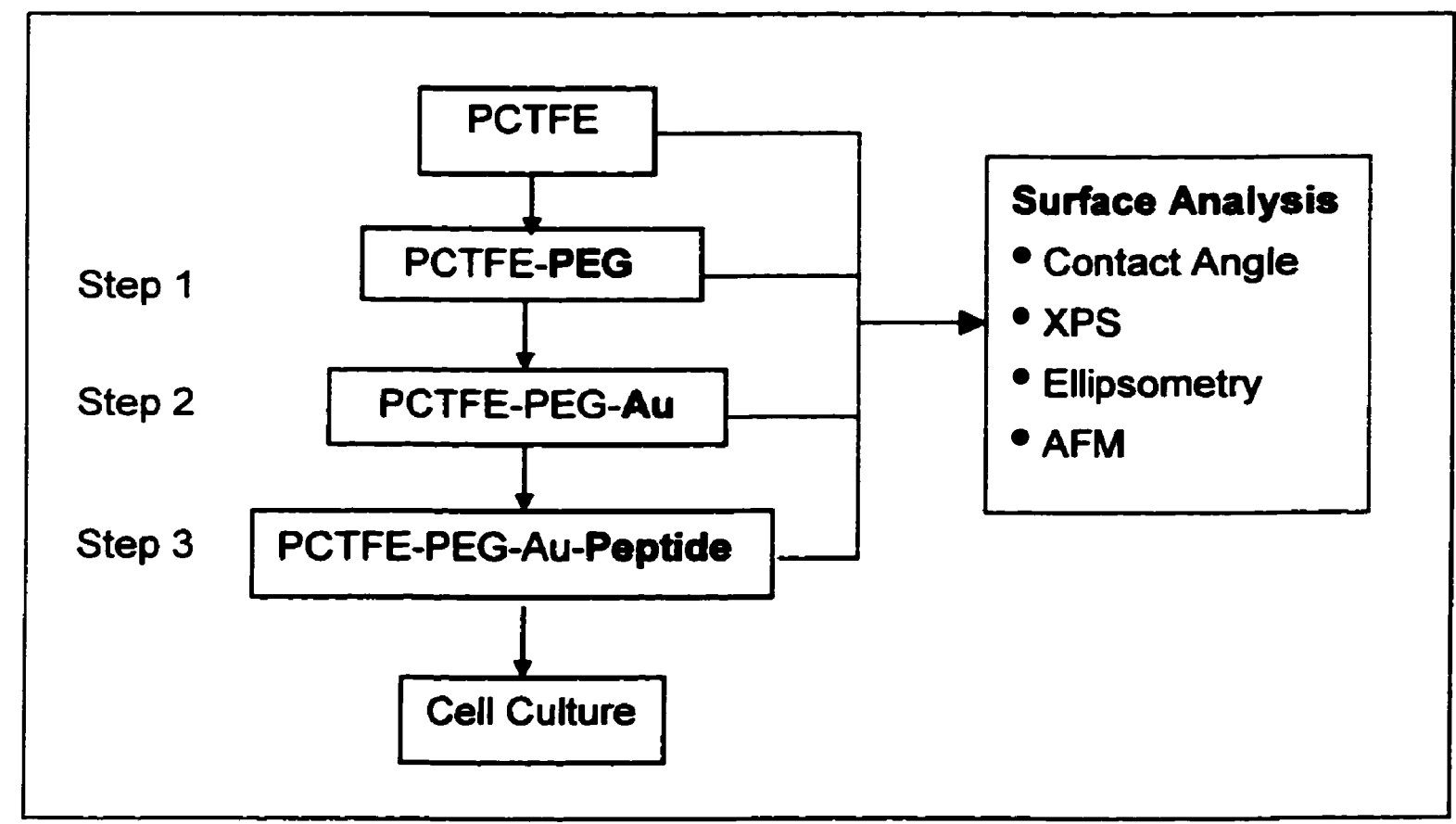

Figure 2.1: The experimental scheme showing the 3 modification steps: 1) PEG modification, 2) Au sputtering, and 3) Peptide modification. 


\subsubsection{PEG Modification}

All glassware was dried in the oven for a minimum of $24 \mathrm{~h}$ before use. The reactions were preformed under inert atmosphere $\left(\mathrm{N}_{2}\right)$.

A $0.3 \mathrm{M}$ solution of M-PEG-OH (MW 750, 2000, or 5000) in toluene was prepared in a round bottom flask. The solution was stirred constantly and heated slightly to fully dissolve the PEG in toluene. $20 \mathrm{ml}$ of toluene and $10 \mathrm{mg}$ of 1,10-phenanthroline were added to a Schlenk tube and the solution was stirred to fully dissolve the indicator. Using a gas-tight syringe, approximately $1.5 \mathrm{ml}$ of tert-butyllithium was added to the stirring solution. The solution immediately turned dark red. The stirring solution was then titrated dropwise with the PEG-alkoxide solution prepared earlier until the colour of the solution turned bright yellow. The colour change was an indication of the endpoint of the reaction between PEG and the tert-butyllithium. A few additional drops of excess PEG solution were added to ensure that no un-reacted tert-butyllithium was present in the solution.

To a Schlenk tube containing PCTFE films was added $20 \mathrm{ml}$ of lithium PEGalkoxide solution via cannula. In some experiments, approximately $5 \mathrm{ml}$ of THF was also added using a gas-tight syringe to improve wetting of the surface of the films. The reaction was allowed to proceed for $1 \mathrm{~h}, 3 \mathrm{~h}$ or $24 \mathrm{~h}$ at RT under constant agitation.

Once the desired reaction time was complete, the alkoxide solution was removed and the films were washed sequentially in toluene (once), methanol ( 3 times), water ( 3 times), methanol (once), and dichloromethane (3 times). They were dried under vacuum overnight at RT. Controls consisted of PCTFE films immersed in PEG instead of PEGalkoxide solution. 


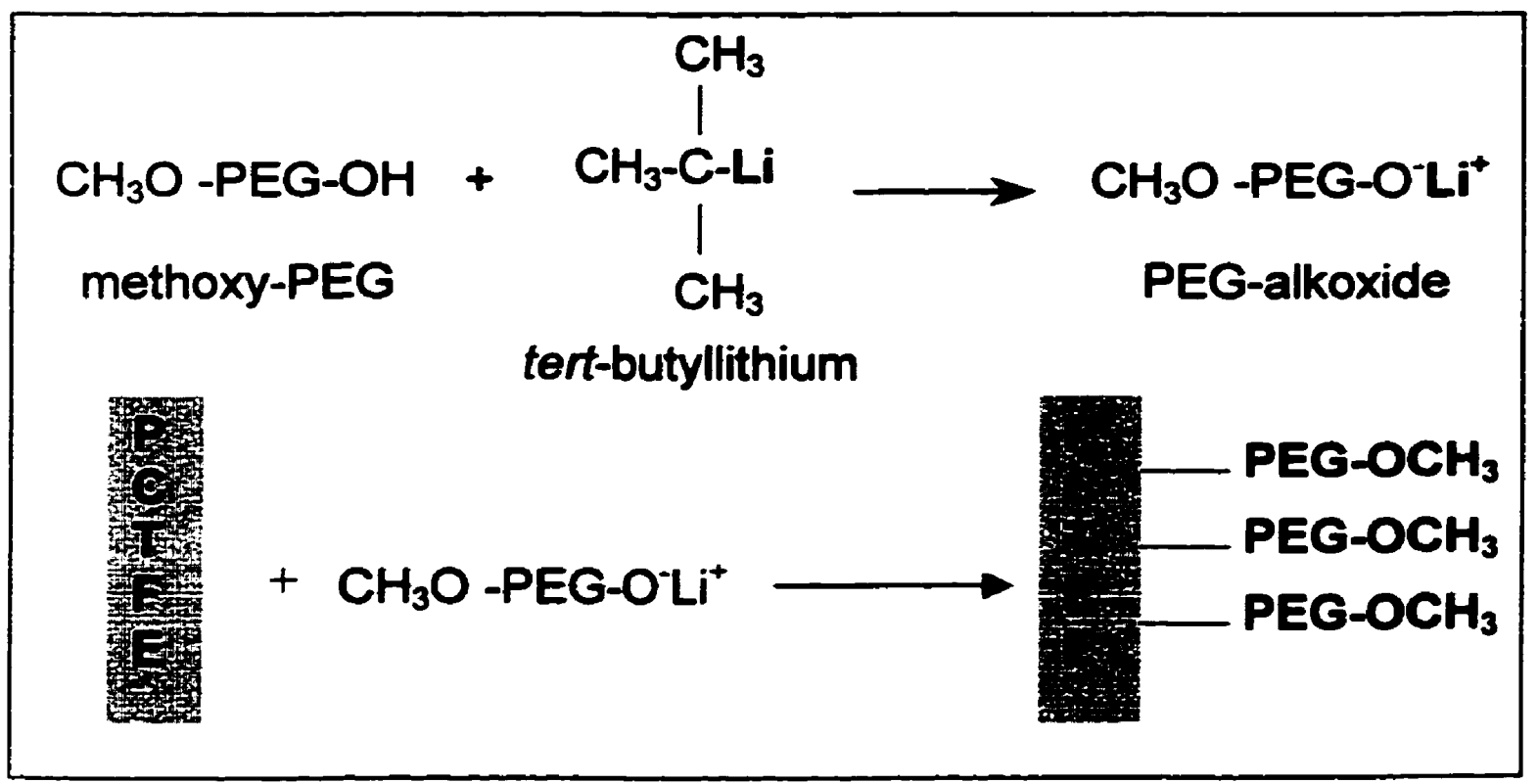

Figure 2.2: PEG alkoxide, prepared by the reaction of PEG and t-butyllithium, reacts with PCTFE, yielding PCTFE-PEG.

\subsubsection{GOLd SPUTTERING}

A sputtering system (model 2400) was used to deposit $500 \AA$ of Au onto the PEG modified films. In order to promote adhesion between the Au and the substrate, $30 \AA$ of titanium was deposited onto the films prior to Au sputtering. The sputtering machine was equipped with an argon ion gun. Argon gas was ionized and charged under vacuum and the ions were accelerated towards the metal target. As the ions struck the target, metal atoms were knocked out and sputtered down onto the films. The system parameters are outlined in Table 2.1. 
Table 2.1: The sputtering system parameters used in the deposition of Au onto modified PCTFE films

\begin{tabular}{|c|c|}
\hline PARAMITER & SETTING \\
\hline Gas & Argon \\
\hline Flow Rate & 12 sccm \\
\hline Pumpdown Pressure & 1 X $10-4$ tor \\
\hline Bell Jar Pressure & 12 mtor \\
\hline Target Bias & 1000 V dc \\
\hline Forward Power & 200 W \\
\hline Reflected Power & $<5$ Watts \\
\hline Substrate Temperature & Room Temperature \\
\hline Pre-Sputter Time & 20 min Ti \\
& 5 min Au \\
\hline Sputter Time & 10 sec Ti \\
& 150 sec Au \\
\hline
\end{tabular}

\subsubsection{PATterning}

Pattems of Au were created on the PEG modified films using a shadow masking technique. A mask with hole and bar dimensions of $2 \mathrm{~mm}$ was designed and custom made (Figure 2.3). To create micrometer sized patterns, EM grids were placed within the holes of the mask. The dimensions of the grids studied are outlined in Table 2.2.

Table 2.2: Grid dimensions used to create micron scale patterns on modified PCTFE

\begin{tabular}{|c|c|}
\hline EM GRID & BAR/HOLE SIZE $(\mu M)$ \\
\hline RB90-Cu & $180 / 90$ \\
\hline G400P-Cu & $40 / 22$ \\
\hline
\end{tabular}




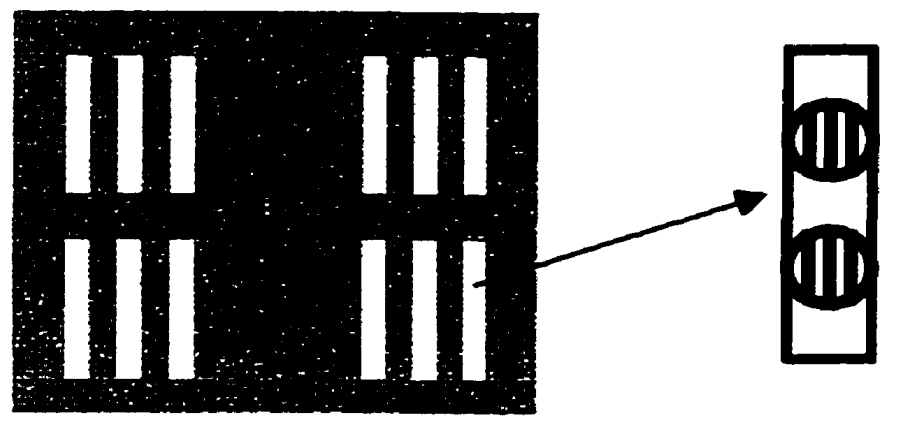

Figure 2.3: The holes of the custom made mask were fitted with EM grids to create micron scale patterns on modified PCTFE

\subsubsection{PePtide Modification}

Peptide modification of Au modified films was performed in a $\mathrm{pH} 6$ buffer solution made up of sodium acetate and acetic acid in water. $4 \mathrm{mg}$ of peptide (CGYIGSR or CSIKVAV) was added to $20 \mathrm{ml}$ of buffer solution. The Au modified films were added to the solution and the reaction was allowed to proceed at RT for $24 \mathrm{~h}$ under constant agitation. Once the reaction was complete, the films were washed in buffer solution 3 times ( 5 min per rinse with agitation) followed by water. They were blotted dry on kimwipes and were left to air dry at RT. As a control, the peptide modification protocol (with CGYIGSR) was also performed with a PEG modified film.

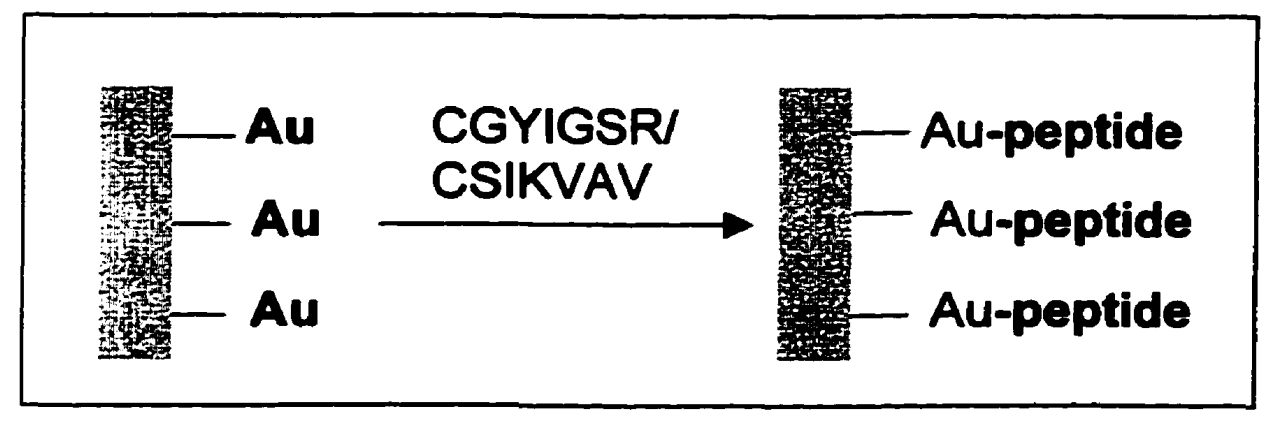

Figure 2.4: Peptide modification of PCTFE-Au surfaces 


\subsubsection{PePtide Labeling aNd Quantification}

The radio-labeling protocol was a modified version of published research (Drumheller and Hubbell, 1994). A pH 11 buffer solution consisting of $20 \mathrm{mM}$ sodium phosphate and $0.15 \mathrm{M}$ sodium chloride was prepared. $1 \mathrm{mCi}$ of carrier-free $\mathrm{Na}^{125} \mathrm{I}$ was diluted with $3 \mathrm{ml}$ of buffer solution in a small vial. $0.2 \mathrm{ml}$ of the diluted solution was added to a vial containing lodobeads. After 5 minutes, the solution from the vial was removed and was added to a beaker containing $2 \mathrm{mg}$ of CGYIGSR in $10 \mathrm{ml}$ of $\mathrm{pH} 6$ buffer solution (sodium acetate/acetic acid buffer). The reaction was left to proceed for 15 minutes. Next, free iodide ions were removed from the peptide solution by passing it through ion exchange columns filled with Dowex 1-X8 anion exchange resin. 3 columns were used and the solution was passed 2 times through each column. Once the iodide ions were removed, Au-modified films were added to the labeled peptide solution and the reaction was left to proceed for $24 \mathrm{~h}$ at RT. After the reaction was complete, the films were washed with pH 6 buffer solution ( 3 times-5 min per rinse) and water ( 3 times-5 min per rinse). Finally, the films were rinsed with $10 \mathrm{mM}$ sodium iodide solution to desorb any trace amounts of ${ }^{125}$ I before counting using a scintillation counter (LKB Wallac 1282-802 Universal $y$-counter) with a $2 \times 2 \mathrm{~cm}$ sodium iodide detector well of $80 \%$ efficiency. 


\subsection{SURFACE CHARACTERIZATION}

The analytical techniques used to characterize the surfaces were contact angle analysis, X-ray photoelectron spectroscopy (XPS), ellipsometry, and atomic force microscopy (AFM). The details of each technique are discussed further in the following sections.

\subsubsection{Contact Angle Analysis}

To obtain information on the changes in hydrophilicity of the surfaces following each modification step, a telescopic goniometer (Rame-Hart, model 100-00) was used to perform dynamic contact angle measurements. The measurements were made using water under ambient conditions. A total of 3 samples from each set of modified surfaces were analyzed and 5 advancing $\left(\theta_{A}\right)$ and receding $\left(\theta_{R}\right)$ angles were measured per sample.

\subsubsection{X-RAY Photoelectron Spectroscopy}

XPS measurements were taken following each modification step to provide information on the relative elemental composition of each surface. A Leybold LH Max $200 \mathrm{X}$-ray photoelectron spectrophotometer was used at an operating pressure of less than $10^{-8}$ Torr. The emitted X-ray photons were from a $\mathrm{Mg} \mathrm{K \alpha}$ source and the instrument largest spot size was used (4 X7 mm). Survey and low resolution spectra were obtained for each sample at take-off angles of $90^{\circ}$ and $15^{\circ}$. The elements analyzed under the low resolution mode included chlorine $\left(\mathrm{Cl}_{2 \mathrm{p}}\right)$, fluorine $\left(\mathrm{F}_{1 \mathrm{~s}}\right)$, carbon $\left(\mathrm{C}_{\mathrm{ls}}\right)$, oxygen $\left(\mathrm{O}_{1 \mathrm{~s}}\right)$, nitrogen $\left(N_{1 s}\right)$, gold (Aurf), and sulfur $\left(S_{2 p}\right)$. The relative percentage of each element on 
the surface was determined using MATLAB software, taking into account the appropriate sensitivity factors.

High resolution spectra of the $C_{i s}$ region of unmodified PCTFE and PEGmodified PCTFE were also obtained at both take-off angles.

\subsubsection{ANGLE-RESOLVED XPS}

To obtain more quantitative information about the PEG-modified surface, low resolution analysis was performed at 4 different angles, $15^{\circ}, 30^{\circ}, 45^{\circ}$, and $90^{\circ}$. The elemental information obtained was then used to estimate the thickness and the surface coverage of PEG on PCTFE. The first step involved calculating the mean free path $(\lambda)$ (the penetration length of the electron) of the desired element through the sample. $\lambda$ is a function of the kinetic energy (KE) of the electron and typically ranges from 10 to $45 \AA$ for polymers (Andrade, 1985). It was calculated using Equation 1 (Andrade, 1985).

$$
\lambda=\left(M E_{K} / \rho n\right) /\left[13.6 \ln \left(E_{K}\right)-17.6-1400 / E_{K}\right]
$$

where:
$\lambda=$ mean free path $(\mathcal{A})$
$M=$ molecular weight of repeat unit $(\mathrm{g} / \mathrm{mol})$
$E_{\mathrm{K}}=$ kinetic energy $(\mathrm{eV})$
$n=$ number of valence electrons in repeat unit
$\rho=\operatorname{density}(\mathrm{g} / \mathrm{ml})$ 
The kinetic energy was calculated using Equation 2.

$$
E_{K}=h v-E_{B}
$$

where:

$E_{B}=$ binding energy of electron (eV)

$$
\mathrm{h} v=\text { photon energy }(\mathrm{eV}) \quad \text { For } \mathrm{Mg} \mathrm{K \alpha}, \mathrm{hv}=1254 \mathrm{eV} \text { (Andrade, 1985) }
$$

Finally, the model for a single patchy overlayer on an infinite uniform substrate was used to estimate the thickness and surface coverage of PEG on PCTFE (Andrade, 1985) (Equation 3).

$$
\frac{I_{B}}{I_{A}}=\frac{\gamma \lambda_{B}\left(1-e^{\left[-t_{B} /\left(\lambda_{B} \sin \theta\right)\right]}\right)}{(1-\gamma) \lambda_{A}+\gamma \lambda_{A} e^{\left[-t_{B} /\left(\lambda_{B} \sin \theta\right)\right]}}
$$

where:

$I_{B} / I_{A}=$ the overlayer/substrate intensity ratio

$\gamma=$ fractional coverage of surface by overlayer

$t_{B}=$ thickness of overlayer $(A)$

$\theta=$ take-off angle $\left({ }^{\circ}\right)$

For Equation 3, the intensities of chlorine (A) and oxygen (B) were used for the substrate and the overlayer, respectively, to obtain four different equations corresponding to the 
four angles studied. An iterative procedure was then used to solve for $\gamma$ and $t_{B}$ simultaneously.

\subsubsection{ELLIPSOMETRY}

A Rudolph Research AutoEL-II null reflection ellipsometer was used to estimate the thickness of the peptide overlayer on gold-modified surfaces. The operating wavelength was $632 \mathrm{~nm}$ and the incident angle was $70^{\circ}$. The refractive index of the peptide overlayer was estimated to be 1.50. This was considered to be a safe assumption since most organic overlayers have refractive indices of around 1.50. The thickness was calculated using built-in software originally developed by McCracken. The software makes several assumptions which include: 1) the sample is homogeneous and nonadsorbing, 2) the sample is smooth, 3) the area of the overlayer is large compared to its thickness, and 4) the substrate is highly reflective. A total of 6 areas on each sample were analyzed.

\subsubsection{ATOMIC FORCE MicROSCOPY}

To study surface topography, AFM images were obtained on a Digital Instruments NanoScope III MultiMode scanning probe microscope (Digital Instruments, Santa Barbara, CA). Tapping mode AFM was performed in air using silicon nitride Vshaped cantilevers. Images were analyzed with the Digital Instruments Nanoscope III version 4.22 software. Scan areas of $10 \mu \mathrm{m} \times 10 \mu \mathrm{m}, 5 \mu \mathrm{m} \times 5 \mu \mathrm{m}$, and $2 \mu \mathrm{m} \times 2 \mu \mathrm{m}$ were analyzed and height, amplitude, and phase images were collected for both PCTFE and PEG surfaces. 


\subsection{Cell Culture EXPeriments}

Cell culture experiments were performed on homogeneously modified surfaces as well as patterned surfaces to study cell-surface interactions. The homogeneous surfaces studied included PCTFE, PEG, Au, CGYIGSR, CSIKVAV, and Poly(L-lysine) (PLL)/laminin (positive control). The patterned surfaces included PCTFE/Au, PEG/Au, PCTFE/peptide, and PEG/peptide.

\subsubsection{STERILIZATION OF SUBSTRATES}

Individual modified films were placed in each well of a 12 -well plate. $70 \%$ ethanol was filtered using a $0.22 \mu \mathrm{m}$ filter and $1 \mathrm{ml}$ was added to each well. The plate was left in the laminar hood for $30 \mathrm{~min}$ at RT. The ethanol was then removed and the films were rinsed with water 3 times and were left to air dry in the hood for a few hours.

\subsubsection{Preparation of the Positive Control}

PLL solution was prepared at a concentration of $1 \mathrm{mg} / \mathrm{ml}$ and $1 \mathrm{ml}$ was added to each well. The plate was incubated for $24 \mathrm{~h}$ at $37^{\circ} \mathrm{C}$. Following incubation, the PLL solution was removed and the wells were rinsed with water 3 times. $1 \mathrm{ml}$ of water and 30 $\mu \mathrm{l}$ of a $0.1 \mathrm{mg} / \mathrm{ml}$ laminin (mouse) solution were added to each of the wells. The plate was incubated for $4 \mathrm{~h}$ at $37^{\circ} \mathrm{C}$. The wells were then rinsed with water and were air dried in the laminar hood. 


\subsubsection{Cell Dissochation and Plating}

The cell dissociation protocol was provided by Greg Brewer (Brewer et al., 1993) and was slightly modified. The hippocampal tissue was provided in $\mathbf{2} \mathbf{~ m l}$ of serum free medium (SFM) in a $15 \mathrm{ml}$ centrifuge tube. Half of the medium was removed and placed in a sterile tube for later use. Using an Eppendorf pipetor set at $400 \mu \mathrm{l}$ and a blue plastic pipet tip, the hippocampal tissue was mechanically dissociated. Next, the $1 \mathrm{ml}$ of medium that had been removed, was re-added and the solution was mixed and allowed to settle by gravity for $1 \mathrm{~min}$. The supernatant was removed and placed into another $15 \mathrm{ml}$ centrifuge tube. The solution was centrifuged at $1100 \mathrm{rpm}$ for $5 \mathrm{~min}$ at RT. Next, the supernatant was discarded and the cells were re-suspended in $1 \mathrm{ml}$ of fresh SFM. The SFM was made with $100 \mathrm{mg}$ chicken egg albumin, $10 \mathrm{mg}$ sodium pyruvate, $2 \mathrm{ml}$ B27 supplement, $1 \mathrm{ml}$ glutamine, and $1 \mathrm{ml}$ penicillin-streptomycin $(10,000 \mathrm{U} / \mathrm{ml}$ and 10,000 $\mu \mathrm{g} / \mathrm{ml}$, respectively) in $100 \mathrm{ml}$ of Neurobasal medium. In order to dissociate any cell clusters, the cell suspension was gently passed through a 22 gauge needle.

To quantify the number of cells, $20 \mu$ of cell solution was mixed with $20 \mu$ of $0.4 \%$ trypan blue. The live cells were then counted under the microscope using a hemacytometer. Once the cell concentration was determined, the appropriate dilutions were made and the cells were plated at a concentration of $2-4 \times 10^{4}$ cells $/ \mathrm{cm}^{2}$. To avoid floating, polymeric films were held in place using glass o-rings (autoclaved). The 12well plate was incubated for $3 \mathrm{~h}$ at $37^{\circ} \mathrm{C}$ and $6 \% \mathrm{CO}_{2}$. After $3 \mathrm{~h}$, the medium was removed from each well, $1 \mathrm{ml}$ of SFM was added to each, and the plate was re-incubated. The cells were fed every 4 days by removing half the medium from each well and replacing it with fresh SFM. 


\subsubsection{Competitive Cell AdHesion AsSay}

The competitive assay experiment involved comparing cell adhesion on peptide surfaces in the presence of SFM with those on surfaces in SFM containing soluble peptides. The cells, once dissociated from tissue, were split into two test tubes (same concentration of cells), one of which contained only SFM and the other, SFM supplemented with a total of $0.1 \mathrm{mg} / \mathrm{ml}$ soluble peptides (CGYIGSR and CSIKVAV). The test tubes were both incubated for 30 minutes prior to cell plating. On day 1 after cell plating, the number of cells per field was counted for 10 random fields on each surface.

\subsubsection{Cell Viabiutty Assay}

The LIVE/DEAD\& viabilitiy/cytotoxicity kit contained a $2 \mathrm{mM}$ ethidium homodimer-1 stock solution and a $4 \mathrm{mM}$ calcein AM stock solution. To prepare the cell staining solution, $10 \mathrm{ml}$ of filtered PBS was added to a sterile $15 \mathrm{ml}$ conical tube. Next, $20 \mu$ of the ethidium homodimer-1 stock solution was added to the PBS and the solution was vortexed. $5 \mu$ lof the calcein AM stock solution was also added and the solution was vortexed again. The medium from each well containing the substrates was removed and replaced with fresh SFM. $150 \mu$ lof the staining solution was added to each well and the plate was incubated for $\mathbf{3 0}$ minutes prior to analysis using a fluorescense microscope. 


\subsubsection{QUANTITATIVE AND QUALITATIVE ANALYSIS}

Cells on each substrate were monitored and images were captured on days 1, 2, 4 and 7 (after cell plating) using an inverted microscope (Axiovert S100, Zeiss, Germany) fitted with an analogue video camera. On day 1, a cell adhesion assay was performed by counting the number of attached cells per field of view for each substrate. A total of 10 random fields were analyzed for each substrate. On day 2 , the number of neurites per cell were quantified by counting only those neurites that were longer than the cell body length. A total of 50 random cells per sample were analyzed. The length of neurite extensions was also quantified on day 2. Using Northern Eclipse software (version 5.0), the length of the longest neurite per cell was measured for $\mathbf{5 0}$ random cells per sample.

\subsubsection{Statistical ANALYSIS}

Student t-tests assuming equal variances were performed to compare the results from each surface with other surfaces. For sample sizes of $n=10$ or less, results are reported with standard deviations ( \pm ). For samples sizes greater than $n=30$, results are reported with standard error of the mean ( \pm ). 


\section{RESULTS}

\subsection{PEG MODIFICATION}

\subsubsection{XPS}

\subsubsection{THE EFFECT OF REACTION TMME}

The surface modification of PCTFE with PEG-alkoxide was performed under several reaction conditions using 3 different MW PEGs. The preliminary experiments with PEG MW5000 focused on the effect of reaction time on the extent of modification. A $24 \mathrm{~h}$ control reaction was also performed using PEG MW5000 without the addition of tert-butyllithium. The low resolution XPS results at take-off angles of $90^{\circ}$ and $15^{\circ}$ are presented in Tables 3.1 and 3.2, respectively.

Table 3.1: XPS results for PEG MW5000 modification of PCTFE (90 take-off angle).

\begin{tabular}{|l|l|l|l|l|l|}
\hline \multirow{2}{*}{ SURFACE } & \multirow{2}{*}{ REACTION CONDITIONS } & \multicolumn{4}{|l|}{ SURFACE ELEMENTAL COMPOSITION(\%) } \\
\cline { 3 - 6 } & & F1s & Ols & Cls & Cl2p \\
\hline PCTFE & NA & 51.7 & 0.3 & 32.0 & 16.0 \\
\hline PCTFE-PEG(5000) & Toluene-1 h & 49.9 & 0.9 & 34.5 & 15.0 \\
\hline PCTFE-PEG(5000) & Toluene-3 h & 44.0 & 2.8 & 39.3 & 13.9 \\
\hline PCTFE-PEG(5000) & Toluene-24 h & 42.6 & 3.4 & 40.2 & 13.8 \\
\hline Control PCTFE & Toluene-24 h & 50.9 & 0.6 & 32.5 & 15.8 \\
\hline
\end{tabular}

Table 3.2: XPS results for PEG MW5000 modification of PCTFE (15॰ take-off angle).

\begin{tabular}{|l|l|l|l|l|l|}
\hline \multirow{2}{*}{ SURFACE } & REACTION CONDITIONS & \multicolumn{4}{|l|}{ SURFACE ELEMENTAL COMPOSITION (\%) } \\
\cline { 3 - 6 } & & Fls & Ols & C1s & Cl2p \\
\hline PCTFE & NA & 52.2 & 0.5 & 31.3 & 16.0 \\
\hline PCTFE-PEG(5000) & Toluene-1 h & 45.9 & 3.9 & 35.5 & 14.7 \\
\hline PCTFE-PEG(5000) & Toluene-3 h & 42.7 & 3.5 & 39.1 & 12.5 \\
\hline PCTFE-PEG(5000) & Toluene-24 h & 41.5 & 4.3 & 42.1 & 12.1 \\
\hline Control PCTFE & Toluene-24 h & 52.3 & 0.7 & 30.8 & 16.2 \\
\hline
\end{tabular}


From the surface elemental composition of PCTFE shown in Tables 3.1 and 3.2, the atomic ratio was calculated to be $\mathrm{C}_{2} \mathrm{~F}_{3.2} \mathrm{Cl}$ (the small percentage of oxygen on PCTFE was due to contamination). This is relatively close to the expected ratio $\left(\mathrm{C}_{2} \mathrm{~F}_{3} \mathrm{Cl}\right)$. Following PEG modification, we observed an increase in both oxygen and carbon concentrations. The ratio of increased carbon to oxygen on the surface was approximately 2-2.5:1. This value is in agreement with the expected $2: 1$ ratio of carbon to oxygen in PEG molecules. The increase in carbon and oxygen following PEG modification was accompanied by a decrease in chlorine and fluorine percentages. In addition to the changes in surface composition, we observed a slight discoloration of the films following PEG modification. Taking into account that discoloration may indicate conjugation on the surface, the XPS data was closely analyzed and a mechanism of reaction was suggested. The details of this mechanism will be discussed in section 4.1.1.

From the survey spectra of PEG-modified films, it was evident that the C1s region had changed significantly following modification. High resolution analyses of this region were performed on PCTFE and PEG-modified PCTFE in order to make a better comparison between the two surfaces. Representative spectra of each surface are shown in Figure 3.1. 


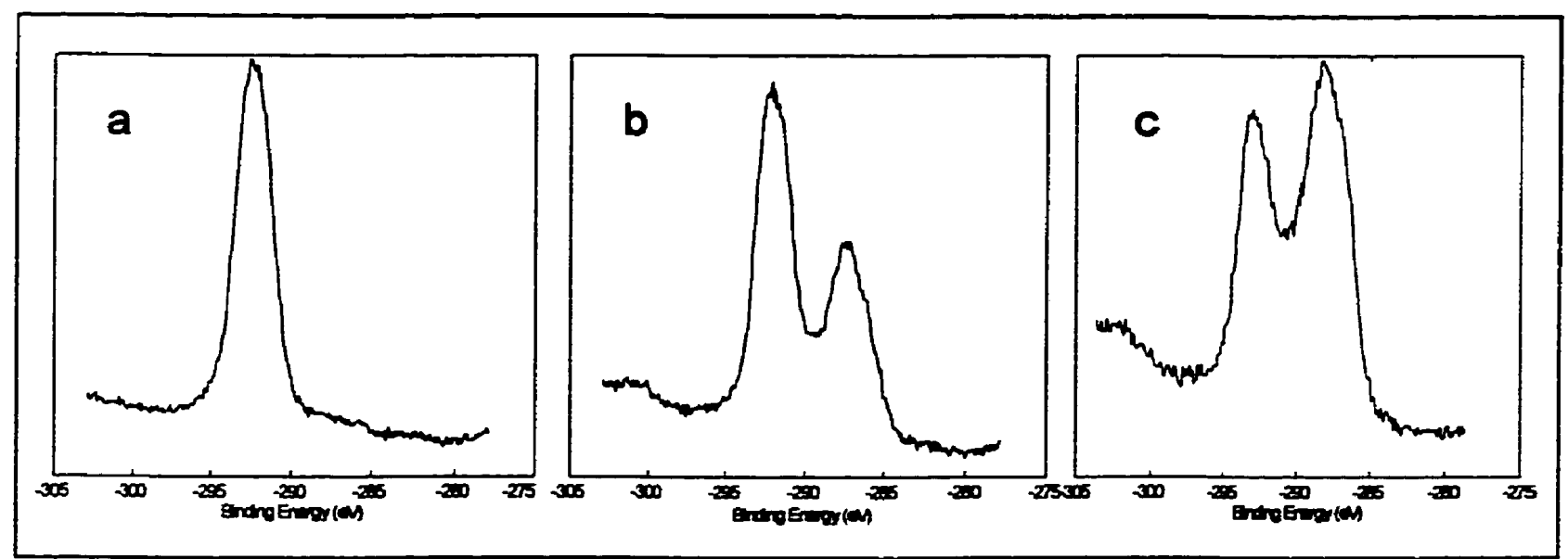

Figure 3.1: High resolution XPS spectra showing the Cls region of a) PCTFE, b) PCTFE-PEG at a take-off angle of $90^{\circ}$, and c) PCTFE-PEG at a take-off angle of $15^{\circ}$.

Looking at Figures $3.1 \mathrm{~b}$ and $3.1 \mathrm{c}$, an additional peak is seen at approximately 287 $\mathrm{eV}$ which is absent on clean PCTFE (Figure 3.1a). This additional peak is attributed to the presence of PEG molecules on the surface. The intensity of this peak is higher for the $15^{\circ}$ data in comparison to the $90^{\circ}$ data, reflecting the surface enrichment of PEG vs. the bulk.

In comparing the $90^{\circ}$ take-off angle results obtained for the different reaction times (Table 3.1), it was found that the percentage of oxygen and carbon on the surface increased with increasing reaction time. The $15^{\circ}$ data also shows this trend with the exception of an unexpected decrease in oxygen from $3.9 \%$ to $3.5 \%$ for the $1 \mathrm{~h}$ and $3 \mathrm{~h}$ reactions, respectively. The increase in carbon and oxygen with increasing reaction time indicates either an increase in the depth of modification or an increase in PEG grafting density. The control reaction of PCTFE with PEG solution instead of the PEG-alkoxide solution resulted in films that were similar in composition to unmodified PCTFE. These 
results confirmed that the alkoxide reaction resulted in the covalent grafting of PEG molecules to the surface rather than their adsorption on the films.

\subsubsection{THE EFFECT OF MW}

The preliminary XPS results for PEG MW5000 confirmed that it was possible to modify PCTFE with PEG using our protocol. There was still, however, a high concentration of chlorine on the surface. This indicated the possibility of low conversion and low surface coverage of PEG on PCTFE. In an attempt to increase PEG surface coverage, the modification was also performed with PEGs of MW 2000 and 750 . The effect of a co-solvent system consisting of toluene and THF was also studied for each MW. Low resolution XPS measurements following each modification were taken at take-off angles of $90^{\circ}$ and $15^{\circ}$ and the results are summarized in Tables 3.3 and 3.4, respectively.

Table 3.3: XPS results comparing different MW PEGs in toluene vs. toluene/THF solvents ( $90^{\circ}$ take-off angle).

\begin{tabular}{|l|l|l|l|l|l|}
\hline \multirow{2}{*}{ SURFACE } & \multirow{2}{*}{ REACTION CONDITIONS } & \multicolumn{4}{|l|}{ SURFACE ELEMENTAL COMPOSITION(\%) } \\
\cline { 3 - 6 } & & F1s & Ols & C1s & Cl2p \\
\hline PCTFE & NA & 51.7 & 0.3 & 32.0 & 16.0 \\
\hline PCTFE-PEG(5000) & Toluene-24 h & 42.6 & 3.4 & 40.2 & 13.8 \\
\hline PCTFE-PEG(5000) & Toluene/THF-24 h & 40.5 & 6.2 & 40.9 & 12.4 \\
\hline PCTFE-PEG(2000) & Toluene-24 h & 37.8 & 6.1 & 43.5 & 12.5 \\
\hline PCTFE-PEG(2000) & Toluene/THF-24 h & 26.5 & 6.6 & 57.9 & 9.0 \\
\hline PCTFE-PEG(750) & Toluene-24 h & 39.8 & 5.4 & 42.1 & 12.6 \\
\hline PCTFE-PEG(750) & Toluene/THF-24 h & 25.8 & 6.4 & 58.3 & 9.5 \\
\hline
\end{tabular}


Table 3.4: XPS results comparing different MW PEGs in toluene vs. toluene/THF solvents ( $15^{\circ}$ take-off angle).

\begin{tabular}{|l|l|l|l|l|l|}
\hline \multirow{2}{*}{ SURFACE } & \multirow{2}{*}{ REACTION CONDITIONS } & \multicolumn{4}{|l|}{ SURFACE ELEMENTAL COMPOSITION (\%) } \\
\cline { 3 - 6 } & & Fls & O1s & Cls & C12p \\
\hline PCTFE & NA & 52.2 & 0.5 & 31.3 & 16.0 \\
\hline PCTFE-PEG(5000) & Toluene-24 h & 41.5 & 4.3 & 42.1 & 12.1 \\
\hline PCTFE-PEG(5000) & Toluene/THF-24 h & 37.3 & 7.9 & 43.4 & 11.2 \\
\hline PCTFE-PEG(2000) & Toluene-24 h & 34.7 & 9.0 & 45.5 & 10.8 \\
\hline PCTFE-PEG(2000) & Toluene/THF-24 h & 18.2 & 9.4 & 67.9 & 4.5 \\
\hline PCTFE-PEG(750) & Toluene-24 h & 25.4 & 9.2 & 57.7 & 7.6 \\
\hline PCTFE-PEG(750) & Toluene/THF-24 h & 15.7 & 10.6 & 69.9 & 3.8 \\
\hline
\end{tabular}

In comparing the results obtained with different MW PEGs, it was found that by decreasing the molecular weight of PEG from 5000 to 2000 (while keeping the solvent the same), the amount of oxygen and carbon on the surface increased at both take-off angles (Tables 3.3 and 3.4). These results indicate either an increase in the depth of modification or an increase in surface density. If we assume that the depth of modification was dependent on reaction time only, then PCTFE was modified to the same depth (h) with PEG alkoxides molecules of MW5000 and 2000 after a 24 h reaction in toluene (Figure 3.2). Since at the same XPS take-off angle, the same depth (d) was analyzed for both samples, it was expected that more oxygen and carbon would be found on the PEG MW5000-modified surface. The fact that we observed more carbon and oxygen on the PEG MW2000-modified surface suggested that PEG surface coverage was increased by decreasing the PEG MW used. 


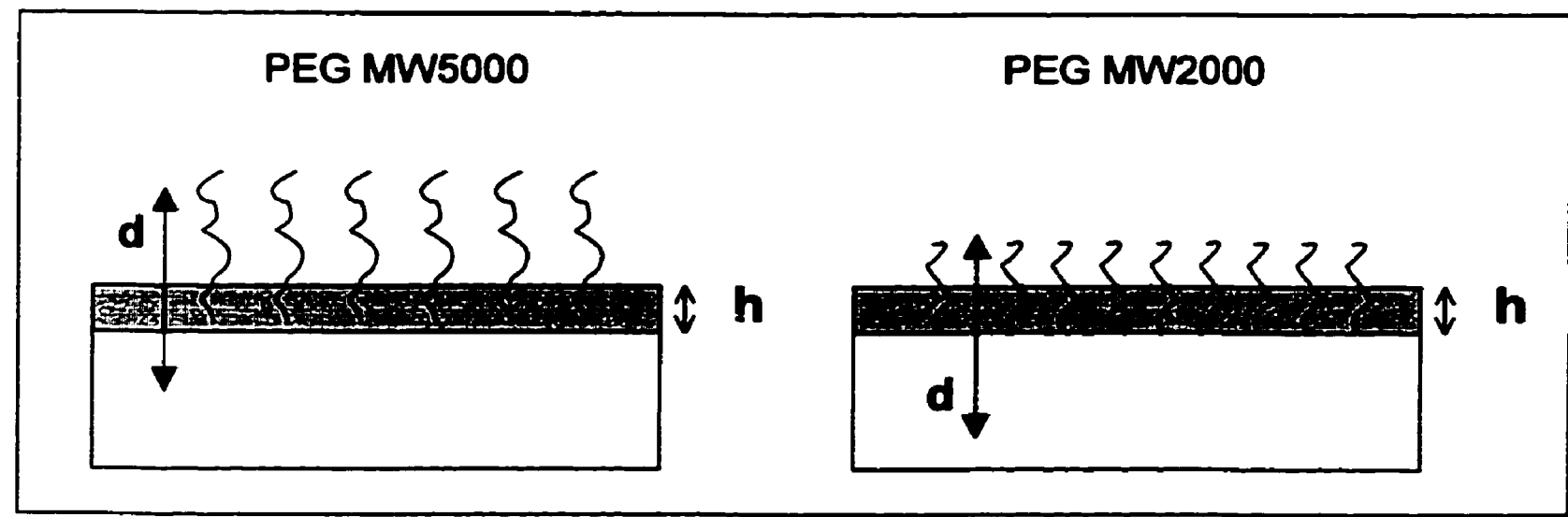

Figure 3.2: For the same depth of modification (h) and the same depth of analysis (d), an increase in surface percentages of carbon and oxygen with decreasing MW PEG suggests that the surface coverage is greater on the PEG MW2000-modified surface.

In decreasing the MW of PEG from 2000 to 750, similar trends in surface oxygen and carbon concentrations were observed for the $15^{\circ}$ data but not for the $90^{\circ}$ data. This result can be explained by again considering the length of the PEG molecules and the depth of analysis at the two different angles. We continue to assume that depth of modification is dependent on reaction time only. PEG MW750 (17 repeat units) is much shorter in length than PEG MW2000 (45 repeat units). If surface density was the same for both MWs, we would have expected to observe less oxygen and carbon for the shorter PEG molecules on the surface at either of the two take-off angles studied. At a $15^{\circ}$ takeoff angle we observed more oxygen and carbon for PEG MW750-modified surfaces indicating higher surface density. At $90^{\circ}$, more of the underlying bulk material was analyzed; therefore, it was not surprising that the bulk composition overshadowed the effects of a higher density of shorter chains on the surface. 


\subsubsection{THE EFFECT OF SOLVENT SYSTEM}

In comparing the results obtained for the toluene versus toluene/THF systems, it was found that for all MW PEGs the percentage of oxygen and carbon on the surface was greater for the co-solvent systems (Tables 3.3 and 3.4). For example, the percentage of oxygen ( $15^{\circ}$ data) increased from $4.3 \%$ to $7.9 \%$ for PEG MW5000 in toluene and toluene/THF, respectively. The increase in carbon was in agreement with the amount of oxygen present on the surface of PEG MW5000 modified films. On films that were modified with PEG MW2000 and MW750 (in the co-solvent system), there was an unexpectedly high increase in carbon percentage. The excess carbon (-25\%) present on these surfaces indicates that undesired chemical reactions may have taken place.

The results of the co-solvent system with PEG MW5000 showed that the addition of THF promoted the reaction between PEG-alkoxide molecules and PCTFE surfaces. Solvents that wet the polymer to greater extents favor the mobility of surface chains and facilitate the reaction between the reagent and the surface (Dias and McCarthy, 1987). With PEG MW2000 and MW750 systems, THF may have promoted alkoxide-surface reactions (as indicated by an increase in oxygen); however, the unaccountable increase in carbon suggests the possible presence of other surface chemistry.

\subsubsection{Contact ANGle}

Following each PEG modification step, advancing and receding contact angle measurements were recorded and the results are summarized in Figure 3.3. 


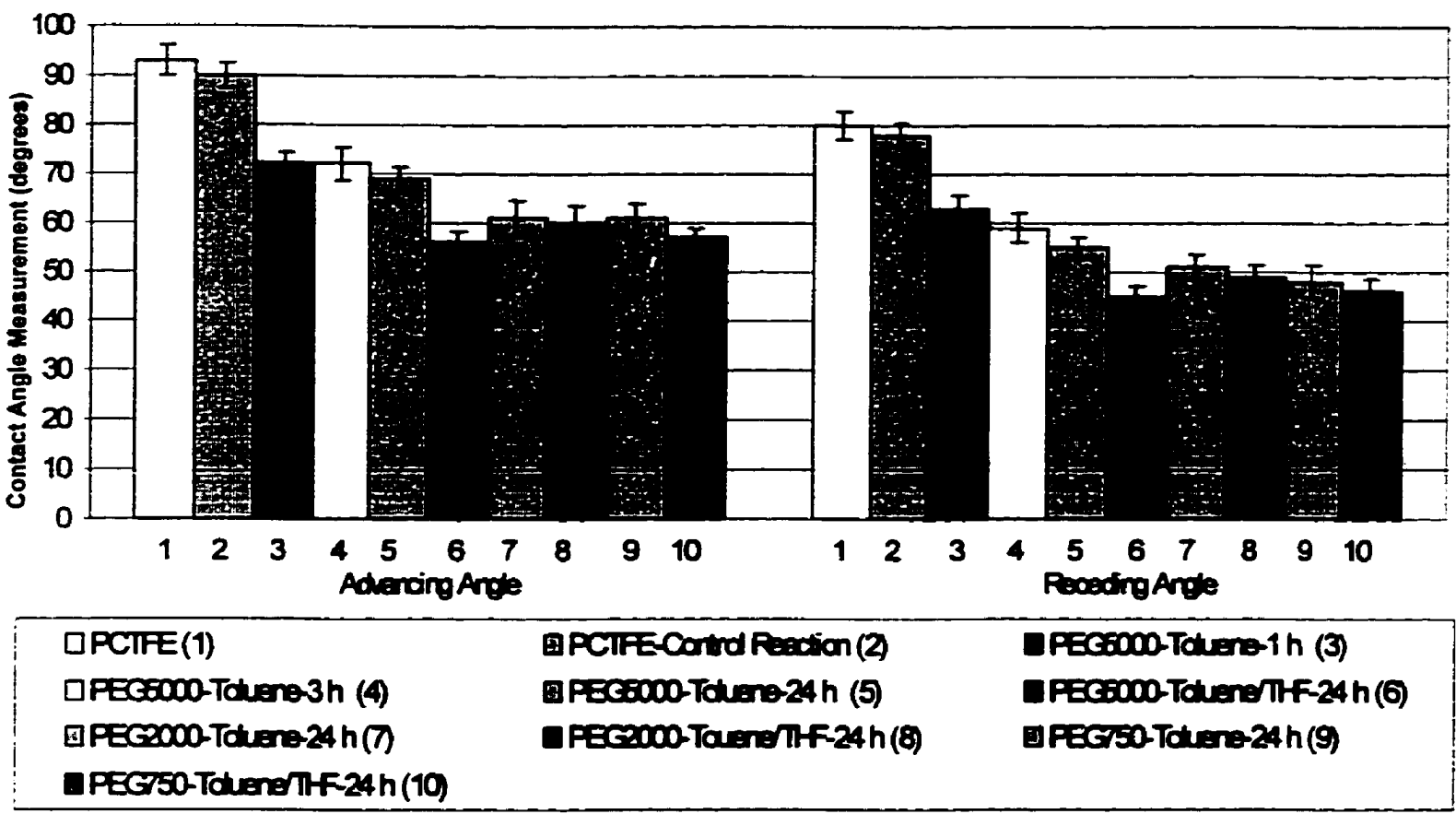

Figure 3.3: Advancing and receding contact angle data for the PEG modification reactions ( \pm standard deviations)

PCTFE is a relatively hydrophobic material as indicated by the high advancing $\left(93^{\circ}\right)$ and receding $\left(80^{\circ}\right)$ contact angles measured. It was expected that the wettability of the surface would increase with PEG modification due to the hydrophilic nature of the PEG molecules. As seen in Figure 3.3, the results confirmed this idea and in all PEG modification reactions, a significant decrease in both advancing $\left(\theta_{A}\right)$ and receding $\left(\theta_{R}\right)$ contact angles were observed. In comparing the data for PEG MW5000 at different reaction times, greater differences were seen in $\theta_{R}$ than in $\theta_{A}$. With increasing reaction time, $\theta_{\mathrm{A}}$ decreased from $72^{\circ}$ to $69^{\circ}$ while $\theta_{\mathrm{R}}$ decreased from $63^{\circ}$ to $55^{\circ}$. On a heterogeneous surface, $\theta_{A}$ tends to represent the low-energy (PCTFE) phase while $\theta_{R}$ represents the high energy (PEG) phase (Andrade et al., 1985). The fact that greater 
differences were seen in $\theta_{R}$ suggests that the surface density of PEG may have increased with increasing reaction time.

In comparing the data for different PEG MWs, there were greater differences in contact angle measurements between MW 5000 and 2000 than between MW 2000 and 750. The differences between MW5000 and 2000 and MW5000 and 750 were significant; however, those between MW2000 and 750 were not. As was indicated by both XPS data (Tables 3.3 and 3.4) and now contact angle data (Figure 3.3), it is likely that the surface density of PEG MW750-modified films was insignificantly different from PEG MW2000-modified films.

The surfaces that were reacted in co-solvent systems had different wettabilities from those reacted in toluene alone; however, only the results with PEG MW5000 were statistically significant. For PEG MW2000 and MW750, $\theta_{A}$ and $\theta_{R}$ were slightly higher than those for PEG MW5000. These results are in agreement with the XPS data where an unexpected increase in carbon was observed on the lower MW PEG-modified films. The increase in hydrophobicity is likely a result of the excess carbon present on these surfaces.

The contact angle data, analogous to XPS data, indicates that the addition of THF was helpful in reactions with PEG MW5000. By better wetting the surface, the probability of surface-alkoxide reaction was increased. With smaller PEG molecules, the addition of THF may have improved surface-alkoxide reactions; however, any effects of increased PEG concentration on surface wettability were likely masked by the presence of excess carbon. 
The results of both XPS and contact angle data showed that there were greater differences between PEG MW 5000 and 2000 in comparison to those observed between PEG MW 2000 and 750. As mentioned earlier, Gombotz et al. reported an optimum MW range (2000 to 3500 ) for decreased protein adsorption that was related to both the length of the attached molecule and its surface density (Gombotz et al., 1992). Although this MW range may not necessarily apply to decreased cell adhesion, for the purposes of further surface characterization and cell culture work, we chose to continue our studies with PEG MW 2000. It was thought that PEG molecules of MW 2000 were long enough to present a hydration shell that would minimize cell adhesion.

\subsubsection{Thickness and Surface Coverage}

Andrade model for a single patchy overlayer on an infinite uniform substrate was used to estimate the thickness and surface coverage of PEG MW2000 on PCTFE (Andrade, 1985). The mean free paths ( $\lambda$ ) of chlorine through PCTFE and oxygen through PEG were calculated using Equation 1 and were found to be $21 \AA$ and $23 \AA$, respectively. Since the values were very close, an average value of $22 \AA$ was used in Equation 3. An iterative procedure was used to solve for thickness and surface coverage simultaneously. The results of the 4 equations (corresponding to the 4 angles studied) converged at a surface coverage $(\gamma)$ value of $56 \%$ and a thickness $\left(t_{B}\right)$ value of approximately $14 \AA$. The theoretical length of a fully extended PEG molecule was determined to be approximately $160 \mathrm{~A}$. This value is much higher than the calculated value; however, since XPS was performed under vacuum and the molecules on the surface collapse under such conditions, a discrepancy between the calculated and the 
estimated thicknesses was expected. In addition, PEG molecules are randomly coiled in structure so the length of the chains would be significantly smaller than fully extended chains.

In previous work involving the modification of glass with PEG, the calculated dry thickness and surface coverage of PEG MW3400 was found to be approximately $19 \AA$ and 16\%, respectively (Saneinejad and Shoichet, 1998). The thickness of PEG MW2000 on PCTFE ( $14 \AA$ ) was in accord with previous work; however, we obtained a much higher surface coverage. This may be due to the fact that in our previous work, we introduced amine groups onto glass prior to PEG modification; therefore, the amount of PEG bound to the surface was dependent on the amount of amine groups available. In the case with PCTFE, the surface is not functionalized prior to PEG modification. The reaction with PEG is, therefore, not limited by a previous reaction. It is important to note that the values obtained from angle resolved XPS are representative of PEG in the dry state and would be different under wet conditions. The surface coverage and thickness under wet conditions would be expected to be higher since the PEG molecules would be hydrated and so would cover more surface area.

\subsubsection{AFM}

AFM studies were originally conducted to obtain the thickness of the PEG layer on PCTFE; however, the surface of PCTFE was found to be very rough and so no quantitative data could be obtained. Nevertheless, topographical changes were observed following the reaction of PCTFE with PEG, confirming surface modification. 
Representative AFM images of PCTFE and PEG surfaces are shown in Figure 3.4. The PEG surface appears to be somewhat smoother than the original PCTFE surface. 


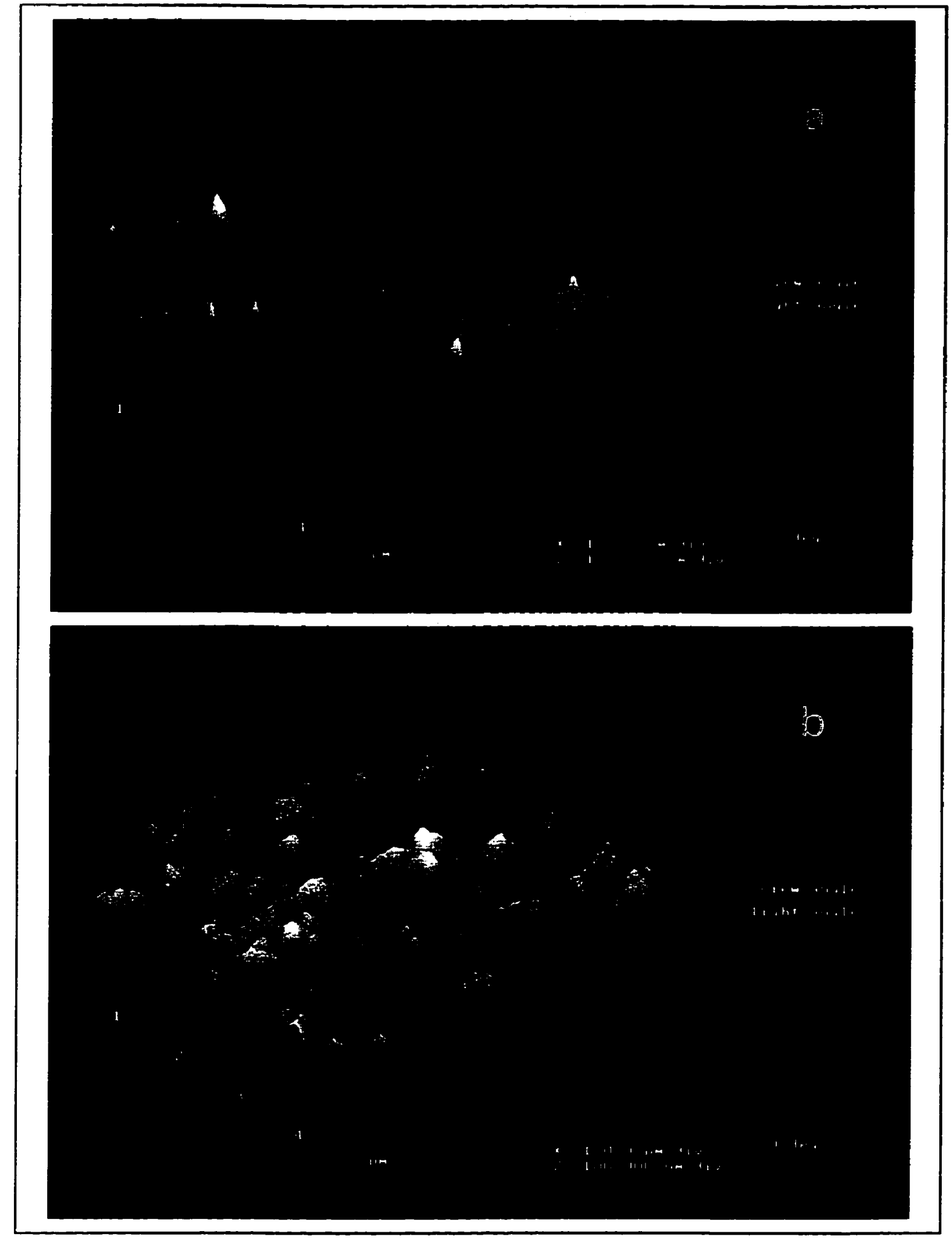

Figure 3.4: AFM height images of a) PCTFE and b) PCTFE-PEG surfaces showing surface topography (scan size of $5 \mu \mathrm{m} X 5 \mu \mathrm{m}$ ) 


\subsection{PePtide Modification}

\subsubsection{XPS}

The results of XPS analyses at take-off angles of $90^{\circ}$ and $15^{\circ}$ for the peptide modification of Au surfaces are presented in Tables 3.5 and 3.6, respectively. The results of the control reaction with a PEG modified film are also included.

Table 3.5: XPS results for peptide modification reactions ( $90^{\circ}$ take-off angle).

\begin{tabular}{|l|l|l|l|l|l|l|l|}
\hline \multirow{2}{*}{ SURFACE } & \multicolumn{6}{|c|}{ SURFACELEMENTAL COMPOSITION } \\
\cline { 2 - 8 } & F1s & O1s & N1s & C1s & C12p & S2p & Au4f \\
\hline PCTFE-PEG-Au & 0.0 & 1.8 & 0.0 & 19.5 & 0.0 & 0.0 & 78.7 \\
\hline PCTFE-PEG-Au-CGYGSR & 0.0 & 10.4 & 6.0 & 44.8 & 0.0 & 0.0 & 38.6 \\
\hline PCTFE-PEG-Au-CSIKVAV & 0.0 & 5.4 & 2.8 & 33.3 & 0.0 & 0.0 & 58.4 \\
\hline PCTFE-PEG (control) & 36.4 & 7.1 & 0.0 & 44.8 & 11.7 & 0.0 & 0.0 \\
\hline
\end{tabular}

Table 3.6: XPS results for peptide modification reactions ( $15^{\circ}$ take-off angle).

\begin{tabular}{|l|l|l|l|l|l|l|l|}
\hline \multirow{2}{*}{ SURFACE } & \multicolumn{6}{|c|}{ SURFACE ELEMENTAL COMPOSITON } \\
\cline { 2 - 8 } & F1s & O1s & N1s & C1s & Cl2p & S2p & Au4f \\
\hline PCTFE-PEG-Au & 0.0 & 6.2 & 0.0 & 45.9 & 0.0 & 0.0 & 47.9 \\
\hline PCTFE-PEG-Au-CGYIGSR & 0.0 & 15.2 & 8.1 & 65.0 & 0.0 & 0.5 & 11.0 \\
\hline PCTFE-PEG-Au-CSIKVAV & 0.0 & 13.4 & 8.1 & 59.0 & 0.0 & 0.1 & 19.4 \\
\hline PCTFE-PEG (control) & 37.3 & 7.9 & 0.2 & 43.2 & 11.2 & 0.0 & 0.0 \\
\hline
\end{tabular}

Following gold deposition on PCTFE-PEG modified films, the composition of the underlying substrate could no longer be detected by XPS at either of the two take-off angles studied, as indicated by the absence of both fluorine and chlorine. The presence of carbon and oxygen on the gold films was due to contamination from the laboratory atmosphere and could not be avoided. Following peptide modification, as expected, there was an increase in both oxygen and carbon percentages accompanied by a decrease in gold. In addition, there was an appearance of nitrogen ( $8.1 \%$ for both peptide-modified 
surfaces at a $15^{\circ}$ take-off angle), that was absent on the gold surface. The results of the control reaction with a PEG modified film showed that the composition of the film did not change after the reaction. There were no noticeable increases in oxygen or carbon and no nitrogen was detected on the surface. These results confirmed the peptides were selectively interacting with the gold regions over PEG regions.

\subsubsection{Contact Angle}

The contact angle measurements for the peptide modification are presented in Figure 3.5.

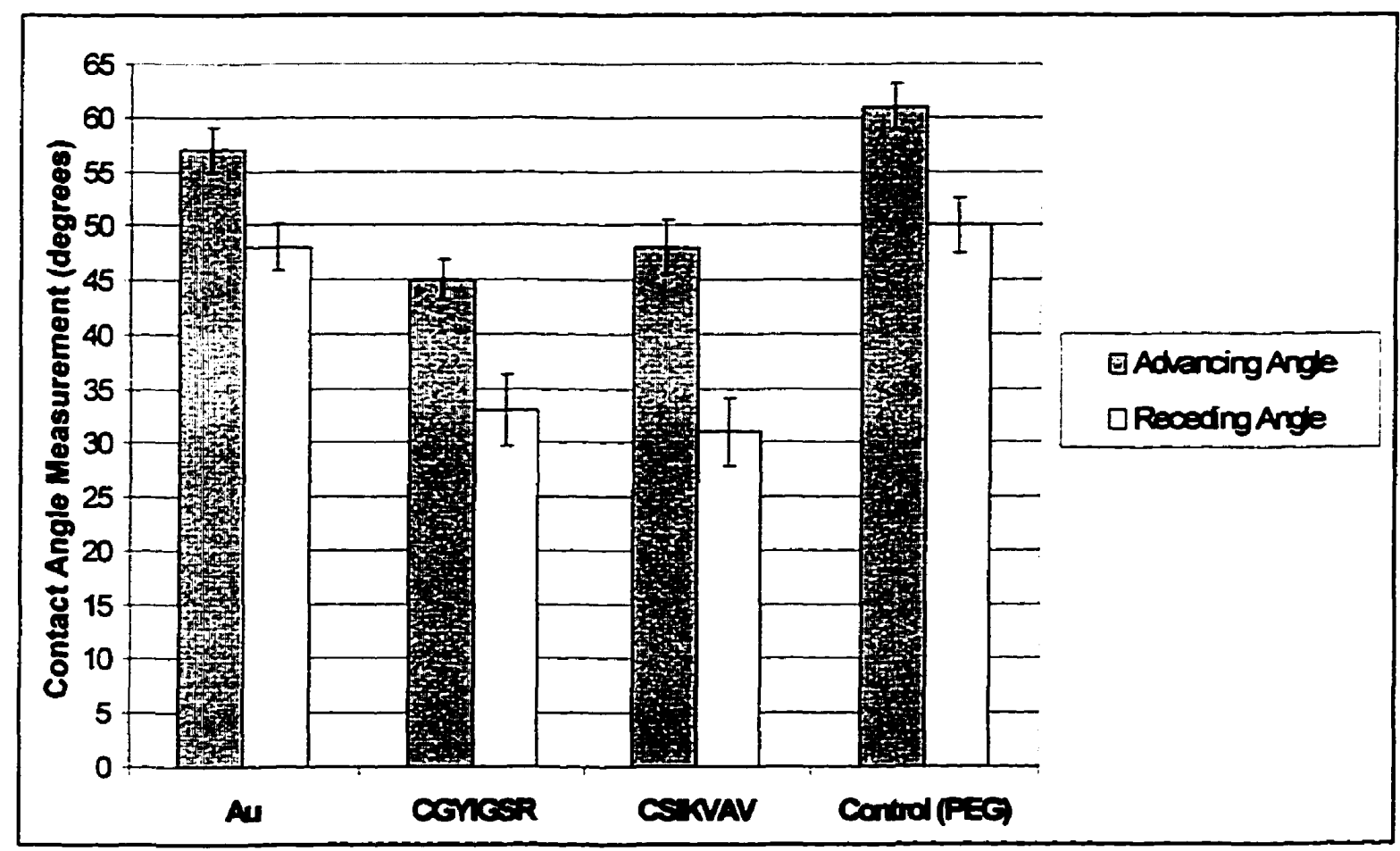

Figure 3.5: Advancing and receding contact angle data for the peptide modification reactions ( \pm standard deviations). 
Clean gold surfaces are highly hydrophilic; however, the measured contact angles are quite high due to adventitious carbon contamination formed on surfaces. The effect of carbon contamination is apparent in the XPS data as well and has been reported by others (Troughton et al., 1988). To avoid excessive contamination, the gold surfaces were modified with peptides immediately after sputtering and if storage was necessary, the films were washed with ethanol prior to use. From the contact angle data, peptide modification is confirmed by a decrease in $\theta_{\mathrm{A}} / \theta_{\mathrm{R}}$ from $57^{\circ} / 48^{\circ}$ for gold to $45^{\circ} / 33^{\circ}$ and $48^{\circ} / 31^{\circ}$ for CGYIGSR and CSIKVAV, respectively (Figure 3.5). This decrease was expected due to the hydrophilic nature of functional groups (e.g. $\mathrm{COOH}, \mathrm{NH}_{2}$ ) present in the peptides. There were no significant differences observed in contact angle measurements of the control PCTFE-PEG surface $\left(61^{\circ} / 50^{\circ}\right)$ in comparison to unmodified PCTFE-PEG surfaces $\left(60^{\circ} / 49^{\circ}\right.$, PEG MW2000 in Figure 3.3). The contact angle data support the XPS results and confirm the peptide modifications.

\subsubsection{Thickness and Surface Coverage}

The thicknesses of both peptide overlayers on gold-sputtered films were measured using ellipsometry. The thickness of CGYIGSR was determined to be approximately 21 $\AA$ but the thickness of CSIKVAV could not be determined. Out of the 6 trials performed, only 2 yielded actual thickness values, both below 5 A. Due to a lack of reproducibility, the thickness results for CSIKVAV were deemed inconclusive.

The thickness of CGYIGSR measured by ellipsometry $(21 \AA)$ is less than that calculated based on chain length ( $40 \AA$ ). This indicates that in the dry state, the chains are not extended linearly but are collapsed or coiled. Similar to PEG, the thickness of the 
peptide on the surface in a hydrated state is expected to be different. One possible reason explaining why the thickness of CSIKVAV could not be measured is that the overlayer was simply too thin to be detected. This idea is supported by XPS data, specifically the $90^{\circ}$ data, where the increase in oxygen (5.4\%), carbon (33.3\%), and nitrogen (2.8 \%) for the CSIKVAV surface is much less intense than that for the CGYIGSR surface $(10.4 \%$, $44.8 \%$, and $6.0 \%$, respectively) following modification of gold. The results seem to suggest that for the same depth of analysis, more of the overlayer is analyzed for the CGYIGSR surface than for the CSIKVAV surface, indicating a thicker overlayer on the surface modified with CGYIGSR. It may be that the CSIKVAV molecules are highly collapsed and so are difficult to detect using ellipsometry.

The surface coverage of CGYIGSR was determined by labeling the tyrosine amino acid of the peptide sequence using ${ }^{125}$ I. PCTFE-Au surfaces were then modified with the labeled peptide and surface density was determined using a gamma counter. The surface concentration of CGYIGSR on Au sputtered films was found to be $18 \pm 2$ fmol/cm ${ }^{2}$. Similar concentrations have been observed by others (Tong and Shoichet, 1998). 


\subsection{Cell Culture}

\subsubsection{QUALITATIVE ANALYSIS}

Images captured from each surface were used to qualitatively compare cellsurface interactions. Figures 3.6-3.10 are representative light micrographs of the different surfaces studied. 


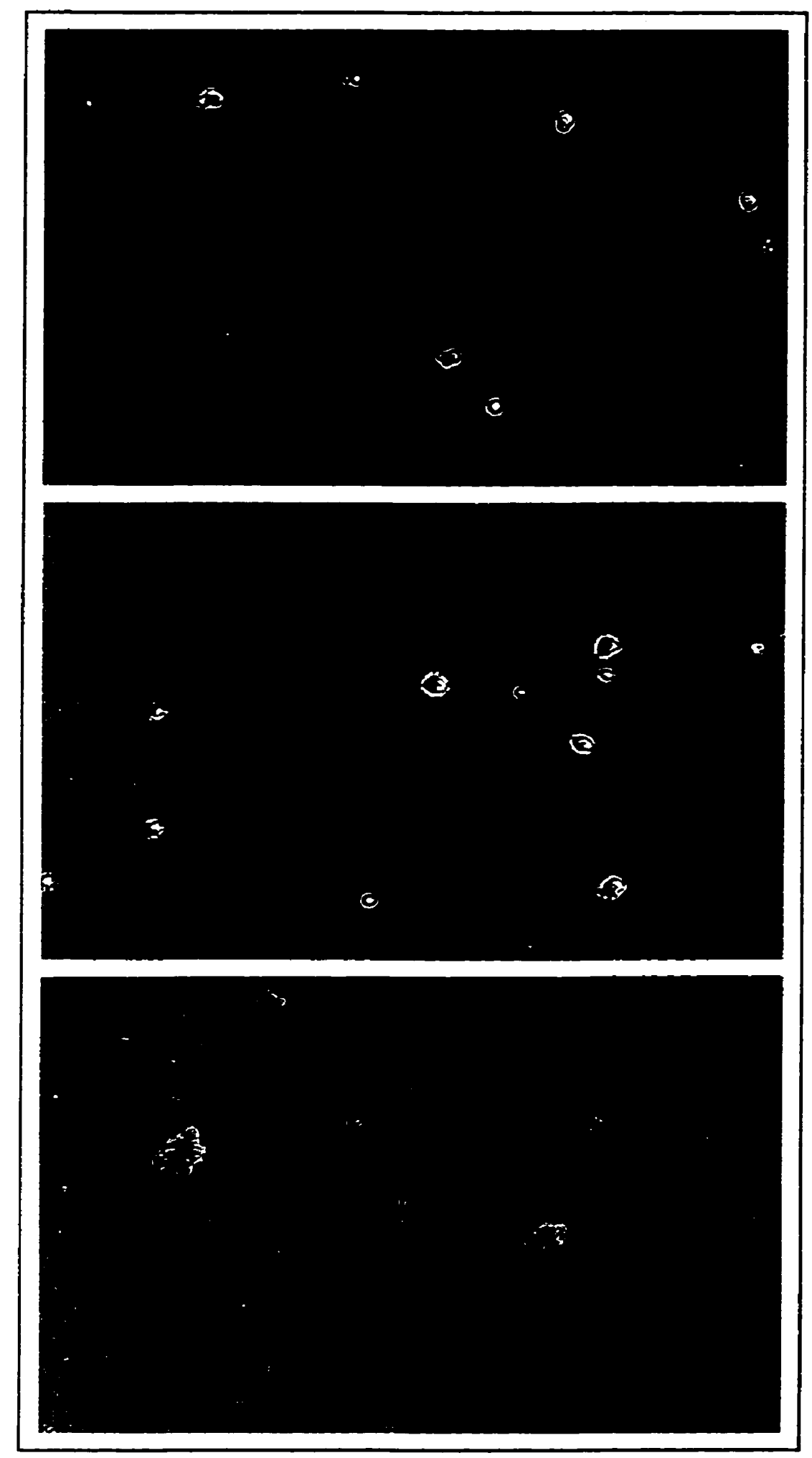

Figure 3.6: Representative images of hippocampal cells on PCTFE on a) day 1, b) day 4, and c) day 7 after cell plating. All Images were captured at 200X magnification. 


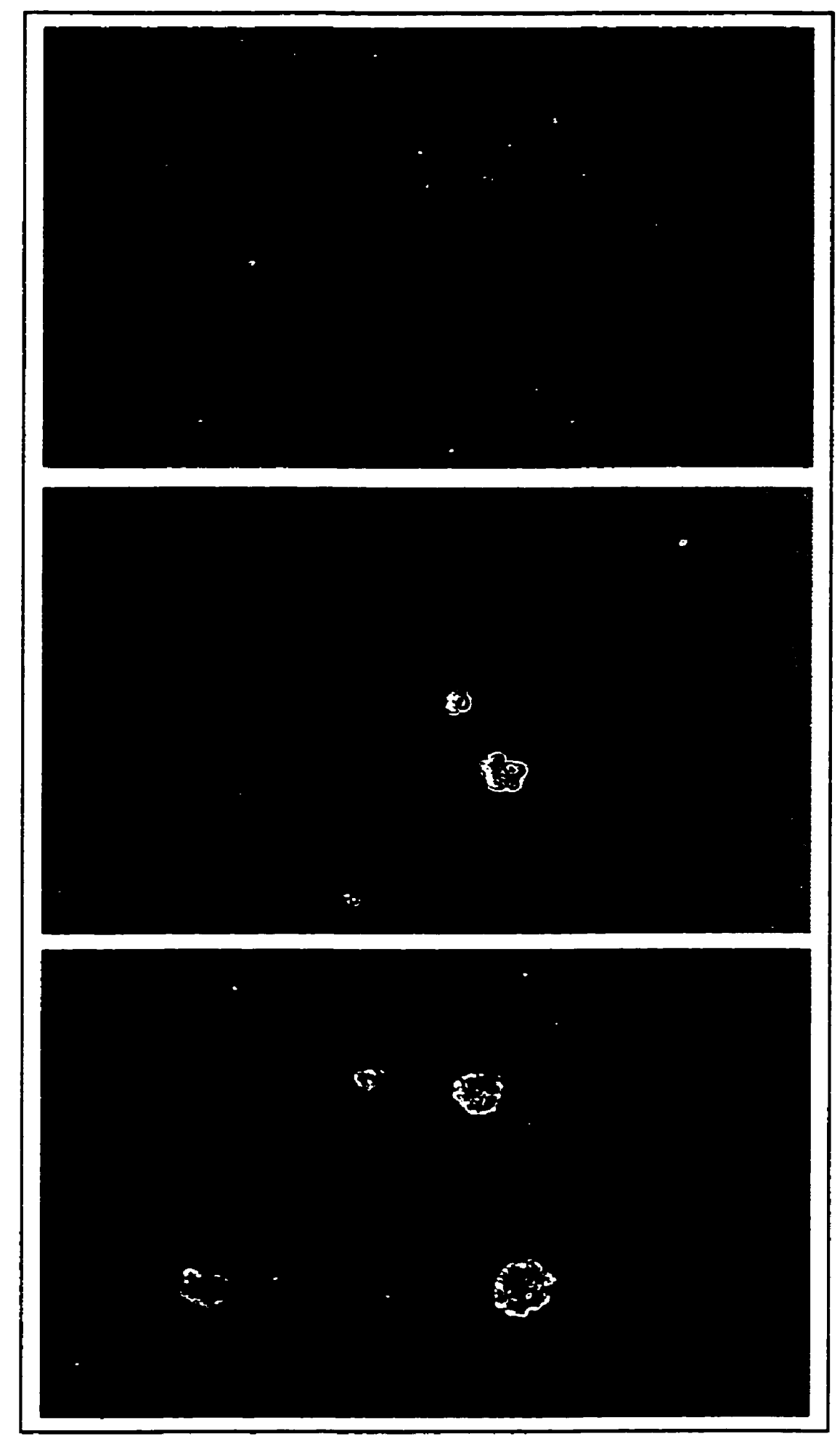

Figure 3.7: Representative images of hippocampal cells on a) PCTFE-PEG - day 1 after cell plating (100X magnification), b) PCTFE-PEG - day 1 after cell plating (200X magnification), and c) PCTFE-PEG-Au - day 1 after cell plating (200X magnification) 


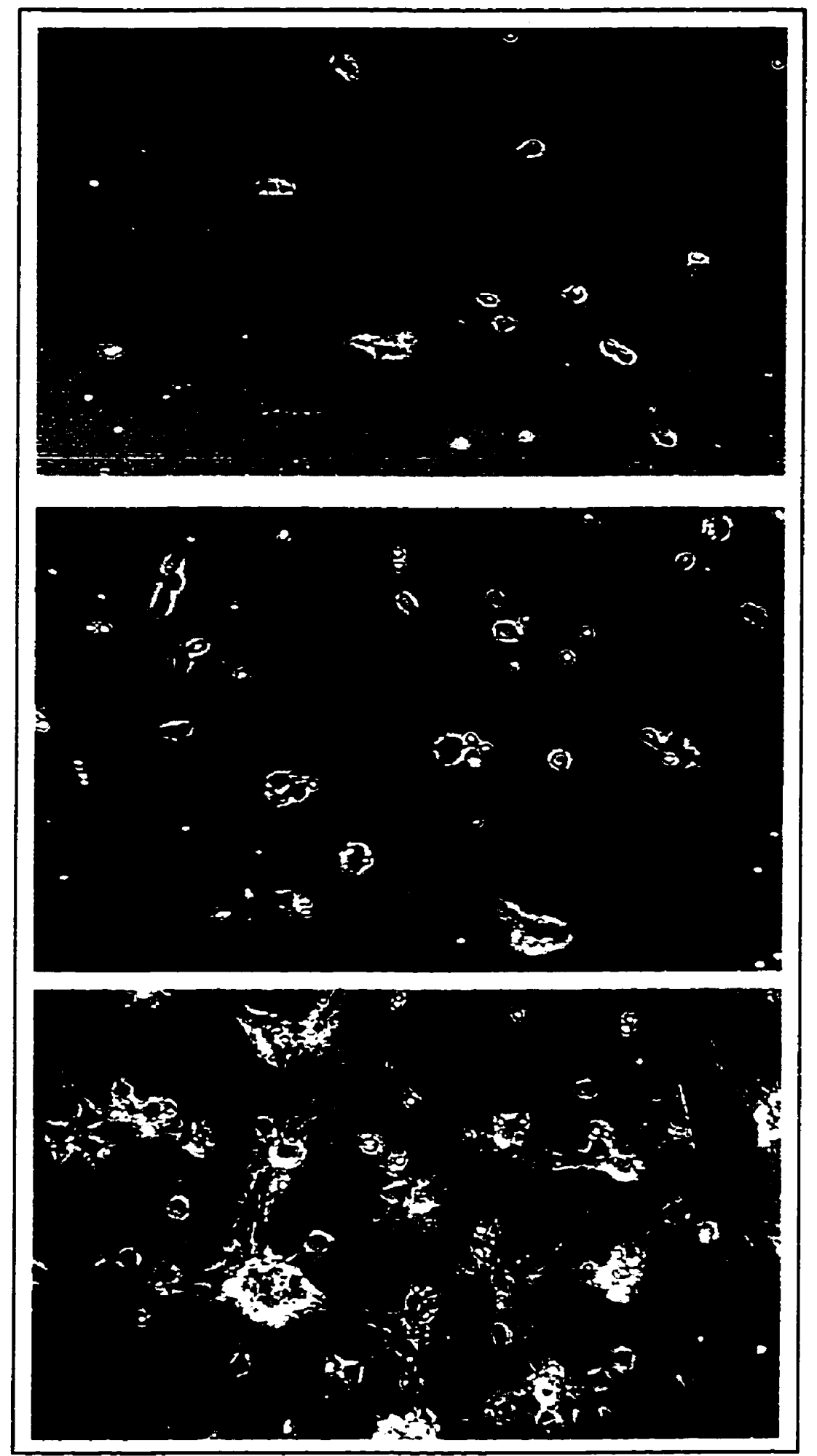

Figure 3.8: Representative images of hippocampal cells on CGYIGSR-modified surfaces on a) day 1 after cell plating, b) day 4 after cell plating, c) day 7 after cell plating. All images were captured at $200 \mathrm{X}$ magnification. 


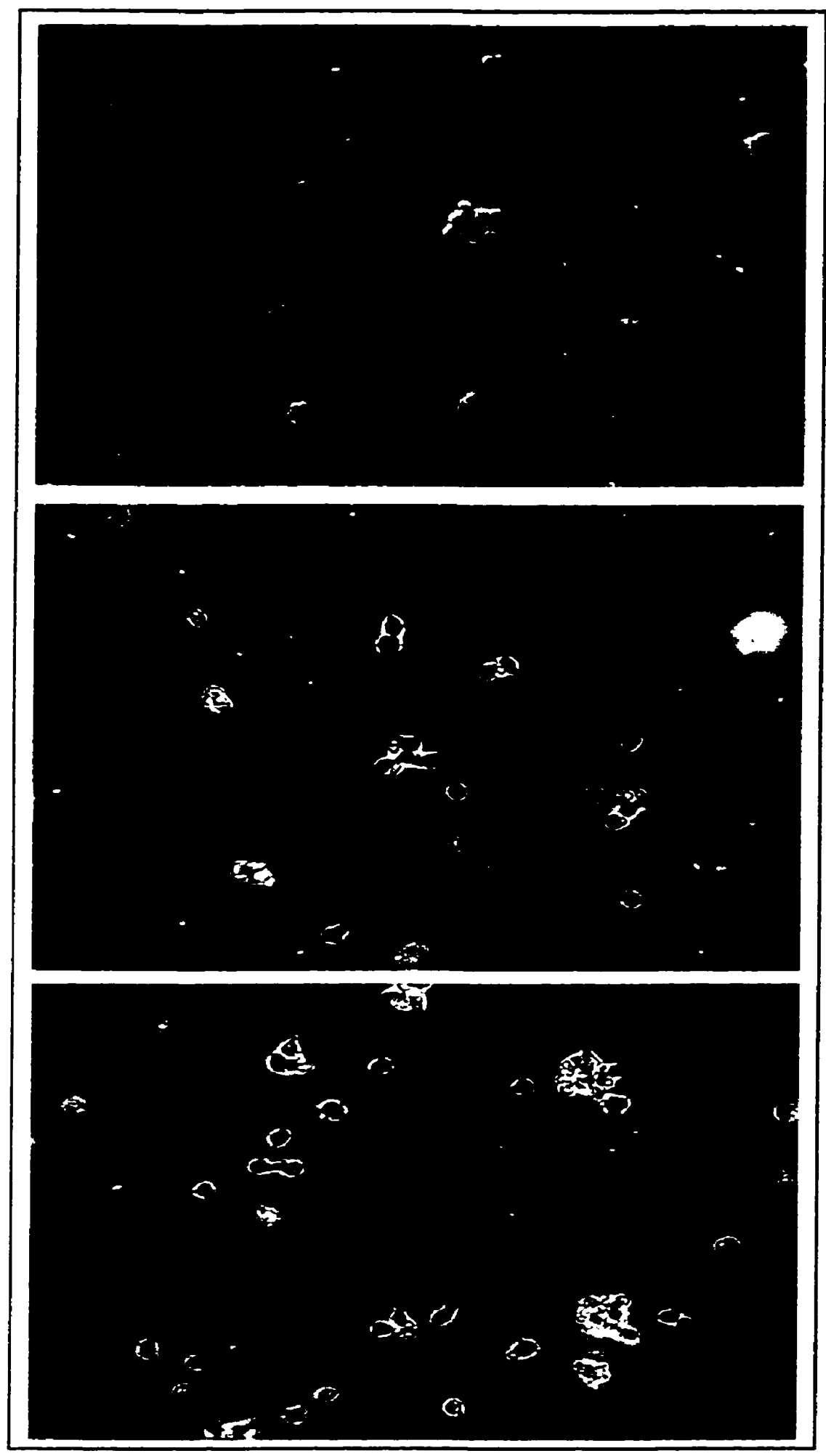

Figure 3.9: Representative images of hippocampal cells on CSIKVAV-modified surfaces on a) day 1 after cell plating, b) day 4 after cell plating, and c) day 7 after cell plating. All images were captured at $200 \mathrm{X}$ magnification. 


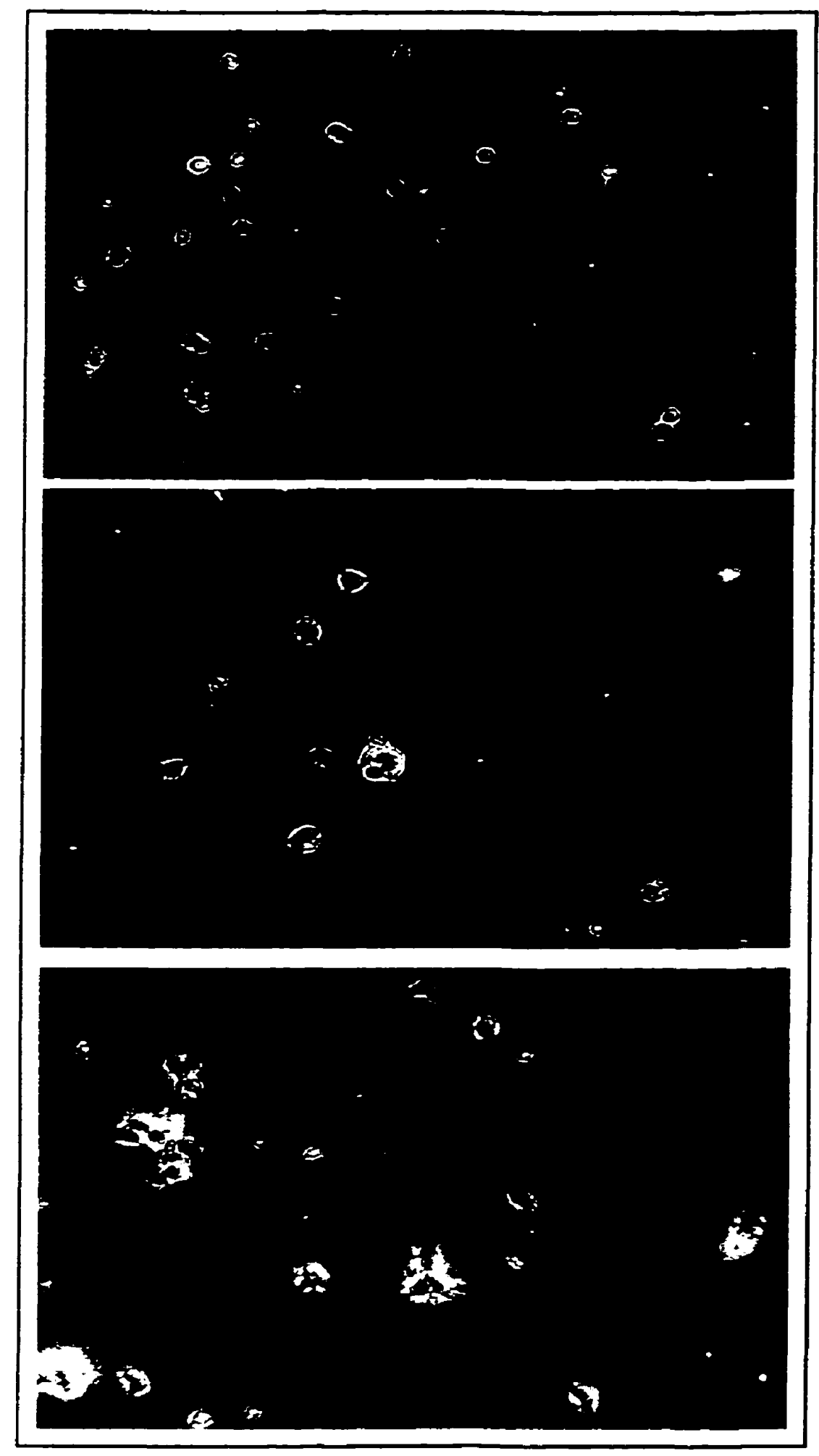

Figure 3.10: Representative images of hippocampal cells on PLL/laminin (positive control) surfaces on a) day 1 after cell plating, b) day 4 after cell plating, c) day 7 after cell plating. All images were captured at $200 \mathrm{X}$ magnification. 
Unlike the results obtained with other fluoropolymer surfaces, such as FEP (Ranieri et al., 1993), PCTFE surfaces did support minimal nerve cell adhesion (Figure 3.6a-c). This was not too surprising since Kingsley and Cole have reported growing a variety of cell types including neurons on Aclar film (Kingsley and Cole, 1988). The number of adherent cells, however, was low and the cells did not spread very well. The diameters of adherent cells were generally less than $10 \mu \mathrm{m}$. Some cells began to extend neurites about 1 day after cell plating. The number of neurites ranged from 1 to 2 per cell and they were short in comparison with those observed on peptide and positive control surfaces. The viability assay confirmed the presence of a some live cells after one week in culture; however, their numbers were few in comparison to the peptide and positive control surfaces.

Following PEG modification, the number of cells observed on the films was reduced significantly (Figure 3.7a and 3.7b). In fact, at low plating concentrations, it was difficult to find cells on the surface at all. The few cells that had adhered, looked similar in morphology to those on PCTFE and extended short, un-branched neurites. Due to the limited number of attached cells on PEG, quantifying neurite extension and length were not statistically sound. After one week in culture, few live or dead cells could be identified on the surface. It is likely that the non-adherent cells had died in solution over the culture period.

The Au surface exhibited a similar cell density to PCTFE after 1 day in culture; however, there were more aggregates present than individual cells (Figure 3.7c). The cells did not spread very well and very few extended neurites longer than their body 
length. Cell viability appeared to decrease significantly after 2 days in culture. After a week in culture, hardly any viable cells were observed on the surface.

Following peptide modification of $\mathrm{Au}$, the number of adherent cells on the surface increased dramatically (Figure 3.8a-c, 3.9a-c). The cell bodies on both CGYGSR and CSIKVAV surfaces appeared more spread out and the cell diameters generally ranged from 10 to $15 \mu \mathrm{m}$. The cells also extended more neurites and after 2 days in culture, the axons could be differentiated from the rest of the dendrites. On the CGYIGSR surface, the neurites exhibited a great degree of branching; a trend that was also seen on the positive control (PLL/laminin) surface. After 4-5 days in culture, the extensions had begun to form networks that made identifying cells and their respective neurites difficult (Figure 3.8c). On both peptide surfaces, the cells remained viable for at least one week in culture.

As expected, the hippocampal cells appeared to interact well with the PLL/laminin modified surface (Figure 3.10a-c). Cell adhesion was high, although surprisingly not as high as on CGYIGSR. The cells adopted a flattened morphology with diameters ranging from 10 to $15 \mu \mathrm{m}$. The neurites were highly branched and formed an intertwining network after 4-5 days in culture (Figure 3.10c). There was some cell aggregation on the surface and the cells that grew in clusters appeared to have longer neurite extensions than individually growing cells. Similar clusters were also seen on both peptide surfaces. The viability assay confirmed that a significant number of cells on the surface were alive after a week in culture. 


\subsubsection{Cell Adhiosion ANALYsis}

The results of the cell adhesion assay performed on day 1 are shown in Figure 3.11. The data represents the average cell count calculated for 10 random fields per surface.

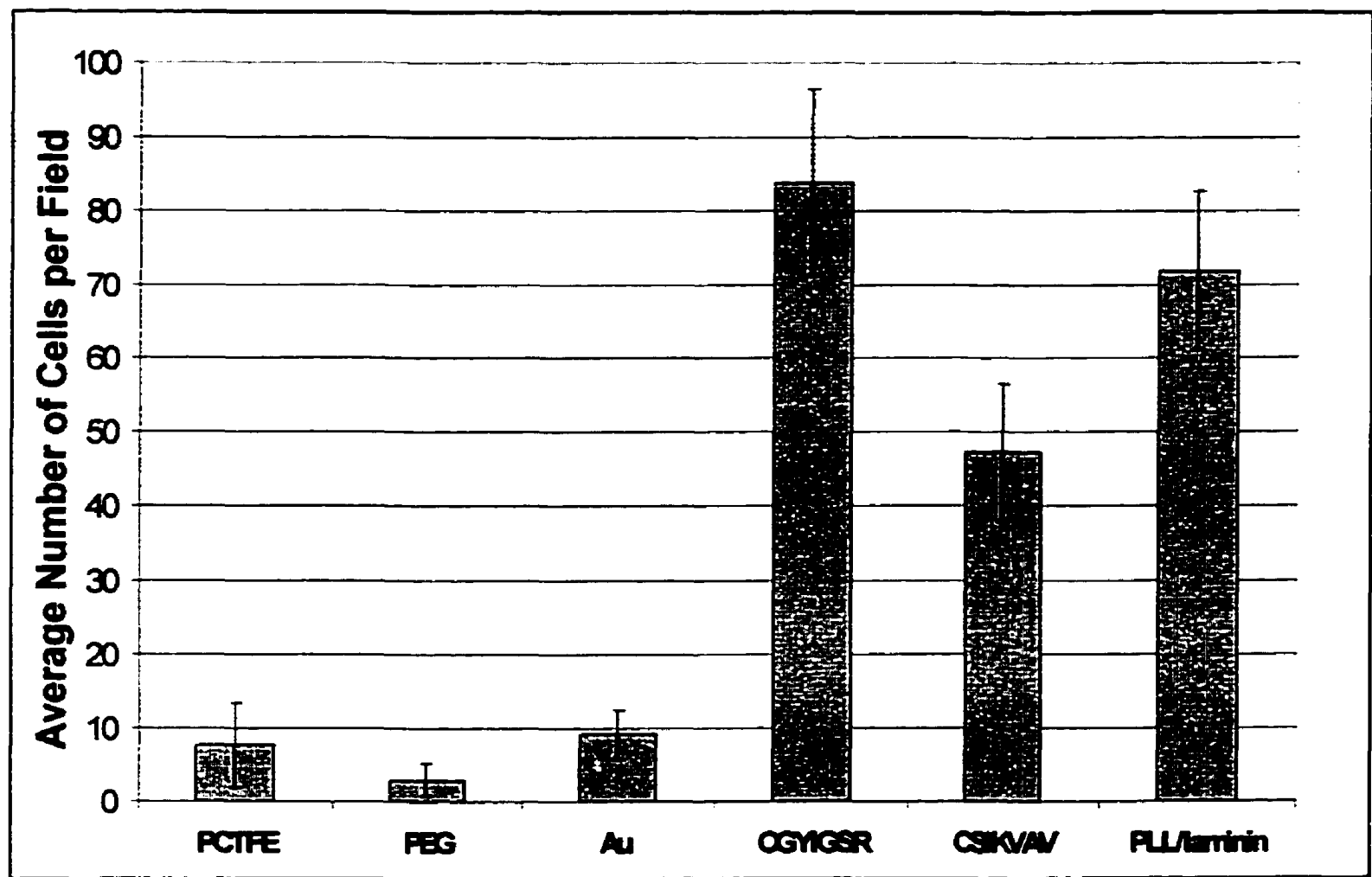

Figure 3.11: Average number of cells/field $\left(1\right.$ field $=25 \mathrm{~mm}^{2}$ ) as determined for 10 random fields per surface ( \pm standard deviations).

As expected, following PEG modification, the number of cells adhered on the surface decreased significantly $(p<0.05)$. There was a dramatic increase in cell adhesion following peptide modification of gold. The CGYIGSR surface exhibited significantly more adhered cells than either CSIKVAV or the positive control $(p<0.05)$. Overall, the order of increasing cell adhesion was:

\section{PEG $<$ PCTFE $\sim$ Au $<$ CSIKVAV $<$ PLL/laminin $<$ CGYIGSR}




\subsubsection{Competitive Cell Adhesion Assay}

The results of the competitive cell adhesion assay are shown in Figure 3.12. The data represents average cell counts over 10 random fields per surface.

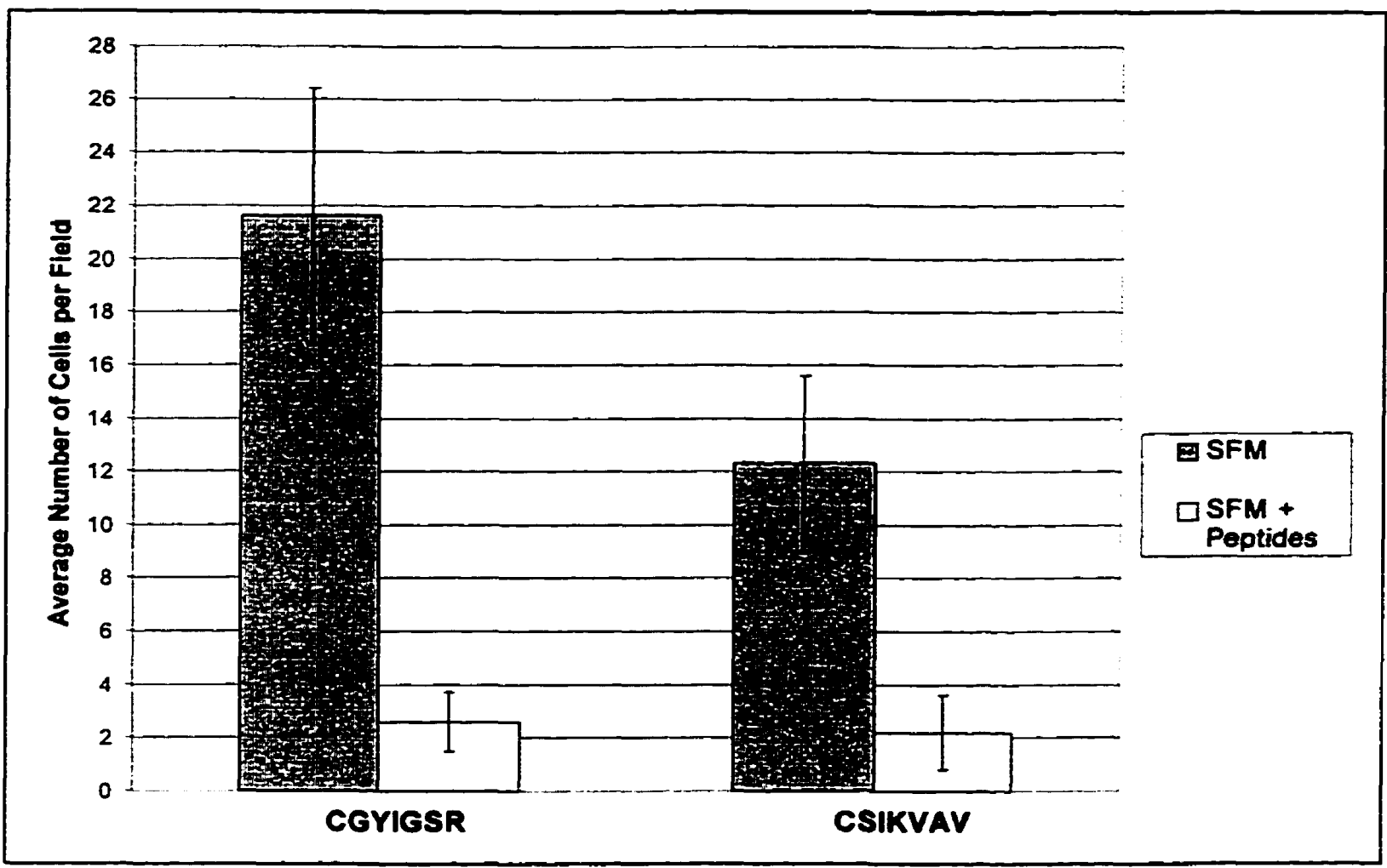

Figure 3.12: Results of the competitive assay showing a significant reduction in the number of cells per field if the cells were pre-incubated with peptides ( \pm standard deviations).

Cell adhesion on both peptide modified surfaces decreased significantly $(p<0.05)$ if the cells were pre-incubated in medium containing the soluble peptides. The results confirm that cell adhesion on CGYIGSR and CSIKVAV surfaces is predominantly receptor specific. This finding has also been confirmed by Ranieri et al. for both YIGSR and IKVAV containing peptide sequences (Ranieri et al., 1995). 


\subsubsection{NEURITE OUTGROWTH ANALYSIS}

The average number of neurites per cell (for 50 random cells per surface) was determined on day 2 and the results are represented in Figure 3.13. Only those neurites that were longer than the cell body length were counted. The PEG-modified films were excluded from this study since there were too few adherent cells on the surfaces. On gold surfaces, most adherent cells exhibited a round morphology with no neurites. There were a small number of cells with neurites; however, the neurites were often much smaller than the cell body length. Due to the cells' poor interaction with these surfaces, the goldmodified films were also excluded from the neurite outgrowth study.

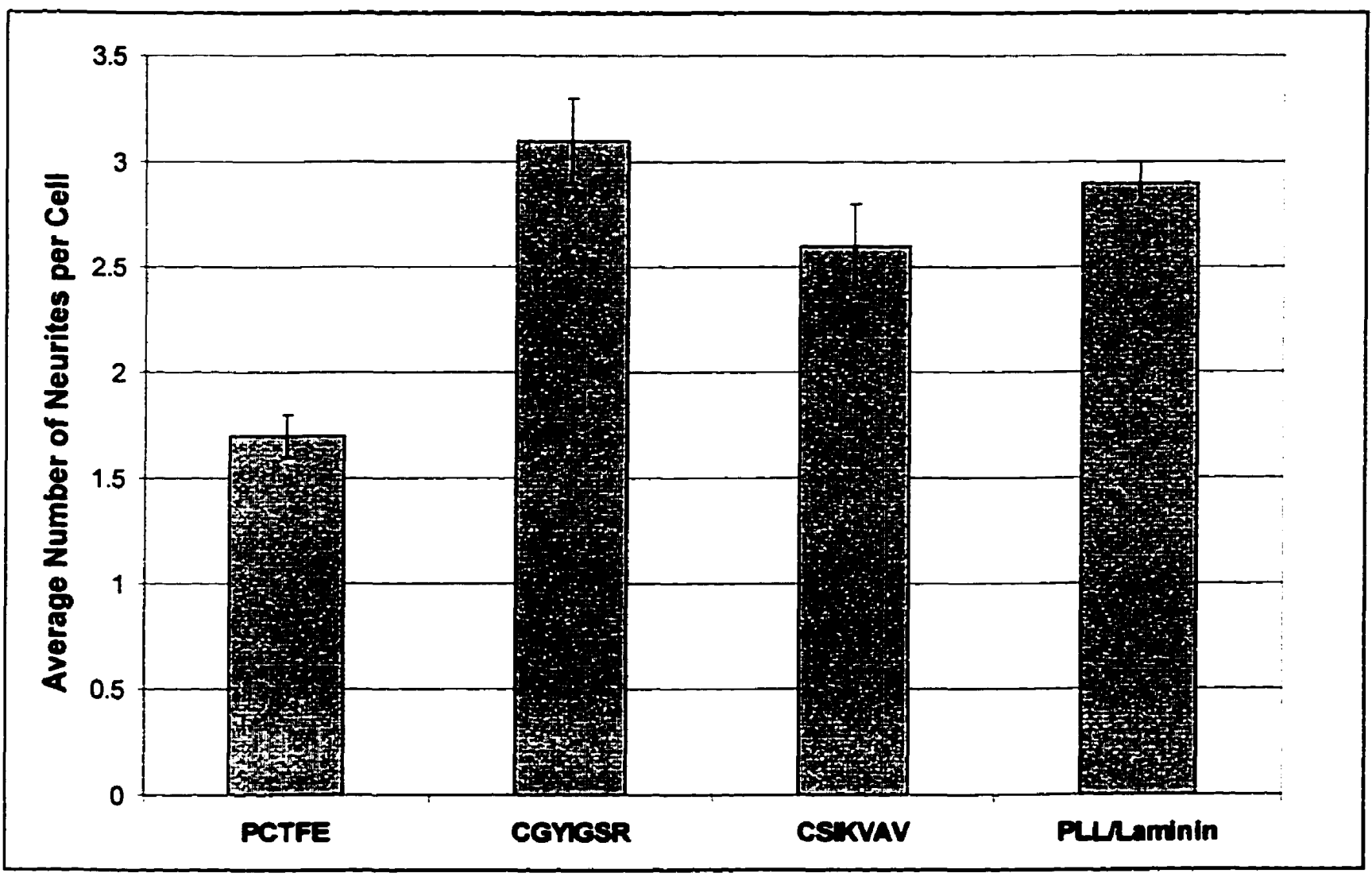

Figure 3.13: Average number of neurites per cell as determined for 50 random cells per surface ( \pm s.e.m.). 
The number of neurites per cell were higher on peptide modified surfaces than on PCTFE alone. In comparing the two peptides, the CGYIGSR surface exhibited significantly more neurites per cell than the CSIKVAV surface $(p<0.05)$. There were, however, no significant differences observed between either of the peptides and the positive control surface.

\subsubsection{NEURTE LENGTH ANALYSTS}

As a measure of cell-surface interaction, the length of the longest neurite per cell on day 2 was determined for 50 random cells. The average length for each surface studied is represented in Figure 3.14. Again, PEG and Au surfaces were excluded from this study since there were not enough adherent cells present with neurite extensions of adequate length (i.e. longer than the cell body). 


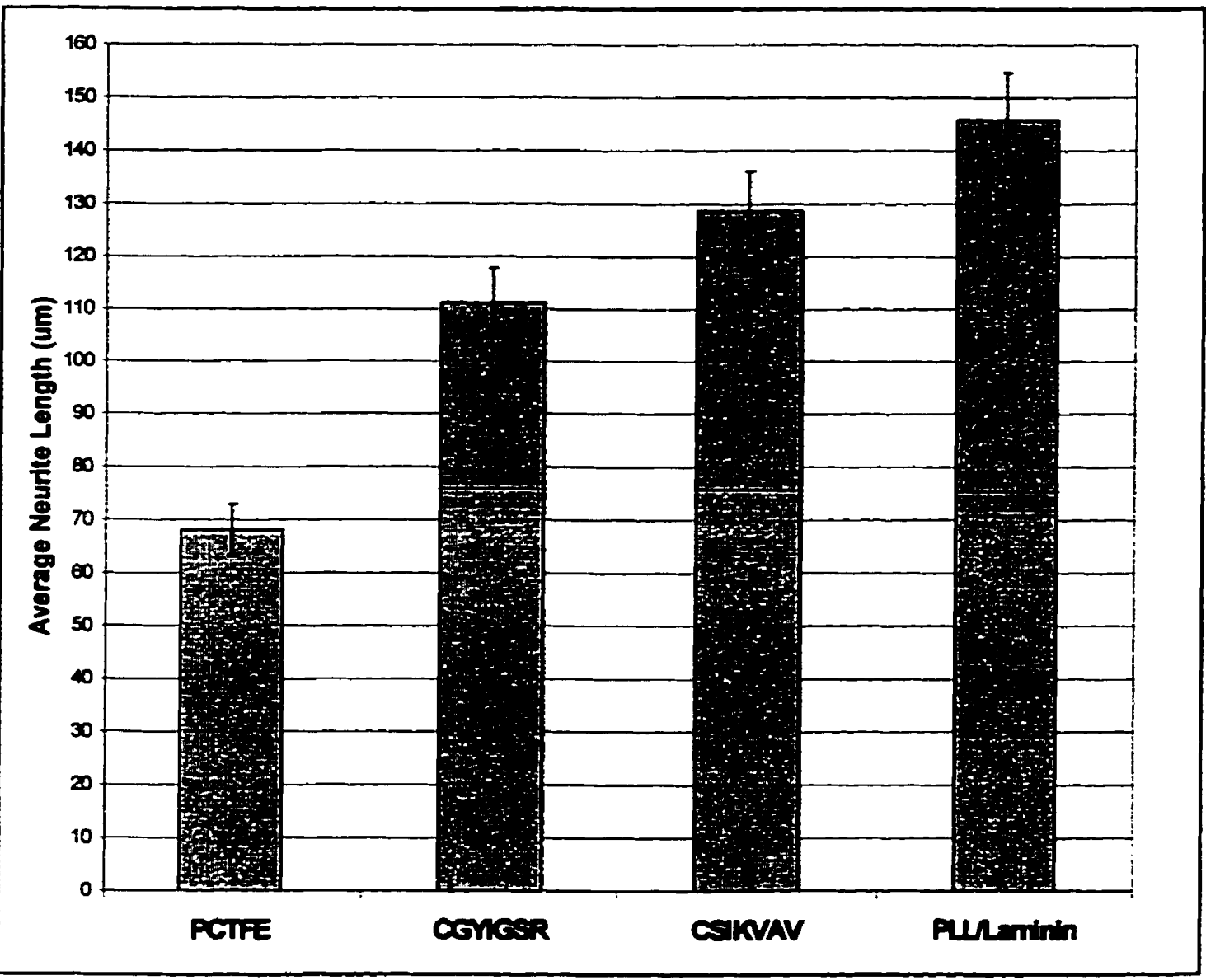

Figure 3.14: Average neurite length as determined for 50 random cells per surface $( \pm$ s.e.m.).

The results of the neurite length analysis showed that the peptide surfaces and the positive control surface exhibited significantly longer neurites than the PCTFE film $(p<0.05)$. In comparing the two peptides, the neurites on CSIKVAV were longer than those observed on CGYIGSR on day 2; although, the differences were less noticeable at longer time points. On average, the positive control exhibited the longest neurites; however, statistically, there were no differences found between the CSIKVAV surface and the positive control $(p<0.8)$. In general, after $3-4$ days in culture, the neurites on the positive control and peptide surfaces began to form connections and so it was difficult to see differences in length. 


\subsubsection{Patterned Surfaces}

All preliminary patterning work was done using the 180/90 EM grids creating 180 $\mu \mathrm{m}$ wide regions of PEG and $90 \mu \mathrm{m}$ wide regions of peptide. Once the effects of these dimensions on neurite outgrowth were determined, other pattern dimensions were investigated. The results of both $180 / 90$ patterns and $40 / 22$ patterns are shown in Figures $3.15-3.21$

On PCTFE/Au surfaces (Figure 3.15), very few adhered cells were found on either of the two regions. The few cells that had adhered on the PCTFE regions extended neurites after about 2 days in culture, but the ones that had adhered to Au remained round and undifferentiated. On PEG/Au surfaces, generally no adherent cells were observed on the PEG regions and the few that had adhered to Au remained viable for only 2-3 days.

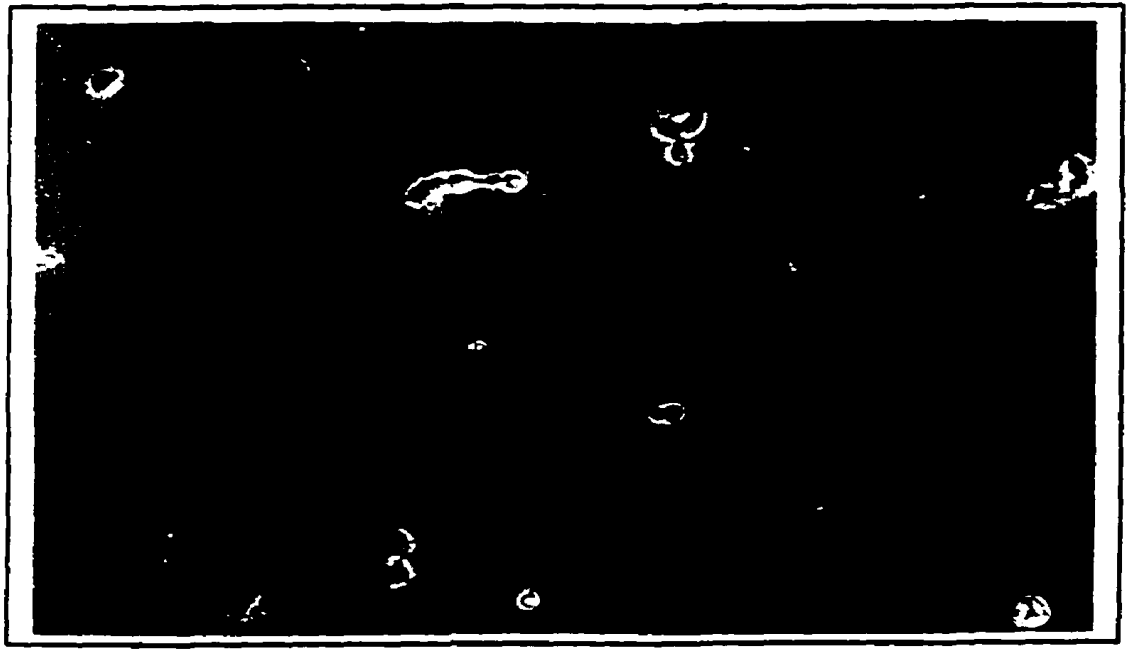

Figure 3.15: An image of hippocampal cells on a PCTFE (light)/Au (dark) patterned surface (180 $\mu \mathrm{m}$ regions of PCTFE/90 $\mu \mathrm{m}$ regions of Au) (200X magnification). 
Figure 3.16 is a representative image of a PCTFE/CGYIGSR surface. The majority of adherent cells were found on the CGYIGSR regions with some cells on PCTFE areas. In general, the cells on the peptide regions had a much more flattened morphology and extended neurites much earlier (after 24 hours) than those on PCTFE (after 2 days). Most neurite extensions remained confined to the peptide regions in the first 2 days after culture. Upon encountering the polymer regions; however, many neurites proceeded to grow onto PCTFE while others changed direction and grew along the peptide surface. After 4 days in culture, the cells continued to remain true to the pattern in some areas; however, in other areas, neurite outgrowth was observed on both PCTFE and peptide regions. Similar results were observed on PCTFE/CSIKVAV surfaces; although, the number of cells adhered on the CSIKVAV surface were less than those adhered on CGYIGSR.

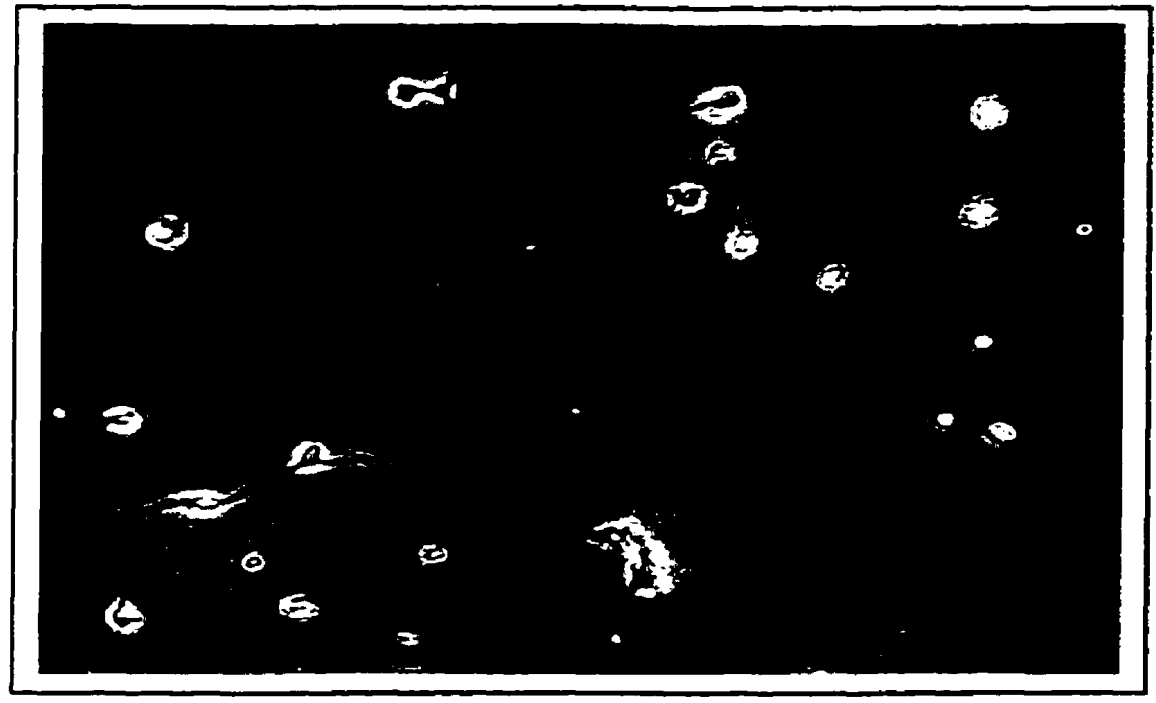

Figure 3.16: An image of hippocampal cells on a PCTFE (light)/CGYIGSR (dark) patterned surface (180 $\mu \mathrm{m}$ regions of PCTFE/90 $\mu \mathrm{m}$ regions of CGYIGSR) (200X magnification). 
Figures 3.17-3.20 are representative images of cells on PEG/CGYIGSR surfaces. After 24 hours, almost all of the adhered cells were found on the peptide patterns with very few cells seen on PEG regions. Neurite outgrowth remained true to the patterns with very few exceptions. After 4 days, it was possible to see long extensions that had traveled along the width of the patterns and had changed direction upon encountering PEG areas. The few neurites that had proceeded off the peptide surface appeared to have stopped growing shortly upon encountering PEG areas. As seen in Figure 3.20, neurite outgrowth was directed onto and remained on the peptide regions for at least one week in culture. Similar results were observed on PEG/CSIVKAV.

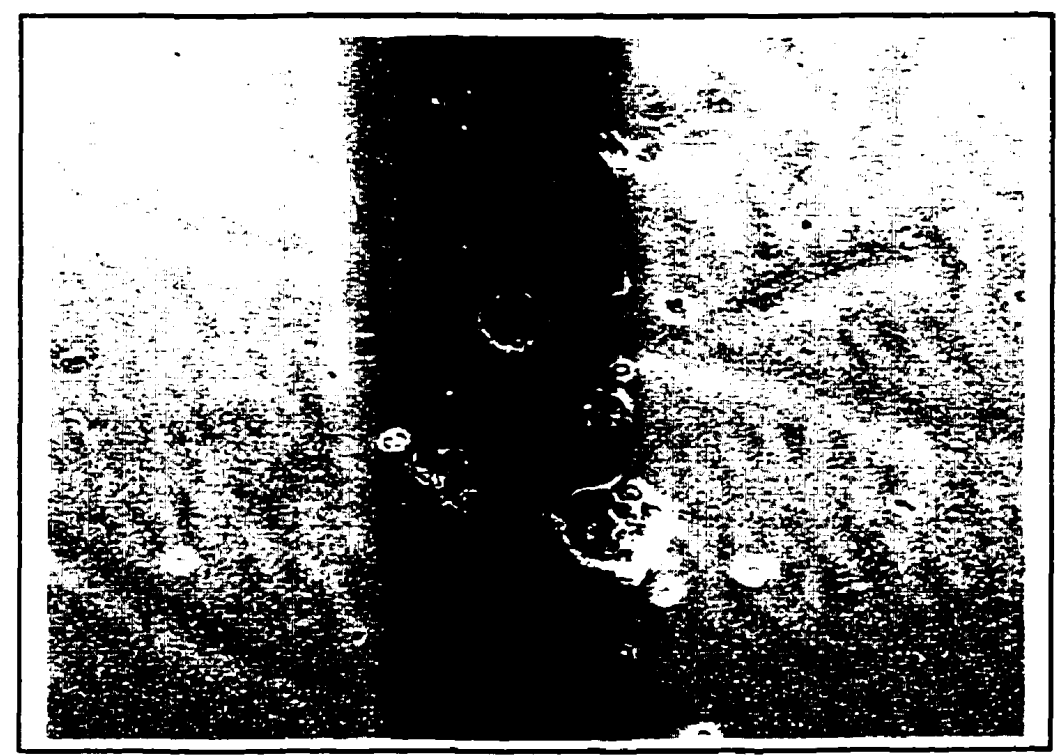

Figure 3.17: An image of hippocampal cells on a PEG (light)/CGYIGSR (dark) patterned surface on day 2 after cell plating (180 $\mu \mathrm{m}$ regions of PEG/90 $\mu \mathrm{m}$ regions of CGYIGSR) (200X magnification). 


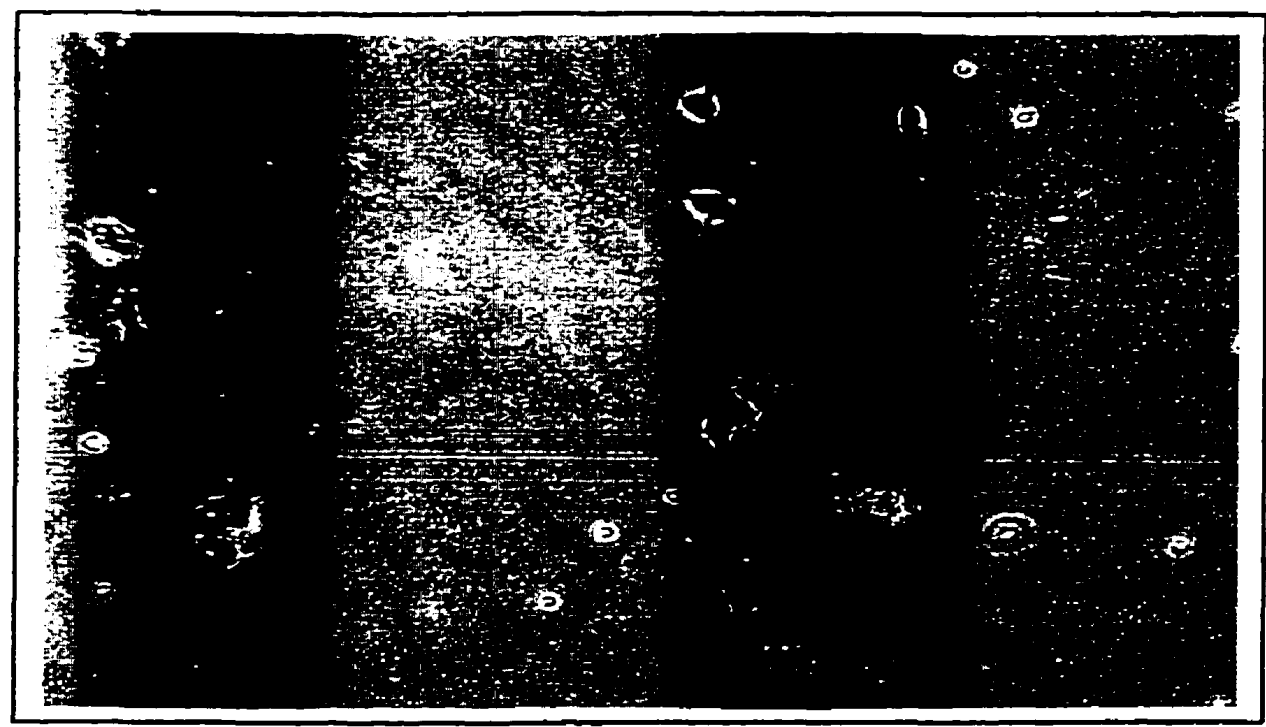

Figure 3.18: An image of hippocampal cells on a PEG (light)/CGYIGSR (dark) patterned surface on day 4 after cell plating (180 $\mu \mathrm{m}$ regions of PEG/90 $\mu \mathrm{m}$ regions of CGYIGSR) (200X magnification).

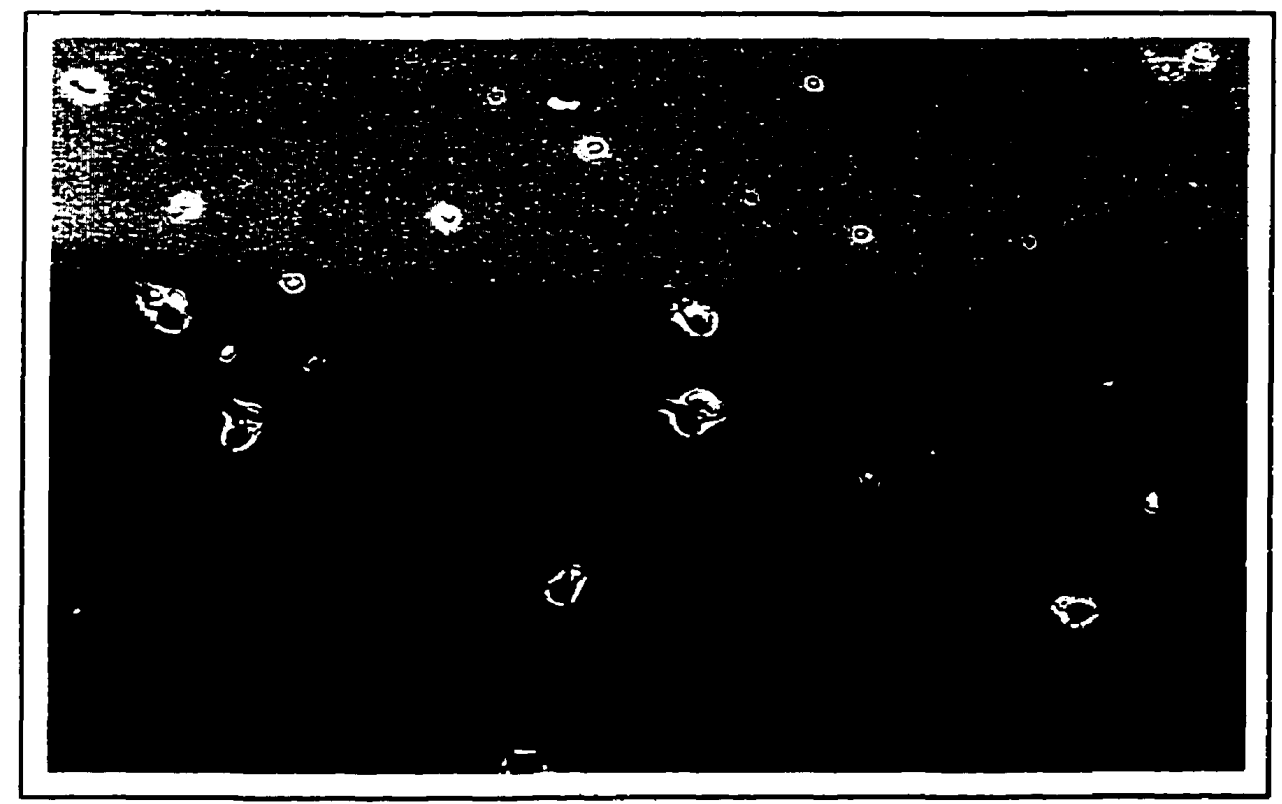

Figure 3.19: An image of hippocampal cells on a PEG (light)/CGYIGSR (dark) patterned surface (day 4). Upon encountering the PEG regions, neurites often change direction and continue to grow on the peptide surface (200X magnification). 


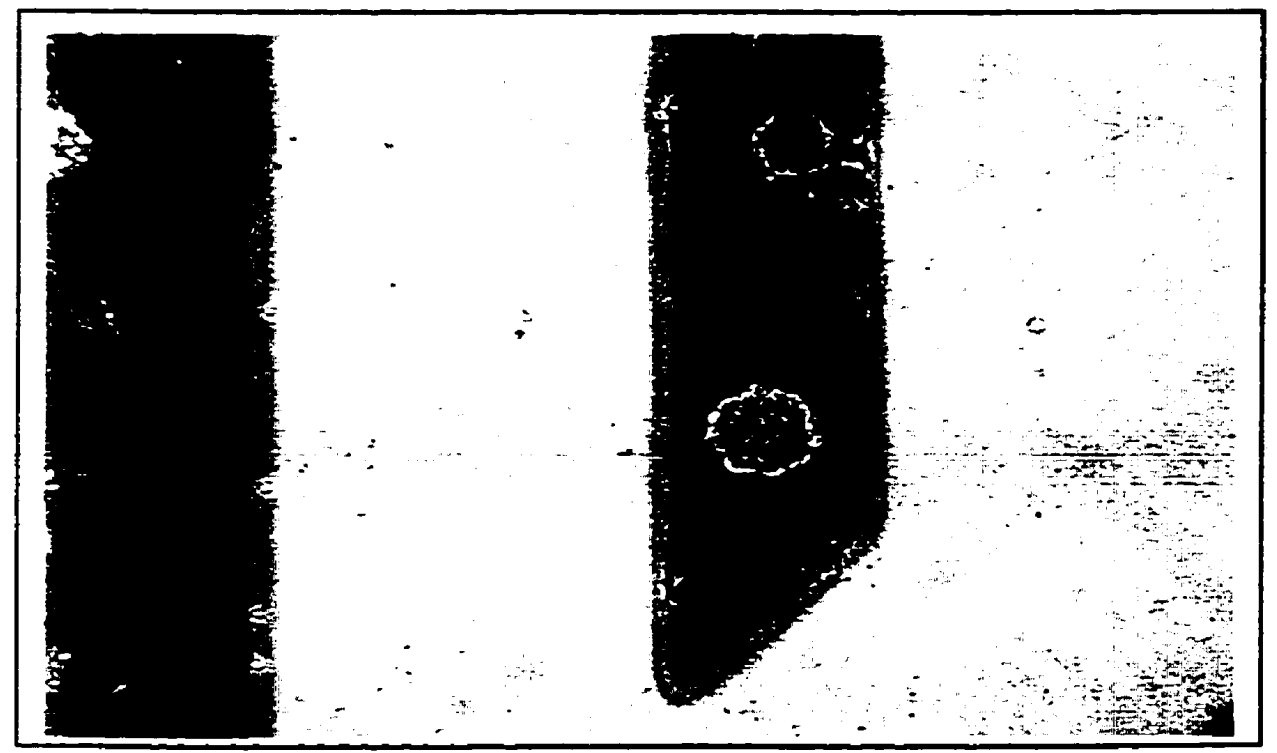

Figure 3.20: An image of hippocampal cells on a PEG (light)/CGYIGSR (dark) patterned surface on day 7 after cell plating ( $180 \mu \mathrm{m}$ regions of PEG/90 $\mu \mathrm{m}$ regions of CGYIGSR) (200X magnification).

We also attempted to create patterns of $40 \mu \mathrm{m}$ PEG/22 $\mu \mathrm{m}$ peptide using 40/22 EM grids. It was, however, not possible to obtain patterns with smooth edges using the shadow masking technique. The resulting patterned surfaces, on average, had parallel 30 $\mu \mathrm{m}$ PEG and $30 \mu \mathrm{m}$ peptide regions (Figure 3.21). We found that in some cases, we were able to direct cell adhesion and neurite outgrowth on these smaller patterned surfaces; however, the results were not always reproducible. On some surfaces, after 2-3 days in culture, neurites had crossed over the PEG regions (Figure 3.22). This indicates that a non-adhesive area of greater than $\mathbf{3 0} \mu \mathrm{m}$ is needed for directing neurite outgrowth. 


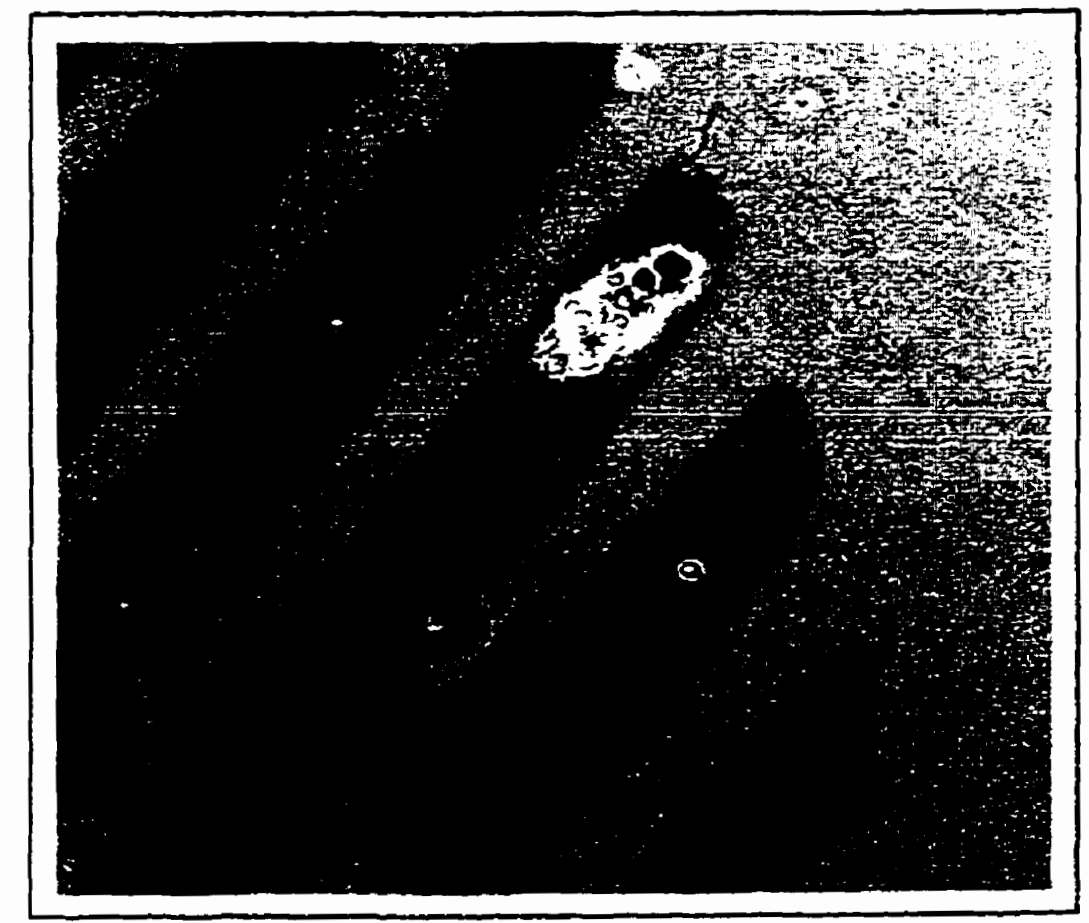

Figure 3.21: An image of hippocampal cells on a PEG (light)/CGYIGSR (dark) patterned surface on day 4 after cell plating (40/22 EM grids were used to pattern the surface; however, the resulting patterns generally consisted of $30 \mu \mathrm{m}$ regions each of PEG and peptide) (200X magnification). 


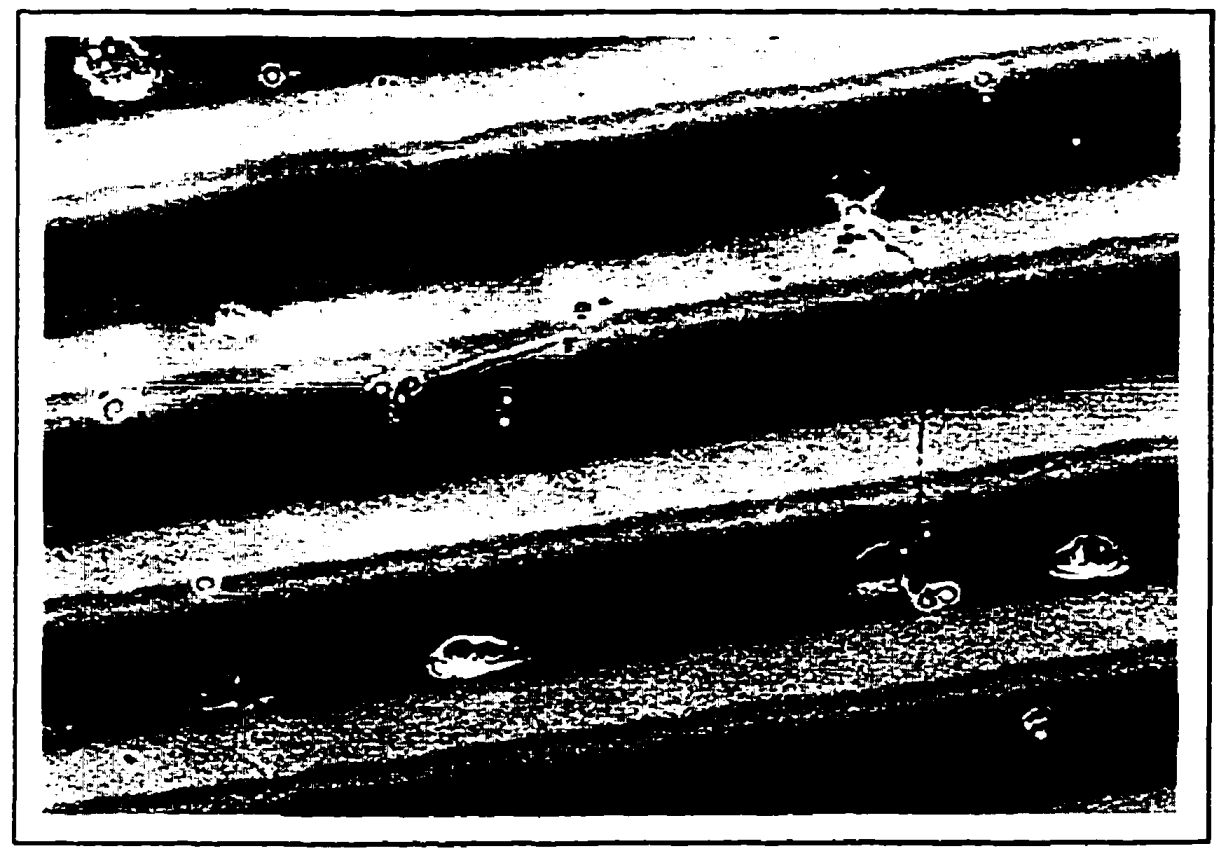

Figure 3.22: An image of hippocampal cells on a PEG (light)/CGYIGSR (dark) patterned surface on day 4 (30 $\mu \mathrm{m}$ PEG/30 $\mu \mathrm{m}$ peptide regions) showing some neurites crossing over the PEG regions (200X magnification). 


\section{Discussion}

\subsection{PEG MODIfICATION}

There have been no previous reports in literature on the modification of PCTFE with PEG. One experimental pathway that was initially considered involved the functionalization of the surface with hydroxyl groups before PEG coupling (Dias and McCarthy, 1987). This procedure, however, involved numerous steps, most of which had to be conducted at $-78{ }^{\circ} \mathrm{C}$ to be surface selective. Overall, the procedure was difficult and time consuming. Our idea of using an alkoxide derivative evolved from studying the work of Gombotz et al. who used PEG-alkoxide to modify the surface of cyanuric chloride activated PET films (Gombotz et al., 1989). They reported that following XPS surface analysis, they observed small polyether peaks, corresponding to PEG. Since PCTFE has a chlorine group per monomer unit, it was thought that similar reactions with PCTFE would incorporate PEG onto the surface via dechlorination. The reaction involved only two steps and could be performed at room temperature. Another incentive to using this method was the relatively cheap cost of the PEG derivatives used. Methoxyterminated PEGs are inexpensive and a variety of different MWs are available. Emoto et al. also reported that surfaces modified with methoxy-terminated PEGs are more stable than those modified with hydroxyl-terminated PEGs for long term storage (Emoto et al., 1998).

The XPS and contact angle results from the preliminary experiments with PEGalkoxide (MW5000) confirmed the surface selective modification of PCTFE. Following PEG modification, carbon and oxygen percentages increased in a ratio of approximately 2 to 1 , confirming the presence of PEG molecules on PCTFE. By following the decrease 
in fluorine and chlorine percentages in conjunction with the changes in oxygen and carbon concentrations, we were able to propose two mechanisms for the PEG alkoxidesurface reaction.

\subsubsection{The Proposed Mechanisms}

As mentioned before, the presence of chlorine groups in PCTFE reduce its chemical resistance thereby make its surface modification easier. In comparing the strengths of the chemical bonds in PCTFE, the $\mathrm{C}-\mathrm{Cl}$ bond $(81 \mathrm{kcal} / \mathrm{mol})$ is significantly weaker than the C-F bond (108 kcal/mol) (Mark et al., 1985). In addition, fluorine is more basic than chlorine and since a strongly basic anion is usually a poorer leaving group than a weakly basic one (Carey, 1992), we expected to predominantly observe dechlorination of PCTFE by the alkoxide ion. The expected mechanism is shown in Figure 4.1.

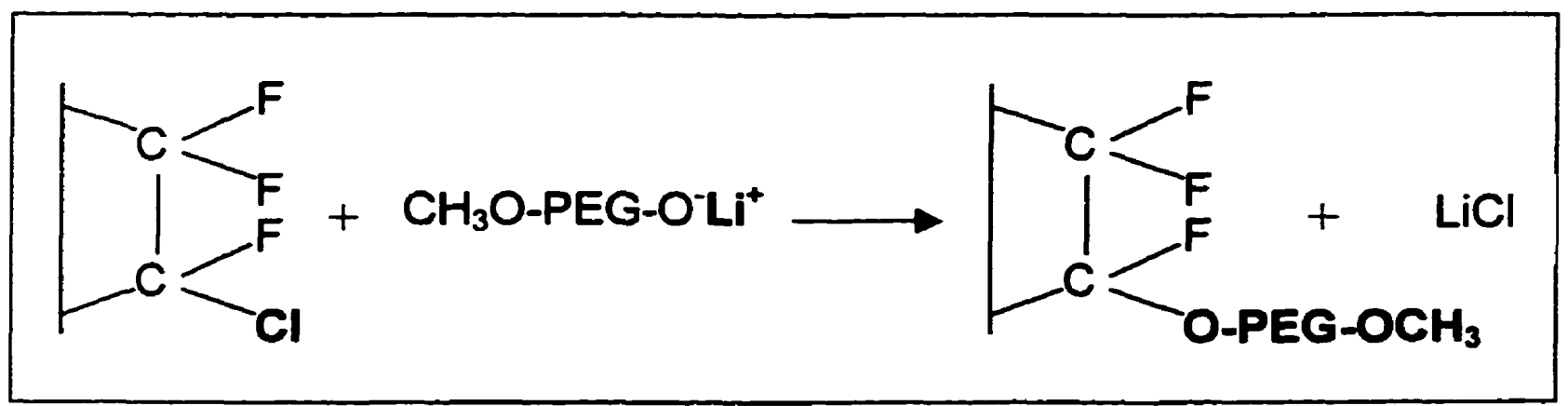

Figure 4.I: Mechanism 1 - The nucleophilic substitution of chlorine on PCTFE by the lithium salt of PEG-alkoxide.

In looking at the XPS data, the amount of fluorine present on PEG-modified films did not support this mechanism. We observed a lower concentration of fluorine than expected and these results suggested that de-fluorination was occurring in conjunction 
with de-chlorination. In addition, we noticed that the films were discolored following PEG modification, indicating the possible presence of $\mathrm{C}=\mathrm{C}$ bonds on the surface.

In their work with the methyllithium modification of PCTFE, Dias and McCarthy proposed a mechanism involving metal-halogen exchange followed by an elimination reaction, where both de-chlorination and de-fluorination occur (Dias and McCarthy, 1985). They also suggested that similar chemistry was possible with alkoxide modification. Our second proposed mechanism is based on this work and is represented in Figure 4.2.<smiles>FC1(F)CCC1(F)Cl</smiles>

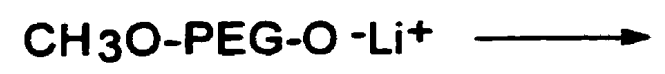<smiles>FC1(F)CCC1(Cl)Cl</smiles>

CH3O-PEG-O - $\mathrm{Li}^{+}$

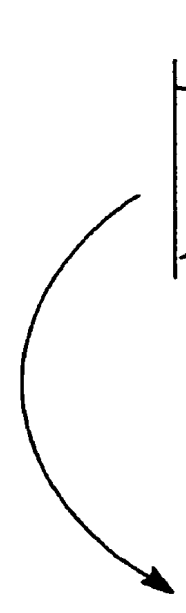<smiles>CC(C)(C)C</smiles>

\section{$F$} $F$

\section{O-PEG-OCH}
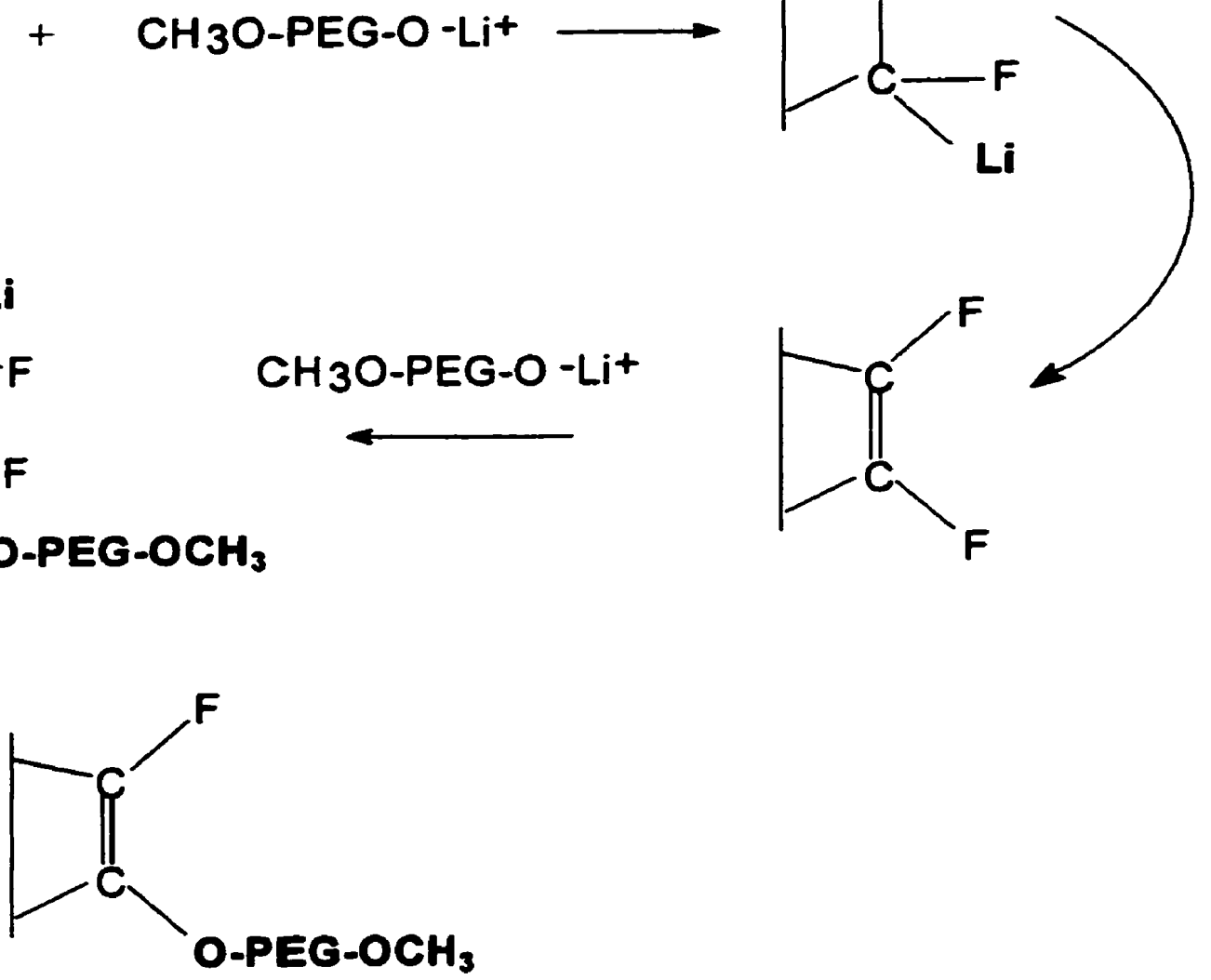

Figure 4.2: Mechanism 2-Metal-halogen exchange/elimination of PCTFE by the lithium salt of PEG-alkoxide. 
Looking at the XPS data, the amount of chlorine that was present following PEGmodification was an indication of un-reacted PCTFE. Knowing the relative atomic ratios of carbon, fluorine and chlorine in PCTFE, the amounts of carbon and fluorine associated with the un-reacted polymer were subtracted from the results. The remaining amounts of fluorine and carbon and the amount of increased oxygen were found to yield a structure similar to that proposed in mechanism 2. The only exceptions were the PEG MW2000and 750-modified films reacted in the co-solvent systems. The excess amount of carbon present on these surfaces could not be accounted for. In reactions involving only toluene as the solvent, mechanism 2 appears to be supported by the fact that we observed both de-fluorination and de-chlorination along with the discoloration of films following PEG modification.

\subsubsection{THE EFFectS OF PEG MW}

The XPS results of preliminary experiments with PEG MW5000 showed the presence of a significant amount of chlorine following PEG modification of PCTFE. These results indicated two possibilities: 1) the depth of modification was shallow and some of the underlying bulk material was also analyzed, or 2) there were patches of unreacted PCTFE on the surface suggesting that PEG coverage on the surface was not homogeneous. Assuming that the depth of modification was dependent on reaction time, we repeated the $24 \mathrm{~h}$ modification reaction with lower MW PEGs in order to increase surface coverage. It was thought that with smaller PEG chains, the probability of their reactive terminal groups being exposed was higher thereby increasing the probability of reaction with the surface. It was also thought that shorter chains, once grafted, would 
take up less space on the surface thereby allowing more PEG molecules to react in a given area. The XPS data (Tables 3.3 and 3.4) showed an increase in both oxygen and carbon in decreasing the MW of PEG from 5000 to 2000 and from 5000 to 750 . Assuming that the depth of modification for all MW PEGs was the same for a $24 \mathrm{~h}$ reaction, the XPS results indicated that surface coverage increased with decreasing PEG MW from 5000 to either 2000 or 750 . The XPS measurement differences between PEG MW2000 and 750 were not statistically significant, indicating two possibilities: 1) surface coverage was similar on both surfaces, or 2) the effects of the bulk material overshadowed any changes in surface coverage between the two surfaces.

\subsubsection{THE EFFECTS OF THE CO-SOLVENT SYSTEM}

Our rationale behind using a toluene/THF solvent system versus toluene alone arose from studying the work of McCarthy and Dias who modified PCTFE in different compositions of heptane/THF solutions and found that higher concentrations of THF promoted the extent of reaction (McCarthy and Dias, 1987). They reported that solvents which wet or swell the polymer to greater extents should favor the mobility of surface chains thereby allowing the reagent to react with the surface. We chose to add THF to our reaction system in order to better wet the PCTFE surface. Our preliminary XPS results with PEG MW5000 showed an increase in both carbon and oxygen that in conjunction with decreases in fluorine and chlorine, supported the proposed mechanism (Mechanism 2 in section 4.1.1). The results indicated that the addition of THF promoted the reaction between the alkoxide molecules and the surface. With lower MW PEGs, however, the increase in carbon was not proportional to increases in oxygen and 
decreases in chlorine and fluorine suggesting that possible side reactions had taken place. The higher contact angle values were also in agreement with the XPS data. The amount of excess carbon present on these modified films was too high to be attributed to adventitious carbon. It is likely that by better wetting the surface, THF promoted alkoxide-surface reactions with the lower MW PEGs; however, the source of excess carbon on the modified surfaces must be identified before any definite conclusions can be made.

\subsection{PEPTIDE MODIFICATION}

The results of our previous work and the work of others have shown that the laminin derived peptide sequences YIGSR and IKVAV promote cell adhesion and neurite outgrowth (Saneinejad and Shoichet, 1998; Huber et al., 1998; Ranieri et al., 1995). The use of these specific peptide sequences rather than the entire laminin protein for surface modification offers several advantages. First, the peptides can be covalently immobilized to the surface offering greater stability than adsorbed proteins that can desorb over time. Huber et al. tried to covalently couple laminin to glassy carbon surfaces but they found that cell-surface interactions were poorer than on surfaces with adsorbed laminin (Huber et al., 1998 ). The second advantage of using peptide sequences is that it is possible to create a conformationally active surface (Massia et al., 1993). The adsorption of large protein molecules, like laminin, often results in a partial obstruction of the active sites that are recognized by cells (Matsuwaza et al., 1997).

The idea of modifying PCTFE with peptides via a gold-thiol bond arose from the work of Dimilla et al. on alkane thiol modifications of gold surfaces (Dimilla and et al., 
1994) where SAMs of alkanethiolates were prepared on gold surfaces via a gold-thiol bond. These adsorbed layers are highly ordered, easy to prepare, and chemically stable. In our study, we took advantage of the gold-thiol bond formed between the cysteine group of each of the peptides and the surface. The peptide modifications were confirmed by XPS and contact angle data. Originally, we expected to see some evidence of sulfur in the XPS data; however, we only saw a very small percentage on the CGYIGSR-modified sample at a take-off angle of $15^{\circ}$. Troughton et al. reported that they found little evidence of sulfur in the XPS data of their thiol-modified surfaces (Troughton et al., 1988). They attributed the absence of sulfur to both its low concentration and the low intensity of the X-ray beam and low corresponding. low signal-to-noise ratio in the spectra. It is not surprising that we also saw little evidence of sulfur since there is only one sulfur group per attached peptide molecule. If we consider the atomic composition of CGYIGSR, the nitrogen to sulfur ratio is approximately 10 to 1 and in the $15^{\circ}$ take-off angle data, the relative atomic percentage of nitrogen was found to be $8.1 \%$. It is therefore not surprising that only a very small percentage of sulfur was detected $(0.5 \%)$.

\subsection{CELL-SURFACE INTERACTIONS ON HOMOGENEOUS SURFACES}

PEG and peptide modifications were performed to create cell- adhesive and nonadhesive surfaces, respectively. Homogeneously modified surfaces were studied in cellculture experiments in order to monitor cell-surface interactions such as adhesion and neurite outgrowth. All cell culture experiments were performed in SFM in order to eliminate the effects of serum proteins on cell-surface interactions. In a study performed 
by Schaffner et al., hippocampal cells were grown in both serum containing and serum free media (Schafiner et al., 1995). The results suggested that in the absence of serum, the substrate played a more dominant role in defining the nature of the cell-surface interactions.

Following PEG modification, as expected, there was a significant decrease in cell adhesion. The few cells that had adhered on PEG remained viable for up to 5-7 days in culture and there was no evidence of toxicity associated with the modified films. The gold surface appeared to support nerve cell adhesion in the first 24 hours after plating; however, after 1 day, cells began to detach and very few differentiated cells were observed on the surface. In addition, most of the attached cells were found in small clusters.

Following peptide modification, a dramatic increase in cell adhesion was observed and cells extended neurites and remained viable for up to 1 week in culture. We saw better cell adhesion on the CGYIGSR surface in comparison to the CSIKVAV surface. Similar results in adhesion were observed by Huber et al. who studied nerve cell adhesion on several oligopeptide-modified surfaces (Huber et al., 1998). They looked at two short oligopeptides (5-8 amino acids) containing the YTGSR and the IKVAV sequences and one long sequence (18 amino acids) containing the IKVAV sequence. In comparing the two short sequences, better cell adhesion was observed on the YIGSR sequence but overall, the long IKVAV containing sequence exhibited the best results.

Based on results obtained by others, we expected to see the best cell adhesion on the PLL/laminin coated surface (Huber et al., 1998). It was, therefore, interesting to find better cell adhesion on the CGYIGSR surface than on the positive control. Laminin is an 
$800000 \mathrm{~g} / \mathrm{mol}$ molecule with only one YIGSR region of approximately $600 \mathrm{~g} / \mathrm{mol}$. It is possible that few active sites were exposed on the laminin-coated surface due to its configuration or denaturing over time.

The results of the competitive assay confirmed that the cells were interacting specifically with the attached peptide molecules. The number of adhered cells decreased dramatically if the cells were pre-incubated with peptide-containing medium. The results suggest that the number of available cell membrane receptors for the peptides had decreased.

Nerve cell interaction with the different surfaces was also studied by looking at the neurites extending from each cell. The number, length, and the morphology of the neurites provided information on how well the cells were growing on each surface. The number of neurites on the two peptide surfaces and the positive control were significantly higher than those on PCTFE. These results were expected since the cells were interacting with specific ligands on the surface of the peptides and the positive control whereas their interaction with PCTFE was non-specific. More neurites per cell were observed on CGYIGSR than on CSIKVAV.

The neurite length data showed that the neurites on CSIKVAV were of comparable length to those found on PLL/laminin. In comparing the two peptides, significantly longer neurites were found on CSIKVAV than on CGYIGSR. This result was expected since the IKVAV sequence in laminin is known to promote neurite outgrowth (Tashiro et al., 1989). A significant amount of branching was observed on both CGYIGSR and positive control surfaces after 2-3 days in culture. The branching of dendrites is a sign of cell development and leads to the formation of a network of 
synaptic connections between cells (Goslin et al., 1998). By day 7, a highly interconnected network of connections was observed on both CGYIGSR and positive control surfaces. The degree of branching was less on the CSIKVAV surface and a less dense network was formed by day 7 . This may be due to the fact that initially there were significantly fewer cells attached on the surface.

Overall, most of the differences in cell-surface interactions on the different substrates were observed in the first 2-3 days of cell culture. While adhesion was greatest on CGYIGSR, neurite outgrowth was found to be more prominent on PLL/laminin and CSIKVAV surfaces. The differences in neurite outgrowth, specifically neurite length, between the peptide and the positive control surfaces diminished over time and by 4 days in culture, it was difficult to obtain any statistically significant quantitative data. These results show that the peptides were able to sufficiently mimic the adhesive and growth promoting nature of laminin.

\subsection{CELl-SURFACE INTERACTIONS ON PATTERNED SURFACES}

The shadow masking technique that was used to create patterns on PCTFE is a simple procedure that can be applied to other surfaces as well. In previous work, we were able to obtain good results using this technique to pattern glass surfaces (Saneinejad and Shoichet, 1998). The amount of gold deposited on the surface can be controlled to obtain a film thin enough for use in microscopy studies. Using this technique, we were able to create patterns of altemating chemistry on PCTFE.

Cell culture experiments were conducted on the following patterned surfaces: 1)PCTFE/Au, 2)PCTFE/peptide, 3)PEG/Au, and 4)PEG/peptide. Cell-surface 
interactions were poor on both PCTFE/Au and PEG/Au surfaces with minimal cell adhesion and neurite outgrowth on PCTFE regions only. On PCTFE/peptide surfaces, soon after cell plating, the majority of cells adhered to the peptide regions with some adhesion on PCTFE areas. After 2 days in culture, some neurites encountering the PCTFE-peptide border continued to grow and crossed over the PCTFE region onto adjacent peptide areas. After 4-5 days in culture, in many regions, cells no longer followed the patterns and grew indisciminantely over the surface. The results obtained from studying PCTFE/peptide patterned surfaces indicated that a certain degree of biopatteming could be achieved on these surfaces for up to 4 days in culture; however, the PCTFE regions were not effective in repelling cells. These results are similar to those obtained by Corey et al. who pattemed glass with poly-D-lysine (PDL) and found that hippocampal neurons remained true to the PDL regions for up to 72 hours (Corey et al., 1991). After 3 days, however, the cells migrated off the PDL and onto glass areas. This was an example of referential adhesion" where cells were presented with two regions on the same surface, one of which was more attractive than the other. The same can be said about our PCTFE/peptide pattemed surfaces on which hippocampal cells adhered preferentially to the more attractive peptide regions.

We incorporated PEG onto the patterned surfaces, hoping to repel cell adhesion and to guide neurite outgrowth onto peptide areas. On PEG/peptide surfaces, the results showed that soon after cell plating, cell adhesion was confined to the peptide regions of the surface with very few cells found on PEG areas. Neurite outgrowth was also confined to the peptide regions. Upon encountering the PEG-peptide border, most neurites either stopped growing or changed direction and continued to grow within the 
peptide region. The hippocampal cells remained viable and true to the patterns for at least 1 week in culture and very few neurites were found on PEG regions. Similar observations were made on both PEG/CGYIGSR and PEG/CSIKVAV surfaces; however, the cell density on CSIKVAV was significantly less than that on CGYIGSR.

The results obtained from studying cell-surface interactions on PEG/peptide patterned substrates confirmed our hypothesis that cell adhesion and neurite outgrowth can be directed on PCTFE. By incorporating PEG and peptide molecules on the surface, we were able to simultaneously mimic cell-repulsive and cell-adhesive cues, respectively.

\subsection{The Effects of Pattern Dimension On Guiding Cell ADHESION AND NEURITE OUTGROWTH}

In their work with neuroblastoma cells plated on OTS (non-adhesive)/EDA (adhesive) patterned surfaces, Matsuzawa et al. found that the cells remained true to the patterns if the OTS regions had a minimum width of $150 \mu \mathrm{m}$ (Matsuzawa et al., 1993). They also found that they could confine the cells to EDA regions of a minimum width of $30 \mu \mathrm{m}$. Kleinfeld et al. also looked at the effects of pattern dimension on cell guidance and found that cerebellar cells remained faithful to patterns as long as the non-adhesive regions had minimum widths of $50 \mu \mathrm{m}$ (Kleinfeld et al., 1988). Once we had established that hippocampal cell adhesion and neurite outgrowth can be directed on $180 \mu \mathrm{m}$ PEG/90 $\mu \mathrm{m}$ peptide patterns, we attempted to investigate the effects of smaller patterns on cell guidance. We were, however, limited by the dimensions of EM grids available for this study. We were able to obtain EM grids of $40 \mu \mathrm{m}$ and $22 \mu \mathrm{m}$ bar and hole sizes, respectively. Using the shadow masking technique, we attempted to create $40 \mu \mathrm{m}$ 
PEG/22 $\mu \mathrm{m}$ peptide patterns on PCTFE; however, the resulting patterns were of lowresolution. We found that the patterns obtained had, on average, dimensions of $30 \mu \mathrm{m}$ PEG and $30 \mu \mathrm{m}$ peptide regions. The cell culture experiments performed on these surfaces showed that bio-patterning could be achieved in some areas; however, the results were not always reproducible. The results indicated that the $30 \mu \mathrm{m}$ PEG regions were too narrow to consistently limit cells to the peptide regions.

The decrease in pattern resolution with decreasing EM grid dimension was found to be a major limitation of the shadow masking technique. The patterns obtained with the 180/90 EM grids, however, were successful in guiding adhesion and outgrowth of hippocampal cells. It may be possible to obtain adequate resolution with grid dimensions between the $180 / 90 \mu \mathrm{m}$ and $40 / 22 \mu \mathrm{m}$ range. 


\section{Conclusions and Future Recommendations}

\subsection{Conclusions}

1. PCTFE surfaces were successfully modified with the alkoxide derivative of PEG and a mechanism for the modification reaction was proposed.

2. PCTFE-Au surfaces were successfully modified with CGYIGSR and CSIKVAV peptides.

3. Cell-surface interactions on homogeneous surfaces showed that,

i) Cell adhesion increased in the following order:

PEG $<$ PCTFE Au $<$ CSIKVAV $<$ PLL/aminin $<$ CGYIGSR

ii) Neurite outgrowth increased in the following order:

PEG Au<PCTFE<CGYIGSR <CSIKVAV PLL/aminin

4. On patterned surfaces,

i) Nerve cell adhesion and neurite outgrowth were directed on $180 \mu \mathrm{m}$ non-adhesive PEG/90 $\mu \mathrm{m}$ adhesive peptide patterns.

ii) Nerve cells were able to cross PEG regions of $\sim 30 \mu \mathrm{m}$. 


\subsection{RECOMMENDATIONS FOR FUTURE WORK}

1. PEG-modified films can be further reacted in order to identify possible functional groups (e.g. $C=C$ bonds) on the surface.

2. Further studies on PEG modification reactions involving the co-solvent systems may lead to more definite conclusions about the effects of THF on surface modification of PCTFE with lower MW PEGs.

3. McCarthy and Dias reported that in their PCTFE modification studies they were able to change the depth of modification by conducting reactions at different temperatures (McCarthy and Dias, 1987). It may be interesting to study the effects of temperature on the PEG-alkoxide modification of PCTFE.

4. Optimum cell adhesion results were observed on CGYIGSR-modified films while CSIKVAV-modified films exhibited the longest neurites. Incorporating a combination of the two peptides on the same surface may further enhance cellsurface interactions.

5. For creating smaller than $90 \mu \mathrm{m}$ patterns, an alternative patterning technique such as photolithography or micro-contact printing should be considered in order to obtain better resolutions. 


\section{References}

Andrade, J.D. X-ray photoelectron spectroscopy. Pp. 105-195 in Surface and Interfacial Aspects of Biomedical Polymers Vol. I, edited by J.D. Andrade. Plenum Press. New York. (1985)

Andrade, J.D. The contact angle and interface energetics. Pp. in 249-292 in Surface and Interfacial Aspects of Biomedical Polymers Vol. 1, edited by J.D. Andrade. Plenum Press. New York. (1985)

Baron-Van Evercooren, A., Kleinman, H.K., Ohno, S., Marangos, P., Schwartz, J.P., and Dubois-Dalq, M.E. Nerve growth factor, laminin, and fibronectin promote neurite growth in human fetal sensory ganglia cultures. J. Neurosci. Res. 8: 179-193 (1982)

Bellamkonda, R. and Aebischer, P. Review: Tissue engineering in the nervous system. Biotech. Bioeng. 43: 543-554 (1994)

Bhatia, S.N., Yarmush, M.L., and Toner M. Controlling cell interactions by micropatterning in co-cultures: Hepatocytes and $3 \mathrm{~T} 3$ fibroblasts. J. Biomed. Mater. Res. 34: $189-199$ (1997)

Blawas, A.S. and Reichert, W.M. Protein Patterning. Biomaterials. 19: 595-609 (1998)

Brewer, G.J., Torricelli, J.R., Evege, E.K., and Price, P.J. Optimized survival of hippocampal neurons in B27-supplemented Neurobasal ${ }^{\text {TM }}$, a new serum-free medium combination. J. Neurosci. Res. 35: 567-576 (1993)

Bunge, R.P. and Wood, P. Studies on the transplantation of spinal cord tissue in the rat. 1. The development of a culture system for hemisections of embryonic spinal cord Brain Res. 57: 261-276 (1973)

Caldwell, K.D. Surface modifications with adsorbed poly(ethylene oxide)-based block copolymers. Pp. 400-419 in Poly(ethylene glycol) Chemistry: Biotechnical and Biomedical Applications, edited by J.M. Harris. Plenum Press. New York. (1992)

Carey, F.A. Organic Chemistry. McGraw-Hill. Toronto. (1992)

Clark, P., Connolly, P., Curtis, A.S.G., Dow, J.A.T., and Wilkinson, C.D.W. Cell guidance by ultrafine topography in vitro. J. Cell Sci. 99: 73-77 (1991)

Corey, J.M., Wheeler, B.C., and Brewer, G.J. Compliance of hippocampal neurons to patterned substrate networks. J. Neurosci. Res. 30: 300-307 (1991)

David, S. and Aguayo, A.J. Axonal elongation into peripheral nervous system ridges" after central nervous system injury in adult rats. Science Wash DC. 214: 931 -933 (1981) 
Davies J.A.S., Fitch, M.T., Memberg, S.P., Hall, A.K., Raisman, G., and Silver, J.

Regeneration of adult axons in white matter of the central nervous system. Nature. 390: $680-683$ (1997)

Desai, N.P. and Hubbell, J.A. Surface physical interpenetrating networks of poly(ethylene terephthalate) and poly(ethylene oxide) with biomedical applications. Macromolecules. 25: 226-232 (1992)

Dias, A.J. and McCarthy, T.J. Introduction of carboxylic acid, aldehyde, and alcohol functional groups onto the surface of poly(chlorotrifluoroethylene). Macromolecules. 20: 2068-2076 (1987)

Dias, A.J. and McCarthy, T.J. Surface modification of poly(chlorotrifluoroethylene) with methyllithium. Macromolecules. 18: 1826-1829 (1985)

Dimilla, P.A., Folkers, J.P., Biebuyck, H.A., Harter, R., Loperz, G.P., and Whitesides, G.M. Wetting and protein adsorption of self-assembled monolayers of alkanethiolates supported on transparent films of gold. J. Am. Chem. Soc. 116: 2225-2226 (1994)

Drumheller, P.D. and Hubbeil, J.A. Polymer networks with grafted cell adhesion peptides for highly biospecific cell adhesive substrates. Anal. Chem. 222: 380-388 (1994)

Drumheller, P.D. and Hubbell, J.A. Densely crosslinked polymer networks of poly(ethylene glycol) in trimethylpropane triacrylate for cell-adhesion-resistant surfaces. J. Biomed. Mater. Res. 29: 207-215 (1995)

Emoto, K., Van Alstine, J.M., and Harris, J.M. Stability of poly(ethylene glycol) graft coatings. Langmuir. 14: 2722-2729 (1998)

Engel, J. Laminins and other strange proteins. Biochemistry. 31: 10643-10651 (1992)

Feiring, A.E. Fluoroplastics. Pg. 339-371 in Organofluorine chemistry: Principles and commercial applications, edited by R.E. Banks et al. Plenum Press. New York (1994)

Fine, E.G., Valentini, R.F., Bellamkonda, R., Aebischer, P. Improved nerve regeneration through piezolelectric vinylidenefluoride-trifluoroethylene copolymer guidance channels. Biomaterials. 12:775-780 (1991)

Fox, S.I., Human Physiology. Wm. C. Brown Publishers.Dubuque, IA. (1996)

Gombotz, W.R., Guanghui, W., Horbett, T.A., and Hoffman, A.S. Protein adsorption to and elution from polyether surfaces. Pp. 247-261 in Poly(ethylene glycol) Chemistry: Biotechnical and Biomedical Applications, edited by J.M. Harris. Plenum Press. New York. (1992)

Gombotz, W.R., Guanghui, W., Horbett, T.A., and Hoffman, A.S. Protein adsorption to poly(ethylene oxide) surfaces. J. Biomed. Mater. Res. 25: 1547-1562 (1991) 
Gombotz, W.R., Guanghui, W., Hoffman, A.S. Immobilization of poly(ethylene oxide) on poly(ethylene terephthalate) using a plasma polymerization process. J.App. Polym. Sci. 37: 91-107 (1989)

Goslin, K., Asmussen, H., and Banker, G. Rat hippocampal neurons in low-density culture. Pp. 339-371 in Culturing Nerve Cells, edited by G. Banker and K. Goslin. MIT Press. Cambridge (1998)

Han, D.K., Park, K.D., Ryu, G.H., Kim, U.Y., Min, B.G., and Kim, Y.H. Plasma protein adsorption to sulfonated poly(ethylene oxide)-grafted polyurethane surface. J. Biomed. Mater. Res. 30: 23-30 (1996)

Harris, J.M. Poly(ethylene glycol) Chemistry: Biotechnical and Biomedical Applications. Plenum Press. New York. (1992)

Healy, K.E., Lom, B., and Hockberger P.E. Spatial distribution of mammalian cells dictated by material surface chemistry. Biotech. Bioeng. 43:792-800 (1994)

Healy, K.E., Thomas, C.H., Rezania, A., Kim, J.E., McKeown, P.J., Lom, B., and Hockberger, P.E. Kinetics of bone cell organization and mineralization on materials with pattemed surface chemistry. Biomaterials. 17: 195-208 (1996)

Hoffman, A.S. Surface modification of polymers: physical, chemical, mechanical, and biological methods. Macromol. Symp. 101: 443-454 (1996)

Huber, M., Heiduschka, P., Kienle, S., Pavlidis, C., Mack, J., Walk, T., Jung, G., and Thanos, S. Modification of glassy carbon surfaces with synthetic laminin-derived peptides for nerve cell attachment and neurite outgrowth. J. Biomed. Mater. Res. 41: 278288 (1998)

Hung, M. and Burch, R.R. Functionalization and metallization of fluoropolymer surfaces through reduction. J. App. Polym. Sci. 55:549-559 (1995)

Jakeman, L.B. and Reier, P.J. Axonal projections between fetal spinal cord transplants and the adult rat spinal cord: A neuroanatomical tracing study of local interactions. $J$. Comp. Neurol. 307: 311-334 (1991)

Kim, S.W. Nonthrombogenic treatments and strategies. Pg. 298-308 in Biomaterials Science: An Introduction to Materials in Medicine, edited by B.D. Ratner, A.S. Hoffman, F.J. Schoen, and J.E. Lemons. Academic Press. San Diego. (1996)

Kim, S.W., Lee, R.G., Oster, H., Coleman, D., Andrade, J.D., Lentz, D.J., and Olsen, D. Platelet adhesion to polymer surfaces. Trans. Amer. Artif. Int. Org. 20: 449-455 (1974) 
Kingsley, R.E. and Cole, N.L. Preparation of cultured mammalian cells for transmission and scanning electron microscopy using aclar film. J. Elec. Micros. Tech. 10: 77-85 (1988)

Kleinfeld, D., Kahler, K.H., and Hockberger, P.E. Controlled outgrowth of dissociated neurons on patterned substrates. $J$. Neurosci. 8(11): 4098-4120 (1988)

Kottke-Marchant, K., Anderson, J.M., Umemura, Y., and Marchant, R.E. Effect of

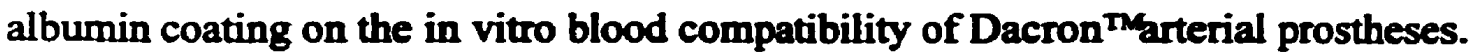
Biomaterials. 10: 147-155 (1989)

Lee, J.H., Khang, G., Lee, J.W., and Lee, H.B. Interaction of different types of cells on polymer surfaces with wettability gradient. J. Colloid Interface Sci. 205: 323-330 (1998)

Lee, J.H., Kopecek, J., and Andrade, J.D. Protein-resistant surfaces prepared by PEOcontaining block copolymer surfactants. J. Biomed. Mater. Res. 23: 351 -368 (1989)

Lee, J., Kaibara, M., Iwaki, M., Sasabe, H., Suzuki, Y., and Kusakabe, M. Selective adhesion and proliferation of cells on ion-implanted polymer domains. Biomaterials. 14: 958-960 (1993)

Lee, K., and McCarthy, T.J. Synthesis of polymer surface containing covalently attached triethoxysilane functionality: Adhesion to glass. Macromolecules. 21 : 3353-3356 (1988)

Lein, P.J., Banker, G.A., and Higgins, D. Laminin selectively enhances axonal growth and accelerates the development of polarity by hippocampal neurons in culture. Dev. Brain Res. 69: 191-197 (1992)

Letourneau, P.C. Cell-to-substratum adhesion and guidance of axonal elongation. Dev. Biol. 44: 92-101 (1975)

Liesi, P. Extracellular matrix and neuronal movement. Experientia. 46: 900-907 (1990)

Liu, S., Peulve, P., Jin, O., Boisset, N., Tiollier, J., Said, G., and Tadie, M. Axonal regrowth through collagen tubes bridging the spinal cord to nerve roots. J. Neurosci. Res. 49: 425-432 (1997)

Litauszki, L., Howard, L., Salvati, L., and Tarcha, P.J. Surfaces modified with PEO by the Williamson reaction and their affinity for proteins. J. Biomed. Mater. Res. 35: 1-8 (1997)

Makohliso, S.A., Giovangrandi, L., L nard, D. Mathieu, H.J., Ilegems, M., and Aebischer, P. Application of Teflon-AFQthin films for bio-patterning of neural cell adhesion. Biosens. Bioelectron. 13: 1227-1235 (1998) 
Malmsten, M., Emoto, K., and Van Alstine, J.M. Effect of chain density on inhibition of protein adsorption by poly(ethylene glycol) based coatings. J. Colloid Interface Sci. 202: 507-517 (1998)

Manthorpe, M., Engvall, E., Ruoslahti, E., Longo, F.M., Davis, G.E., and Varon, S. Laminin promotes neuritic regeneration from cultured peripheral and central neurons. $J$. Cell. Biol. 97: 1882-1890 (1983)

Mark, H.F., Bikales, N.M., Overberger, C.G., Menges, G., and Kroschwitz, J.I. Encyclopedia of Polymer Science and Engineering. 3: 463-480. John Wiley \& Sons. Toronto. (1985)

Massia, S.P. and Hubbell, J.A. Immobilized amines and basic amino acids as mimetic heparin-binding domains for cell surface proteoglycan-mediated adhesion. J. Biol. Chem. 267: 10133-10141 (1992)

Massia, S.P., Rao, S.S., and Hubbell, J.A. Covalently immobilized laminin peptide TyrIle-Gly-Ser-Arg- (YIGSR) supports cell spreading and co-localization of the 67kilodalton laminin receptor with $\alpha$-actinin and vinculin. J. Biol. Chem. 268: 8053-8059 (1993)

Matsuzawa, M., Liesi, P., Knoll, W. Chemically modifying glass surfaces to study substratum-guided neurite outgrowth in culture. J. Newrosci. Meth. 69: 189-196 (1996a)

Matsuzawa, M., Potember, R.S., Stenger, D.A., and Krauthamer, V. Containment and growth of neuroblastoma cells on chemically pattemed substrates. J. Neurosci. Meth. 50: 253-260 (1993)

Matsuzawa, M., Umemura, K., Beyer, D., Sugioka, K., and Knoll, W. Micropatterning of neurons using organic substrates in culture. Thin Solid Films. 305: 74-79 (1997)

Matsuzawa, M., Weight, F.F., Potember, R.S., and Liesi, P. Directional neurite outgrowth and axonal differentiation of embryonic hippocampal neurons are promoted by a neurite outgrowth domain of the B2-chain of laminin. Int. J. Devl. Neurosci. 14: 283-295 (1996b)

Neff, J.A. and Caldwell, K.D. Property modification. Pg. 201-226 in Handbook of Biomaterials Evaluation: Scientific, Technical, and Clinical Testing of Implant Materials, edited by A.F. Von Recum. Taylor and Francis. Philadelphia (1999)

Nicolau, D.V., Taguchi, T., Taniguchi, H., Tanigawa, H., Yoshikawa, S. Patterning neuronal and glia cells on light-assisted functionalized photoresists. Biosens. Bioelectron. 14: 317-325 (1999)

Powell, S.K. and Kleinman, H.K. Neuronal laminins and their cellular receptors. Int. J. Biochem. Cell. Biol. 29: 401-414 (1997) 
Ranieri, J.P., Bellamkonda, R., Bekos, E.J., Gardella, Jr., J.A., Mathieu, H.J., Ruiz, L., Aebischer, P. Spatial control of neuronal cell attachment and differentiation on covalently patterned laminin oligopeptide substrates. Int. J. Devl. Neurosci. 12: 725-735 (1994)

Ranieri, J.P., Bellamkonda, R., Bekos, E.J., Vargo, T.G., Gardella Jr., J.A., and Aebischer, P. Neuron cell attachment to fluorinated ethylene propylene films with covalently immobilized laminin oligopeptides YIGSR and IKVAV. II. J. Biomed. Mater. Res. 29: 779-785 (1995)

Ranieri, J.P., Bellamkonda, R., Jacob, J., Vargo, T.G., Gardella, J.A., and Aebischer, P. Selective neuronal cell attachment to a covalently patterned monoamine on fluorinated ethylene propylene films. J. Biomed. Mater. Res. 27: 917-925 (1993)

Ratner, B.D. and Hoffman, A.S. Thin films, grafts, and coatings. Pg. 105-118 in Biomaterials Science: An Introduction to Materials in Medicine, edited by B.D. Ratner, A.S. Hoffman, F.J. Schoen, and J.E. Lemons. Academic Press. San Diego. (1996)

Ruoslahti, E. and Pierschbacher, M.D. New perspectives in cell adhesion: RGD and integrins. Science. 238: 491-497 (1987)

Saneinejad, S. and Shoichet, M.S. Patterned glass surfaces direct cell adhesion and process outgrowth of primary neurons of the central nervous system. $J$. Biomed. Mater. Res. 42(1): 13-19 (1998)

Schaffiner, A.E., Barker, J.L., Stenger, D.A., and Hickman, J.J. Investigation of the factors necessary for growth of hippocampal neurons in a defined system $J$. Neurosci. Meth. 62: 111-119 (1995)

Schwab, M.E. and Bartholdi, D. Degeneration and regeneration of axons in the lesioned spinal cord. Physiol. Rev. 76 (2): 319-370 (1996)

Shoichet, M.S., Winn, S.R., Athavale, S., Harris, J.M., and Gentile, F.T. Poly(ethylene oxide)-grafted thermoplastic membranes for use as cellular hybrid bio-artificial organs in the central nervous system. Biotech. Bioeng. 43: 563-572 (1994)

Singhvi, R., Kumar, A., Lopez, G.P., Stephanopoulos, G.N., Wang, D.I.C., Whitesides, G.M., and Ingber, D.E. Engineering cell shape and function. Science. 264: 696-698 (1994)

Sofia, S.J., Premnath, V., and Merrill, E.W. Poly(thylene oxide) grafted to silicon surfaces: Grafting density and protein adsorption. Macromolecules. 31: 5059-5070 (1998)

Stevens, M.J. Thoughts on the structure of alkysilane monolayers. Langmuir. 15: 27732778 (1999) 
Tashiro, K., Sephel, G.C., Weeks, B., Sasaki, M., Martin, G.R., Kleinman, H.K., and Yamada, Y. A synthetic peptide containing the IKVAV sequence from the A chain of laminin mediates cell attachment, migration, and neurite outgrowth. J. Biol. Chem. 264: 16174-16182 (1989)

Tessier-Lavigne, M. and Goodman, C.S. The molecular biology of axon guidance. Science. 274 (15): 1123-1132 (1996)

Tong Y.W. and Shoichet, M.S. Peptide surface modification of poly(tetrafluoroethyleneco-hexafluoropropylene) enhances its interaction with central nervous system neurons. $J$. Biomed. Mater. Res. 42: 85-95 (1998a)

Tong, Y.W. and Shoichet, M.S. Enhancing the interaction of central nervous system neurons with poly(tetrafluoroethylene-co-hexafluoropropylene) via a novel surface amine-functionalization reaction followed by peptide modification. Pp.127-143 in Polymers for Tissue Engineering, edited by M.S. Shoichet and J.A. Hubbell. VSP (1998b)

Troughton, E.B., Bain, C.D., and Whitesides, G.M. Monolayer films prepared by the spontaneous self-assembly of symmetrical and unsymmetrical dialkyl sulfides from solution into gold substrates: Structure, properties, and reactivity of constituent functional groups. Langmuir. 4: 365-385 (1988)

Valentini, R.F., Sabatini, A.M., Dario, P., and Aebischer P. Polymer electret guidance channels enhance peripheral nerve regeneration in mice. Brain Res. 480: 300-304 (1989)

Vargo, T.G., Bekos, E.J., Kim, Y.S., Ranieri, J.P., Bellamkonda, R., Aebischer, P., Margevich, D.E., Thompson, P.M., Bright, F.V., and Gardella, Jr., J.A. Synthesis and characterization of fluoropolymeric susbtrata with immobilized minimal peptide sequences for cell adhesion studies. I. J. Biomed. Mater. Res. 29: 767-778 (1995)

Ventimiglia, R. Mather, P.E., Jones, B.E., and Lindsay, R.M. The neurotrophins BDNF, NT -3 , and NT $-4 / 5$ promote survival morphological and biochemical differentiation of striatal neurons in vitro. Eur. J. Newrosci. 7: 213-222 (1995)

Yamamoto, Y. and Sefton, M.V. Surface grafting of poly(ethylene glycol) onto poly(acrylamide-co-vinyl amine) cross-linked films under mild conditions. In Polymers for Tissue Engineering, pp.127-143, edited by M.S. Shoichet and J.A. Hubbell. VSP (1998)

Zhang, S., Yan, L., Altman, M., L sle, M.,Nugent, H., Frankel, F., Lauffenburger, D.A., Whitesides, G.M., and Rich, A. Biological surface engineering: a simple system for cell pattern formation. Biomaterials. 20:1213-1220 (1999) 